\title{
Optimizing IVF results
}

Citation for published version (APA):

Mansour, R. T. A. (2003). Optimizing IVF results. [Doctoral Thesis, Maastricht University]. Universiteit Maastricht. https://doi.org/10.26481/dis.20030227rm

Document status and date:

Published: 01/01/2003

DOI:

10.26481/dis.20030227rm

Document Version:

Publisher's PDF, also known as Version of record

\section{Please check the document version of this publication:}

- A submitted manuscript is the version of the article upon submission and before peer-review. There can be important differences between the submitted version and the official published version of record.

People interested in the research are advised to contact the author for the final version of the publication, or visit the DOI to the publisher's website.

- The final author version and the galley proof are versions of the publication after peer review.

- The final published version features the final layout of the paper including the volume, issue and page numbers.

Link to publication

\footnotetext{
General rights rights.

- You may freely distribute the URL identifying the publication in the public portal. please follow below link for the End User Agreement:

www.umlib.nl/taverne-license

Take down policy

If you believe that this document breaches copyright please contact us at:

repository@maastrichtuniversity.nl

providing details and we will investigate your claim.
}

Copyright and moral rights for the publications made accessible in the public portal are retained by the authors and/or other copyright owners and it is a condition of accessing publications that users recognise and abide by the legal requirements associated with these

- Users may download and print one copy of any publication from the public portal for the purpose of private study or research.

- You may not further distribute the material or use it for any profit-making activity or commercial gain

If the publication is distributed under the terms of Article $25 \mathrm{fa}$ of the Dutch Copyright Act, indicated by the "Taverne" license above, 


\title{
Optimizing IVF results
}

\author{
Ragaa Taha Ahmed Mansour
}


ISBN: $90-5681-150-9$

Cover illustration:

A scarab beetle carrying a $2 \mathrm{PN}$ fertilized oocyte in place of the sun disc. The Ancient Egyptians believed that the scarab was a symbol of spontaneous creation; representing the God Khepri making the sun rise. The hieroglyphic inscription added to the figure is the instructions of Ptahhotep (Sixth Dynasty: $2300-2150$ BC). The translation:

"No limit may be set to art, neither is there any craftsman that is fully master of his craft." 


\section{Optimizing IVF results}

\section{Proefschrift}

ter werkrijging van de graad van doctor aan de Universiteit Maastricht, op gezag van de Rector Magnificus,

Prof. Dr. A.C. Nieuwenhuijzen Krusemary volgens het besluit van het College van Decanen, in het openbaar te verdedigen op donderdag 27 februari 2003 om 16.00 uur

door

\section{Ragaa Taha Ahmed Mansour}

geboren 1 januari 1950

Kalyobia te Egypte 
promotores

Prof. Dr. J.L.H. Evers

Prof. Dr. M. Aboulghar (Cairo University, Egypt)

\section{beoordelingscommissie}

Prof. Dr. J.P.M. Geraedts, voorzitter

Prof. Dr. D.D.M. Braat (UMC St. Radboud, Nijmegen)

Prof. Dr. P. Devroey (Vrije Universiteit. Brussel)

Dr. J.A. Land

Prof. Dr. Ph.E. van Kerrebroeck 
This work has been performed at the Egyptian IVF-ET Center and Cairo University Acadenic Hospital, under the guidance of Prof. Dr. M. Aboulghar.

I am indebted to Prof. Dr. J.L.H. Evers for giving me the opportunity of obtaining a doctoral degree in The Netherlands and for his help during the preparation of this thesis. 



\section{Contents}

Abbreviations

Chapter 1

General Introduction

History

Results of TVF

Ovarian stimulation protocols

Simplification and accuracy of ovum pick-up techniques

Improvement in fertilization

Improvement of tissue culture media

Synopsis

Chapter 2

Aims of the study

Chapter 3

Fluid accumulation of the uterine cavity before embryo transfer: a possible hindrance for implantation

Chapter 4

Dummy embryo transfer: a technique that minimizes the problems of embryo transfer and improves the pregnancy rate in human in vitro fertilization

Chapter 5

Dummy embryo transfer using methylene blue dye

Chapter 6

The effect of sperm parameters on the outcome of intracytoplasmic sperm injection

Chapter 7

Intracytoplasmic sperm injection using microsurgically retrieved epididymal and testicular sperm

Chapter 8

Successful intracytoplasmic sperm injection without performing cytoplasmic aspiration

Chapter 9

Intracytoplasmic sperm injection in obstructive and non-öbstructive azoospermia.

Chapter 10

Multifetal pregnancy reduction: modification of the technique and analysis of the outcome.

Chapter 11

General Discussion

Chapter 12

Summary

Samenvatting

Dankwoord

Curriculum vitae

Publications 
Abbreviations

IVF-ET In vitro fertilization and embryo transfer

ART

Assisted Reproduction Techniques

ICSI

Intracytoplasmic sperm injection

$\mathrm{CC}$

Clomiphene Citrate

hMG

Human menopausal gonadotropins

GnRH

Gonadotropin releasing hormone

LH

Luetinizing hormone

FSH

Follicle stimulation hormone

r-hFSH

Recombinant human follicle stimulating hormone

US

Ultrasound

MESA

Microsurgical epididymal sperm aspiration

PESA

Percutaneous epididymal sperm aspiration

CAVD

Congenital absent vas deferens

TESA

Testicular sperm aspiration

$\mathrm{KCl}$

Potassium chloride

eSET

Elective single embryo transfer 

Chapter 1

General Introduction 
History

The advent of human in vitro fertilization and embryo transfer (VF-ET) is a breakthrough in the field of infertility. The first IVF baby was born in 1978 after ten long years of hard effort by two pioneers, Robert Edwards and Patrick Steptoe $(1,2)$. The technique of IVF-ET entalls retrieving the oocytes, fertilizing them in vitro, and then transferring the resulting embryos into the uterine cavity. The idea seems very simple, however, it is a series of delicate and complicated procedures. Robert Edwards spent many years conducting research in England and the United States, trying to obtain human oocytes to fertilize them in vitro. He obtained pieces of ovarian tissues, taken during laparotomies for ovarian wedge resection in polycystic ovaries, and tried to mature them in vitro $(3,4)$. The first culture of human oocytes in vitro from ovarian tissue removed at laparotomy is ascribed to Gregory Pincus about 25 years before the same experiment was tried by Edwards (3). After many years of research the first observation of a human oocyte fertilized in vitro was reported in "Nature" in 1969 (5). Then, Edwards and Steptoe were ready to begin clinical IVF. Human oocytes. were successfully fertilized and grown in vitro to become cleaved embryos, however no pregnancy occurred for the first seven years. These years were characterized by criticism from various groups in society including religious people, theologians, and most of all, unfortunately, scientists and medical professionals. However, these waves of criticism stimulated Edwards and Steptoe and they continued research in every area. It was then that they realized that the failure of embryos to implant was due to luteal phase distuption (3). They were using primolut depot for lateal phase support, which unfortunately has a leuteolytic effect. Consequently, natural cycle IVF was used and the first IVF pregnancy was achiewed. This event was the culmination of many years of research that had been simultaneously carried out in different places, mainly, England, Australia, and the United States (6). When the first IVF baby was born, Patrick Steptoe said "This is the first time 
we"ve solved all the problems at onee. We are at the end of the beginning-not the beginning of the end" (7). Ever since, human IVF has spread throughout the world and medical science has been getting deeper into in-vitro conception. Since the beginning of IVF, a steady stream of discoveries and progress in technology has resulted in the expansion of the indications to be treatable by IVF. Different techniques developed and the term "Assisted Reproduction Techniques" (ART) was introduced.

\section{Results of IVF}

IVF results have improved gradually and significantly over the years. The pregnancy rates differ from country to country and from one clinic to another in the same country. Tables 1 3 show the results of IVF and ART in the United Kingdom, Europe, and the USA in different years (8-17). The improvement in the overall success rates of assisted reproduction is attributed to several factors including the increased level of expertise, the improvement in controlled ovarian stimulation protocols after the introduction of gonadotropin releasing hormone agonist analogues, the improvement of tissue culture media, the simplification of ovum pick-up after the development of transvaginal US technique, the remarkable improvement in fertilization rates after the introduction of intracytoplasmic sperm injection (ICSI), the increased awareness and experience in the embryo transfer technique, and the improvement in luteal phase support. The following are more details of some factors that improved the IVF results:

\section{Ovarian stimulation protocols:}

The first IVF pregnancy was conceived in a natural cycle (1). However, to increase the chances of pregnancy, superovulation was introduced to induce the growth of multiple follicles. Until the late 1980 s, the most common ovulation induction drugs were clomiphene 
citrate (CC) and human menopausal gonadotropins (hMG) (6). The results of $\mathrm{CC} / \mathrm{hMG}$ stimulation protocols demonstrated its efficacy with an overall clinical pregnancy rate per transfer of $25 \%(18,19)$. However, a premature LH surge was a major disadvantage that necessitated the cancellation of approximately $15 \%$ of all cycles (20). Gonadotropin releasing hormone agonists (GnRH agonists) were introduced as a means of pituitary down regulation to prevent premature $\mathrm{LH}$ surges (21). Since their introduction, GnRH agonists have become the gold standard for ovulation induction and the pregnancy rates have increased significantly $(22,23)$. Two large, well-controlled studies demonstrated that the take home baby rate was doubled when GnRH agonist was used instead of the CC/hMG protocol $(24,25)$. Very recently, another way of prevention of premature LH surges was introduced through the use of GnRH antagonist. GnRH antagonist is a competitive inhibitor to GnRH that leads to an immediate decrease in $\mathrm{LH}$ and FSH secretion (26). In a recent multicenter study, the antagonist in comparison with the agonist resulted in a significantly shorter period of stimulation, a reduction in the amount of FSH consumed, a decrease in the estradiol level and about 1.3 oocytes less per pick-up (27). The clinical pregnancy rate per attempt was $32.8 \%$ in the antagonist and $37.8 \%$ in the agonist protocol with no statistically significant difference (27). A recent meta-analysis showed that there is a small, but significant difference in the pregnancy rate in favour of the agonist. However, there was no significant difference in the incidence of ovarian hyperstimulation syndrome (28). More research is needed in order to fine-tune the use of the antagonist such as using it in a more flexible way on the starting day and giving a weight adjusted dose.

Another recent development in ovulation induction drugs is the use of recombinant technology. The clinical efficacy of $\mathrm{r}$-hFSH was demonstrated in IVF when multiple follicular growth, fertilization, and pregnancies were achieved $(29,30)$. In a prospective, multicenter study r-hFSH was compared with urinary hFSH in an IVF program. In patients 
receiving r-hFSH, a significantly higher number of oocytes were retrieved with a lower total dose of FSH over a shorter period of stimulation compared with urinary hFSH. There was no significant difference in the implantation rates or the pregnancy rates, but more embryos were cryopreserved in the r-hFSH group (31). However, in a prospective randomized study comparing hMG with rFSH, when only first attempt IVFICSI cycles were considered, the live birth and implantation rates were significantly higher in the hMG group (32). In a metaanalysis comparing r-FSH and urinary FSH it was concluded that r-FSH was associated with a better pregnancy rate per started cycle (33). However, when this meta-analysis was updated $(34)$ by adding five more recent trials, there was no difference (OR $1.06,95 \% \mathrm{CI}$ $0.94,1.20$ ). It is clearly demonstrated from the above that the efficacy of urinary and recombinant gonadotropins is the same, however, the cost-effectiveness will be the determining factor in choosing one over the other.

\section{Simplification and accuracy of ovum pick-up techniques}

One of the main reasons for improving IVF results is that the ovam pick-up technique became simple and accurate. In the beginning of IVF, ovum pick-up was only done through abdominal laparoscopy under general anaesthesia. A good view of the pelvic organs is essential, particularly the ovaries. For most IVF patients, due to the presence of pelvic adhesions, the procedure was not a straightforward one and could be lengthy due to adhesions covering the ovaries, endometriosis, bleeding, and difficulty in recovering oocytes.

Ultrasound-guided oocyte recovery has revolutionized the way IVF is practiced. It made IVF possible without general anaesthesia and as an outpatient procedure. The technology continuously improved, particularly in real time scanning, leading to successful oocyte recovery through trans-abdominal ultrasound guidance (35). With further improvement in the technology, transvaginal ultrasonic-guided oocyte recovery became possible (36). Currently, 
oocyte recovery is done almost universally through the transvaginal US-guided route, since it is the easiest, and the most accurate method.

\section{Improvement in fertilization}

The development of ICSI was a breakthrough in the field of assisted reproduction (37). It simply made fertilization possible in many cases that used to result in total failure of fertilization using conventional IVF and cases that were not acceptable in the IVF program in the first place. The technique of ICSI entails the injection of one spermatozoon inside the ooplasm. ICSI has been widely and successfully used to achieve fertilization in cases of olligoasthenozoospermia (38-41). It has also been successful in achieving fertilization and pregnancies using epididymal and testicular sperm in cases of obstructive and nonobstructive azoospermia (42-49). The use of ICSI in suspected male factor infertility or borderline semen $(40,50)$ and unexplained infertility (51) was also recommended. It significantly improved the fertilization rate and avoided the occurrence of total failure of fertilization in these cases (52). Naturally, ICSI is the first line of treatment in cases with previous failure of fertilization using conventional IVF (41). ICSI has also proven to be of value to patients with malle immunological infertility (53) and with acrosomeless spermatozoa (54-56). Even in cases of totally immotile spermatozoa, although the fertilization rate is low, pregnancy and birth have been reported (57-59). Another use of ICSI is to fertilize cryothawed oocytes $(60,61)$ and in-vitro matured oocytes $(62-64)$, It has even been suggested that ICSI might completely replace conventional IVF. However, data from prospective randomized studies showed no significant benefit from ICSI over conventional IVF in cases with normal semen (65). A multi-center randomized controlled trial comparing clinical outcome after ICST or conventional IVF in couples with non-male factor infertility was recently performed (66). It was concluded that ICSI offers no advantage over IVF in 
terms of clinical outcome in cases of non-male factor infertility (66). From both safety and scientific viewpoint, it is concluded that ICSI should only be used if success at conventional IVF is regarded unlikely (67). The technique of ICSI has significantly improved fertilization. Cases of severe oligoathenospermia can achieve fertilization rates from 60 to $76 \%(41,68$, 69). Moreover, the results of ICSI using either ejaculated, epididymal or testicular spermatozoa did not differ significantly (70). The results of a Cochran systematic review showed that there is evidence that fertilization rates are significantly better with ICSI than IVF in couples with borderline semen (71). When the semen parameters are normal there is insufficient evidence that ICSI is more effective than IVF when the fertilization rate is calculated per retrieved oocyte. However there is small but statistically significant improvement in fertilization rate per inseminated oocyte ( 71$)$.

\section{Improvement of tissue culture media}

Basically, tissue culture media is composed of a balanced salt solution with added carbohydrates and amino acids. Extensive scientific research has been done to develop tissue culture media that will successfully support the development of viable human embryos. Many controlled studies have demonstrated that fertilization and cleavage can successfully occur in a variety of simple and complex media (72). Not only the composition of the media is important but also rigorous quality control is essential. Each batch of culture media must be free of endotoxins, microorganisms, and low in ion content. It should be checked for embryo toxicity before use (73).

\section{Synopsis}

The development of IVF is a breakthrough in the field of infertility. After many years of research, the first IVF baby was born in 1978. The results of IVF have improved gradually but significantly over the years. The improvement in the results of IVF is due to several factors including the increased level of expertise, the improvement of controlled ovarian 
stimulation protocols, the improvement of tissue culture media, the simplification of ovum pick-up through the use of transwaginal ultrasonic route, the significant improvement in fertilization due to the development of ICSI, the increased awareness and experience in the embryo transfer technique, and improving the luteal phase support. 


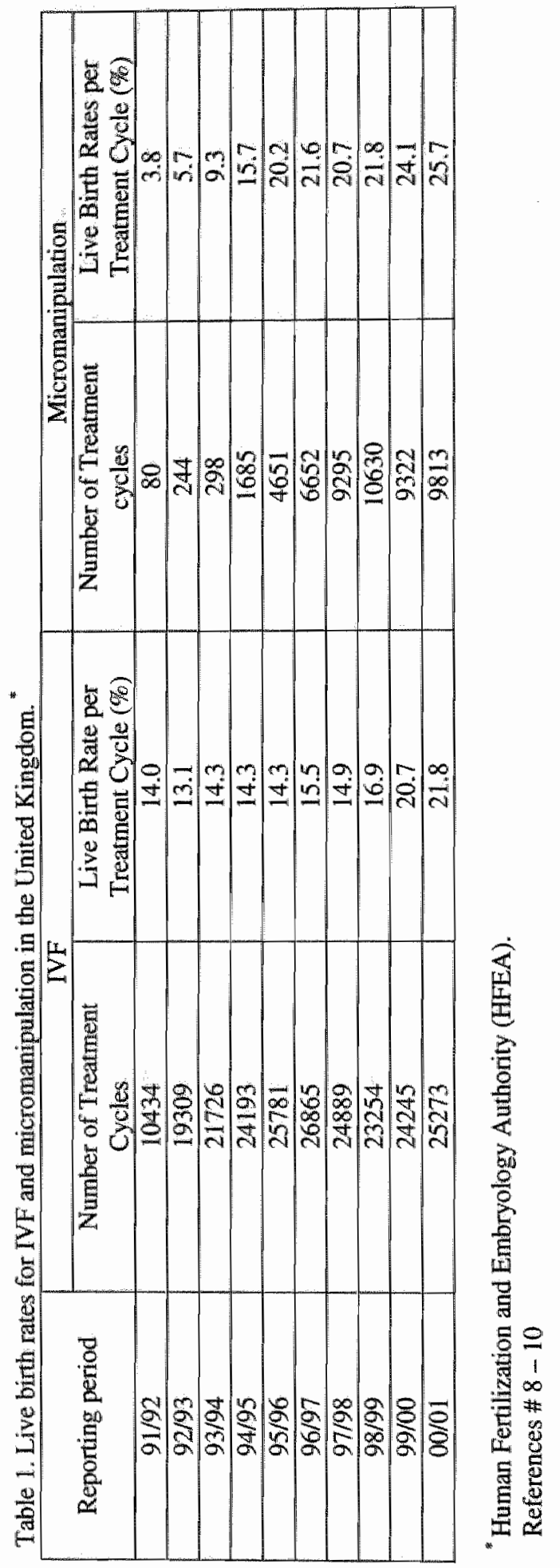


Table 2. Results of IVF and ICSI in Europe from cycles initiated in 1997,1998 \& $1999^{*}$

\begin{tabular}{|c|c|c|c|c|c|c|}
\hline & \multicolumn{2}{|c|}{1997} & \multicolumn{2}{|c|}{1998} & \multicolumn{2}{|c|}{1999} \\
\hline 8 & IVF & ICSI & IVF & ICSI & IVF & ICSI \\
\hline Number of transfer cycles & 80209 & 62253 & 84066 & 80785 & 98313 & 78452 \\
\hline Number of pregnancies & 20937 & 16462 & 22683 & 21665 & 27196 & 21916 \\
\hline Pregnancy rate per transfer $(\%)$ & 26.1 & 26.4 & 27.0 & 26.8 & 27.7 & 27.9 \\
\hline
\end{tabular}

* European registers by ESHRE

References \#11-13 
Table 3. IVF/ART success rates in USA."

\begin{tabular}{|c|c|c|}
\hline Year & Number of Cycles & $\begin{array}{c}\text { Live Birth rate } \\
\text { Per Retrieval (\%) }\end{array}$ \\
\hline 1985 & 3921 & 5.3 \\
1986 & 4867 & 5.2 \\
1987 & 11806 & 8.3 \\
1988 & 17411 & 9.4 \\
1989 & 18211 & 11.3 \\
1990 & 19079 & 12.1 \\
1991 & 24671 & 12.9 \\
1992 & 29404 & 14.2 \\
1993 & 31900 & 15.8 \\
1994 & 26961 & 18.0 \\
1995 & 45906 & 22.8 \\
1996 & 49586 & 22.7 \\
1997 & 55002 & 23.5 \\
1998 & 61650 & 28.9 \\
1999 & 65751 & 29.2 \\
\hline
\end{tabular}

From references \# 14-17 


\section{REFERENCES}

1. Steptoe PC, Edwards RG. Birth after the reimplantation of a human embryo. Lancet. 1978 Aug $12 ; 2(8085): 366$.

2. Steptoe PC, Edwards RG, Purdy JM. Clinical aspects of pregnancies established with cleaving embryos grown in witro. Br J Obstet Gynaecol. 1980 Sep;87(9):757-68.

3. Robert G Edwards. The beginnings of human in vitro fertilization. In: Gardner D, Weissman A, Howles C, Shoham Z eds. Assisted Reproductive Techniques. Laboratory and Clinical Perspectives. UK Martin Dunitz. 2001:1-15.

4. Edwards R, Steptoe P. A Matter of life. The story of a Medical Breakthrough, ${ }^{\text {st }}$ ed. London: Hutchinson. 1980:40.

5. Edwards RG, Bavister BD, Steptoe PC. Early stages of fertilization in vitro of human oocytes matured in vitro. Nature. 1969 Feb 15;221(181):632-5.

6. Brinsden PR. An introduction to Bourn Hall. In: Brinsden PR ed. In Vitro Fertilization and Assisted Reproduction. $2^{\text {nd }}$ ed. London The Parthenon Publishing Group. 1999:5-11.

7. Steptoe P. Time Magazine, August 1978:28.

8. Human Fertilization and Embryology Authority (HFEA) Website. www.hfea.gov.uk/Downloads/Annual_Report/AnnualReport2000.pdff

9. Human Fertilization and Embryology Authority (HFEA) Website. www.hfea.gov.uk/Downloads/Annual_Report/HFEA_Annual\%20Report2001.pdf

10. Human Fertilization and Embryology Authority (HFEA) Website. www.hfea.gov.uk/Downloads/Annual_Report/HFEA_Annual\%20Report2002.pdf

11. Nygren $\mathrm{KG}$, Andersen AN. Assisted reproductive technology in Europe, 1997. Results generated from European registers by ESHRE. European IVF-Monitoring Programme (EIM), for the European Society of Human Reproduction and Embryology (ESHRE). Hum Reprod. 2001 Feb;16(2):384-91.

12. Nygren KG, Andersen AN. Assisted reproductive technology in Europe, 1998. Results generated from European registers by ESHRE. European Society of Human Reproduction and Embryology. Hum Reprod. 2001 Now; 16(11):2459-71.

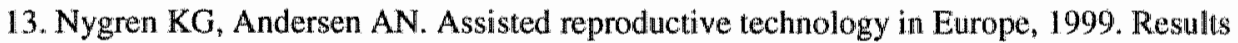
generated from European registers by ESHRE. Hum Reprod. 2002 Dec;17(12):3260-74.

14. Summary of IVF Registry, 1985-1995

www.fertilethoughts.net/infertility/iwfreg.html

15. Assisted Reproductive Technology Success Rates National Summary and Fertility Clinic Reports. 1995-1998. http://www.cdc.gov/nccdphp/drh/art.htm 
16. ASRM 1999

www.cdc.gov/ncedphp/drh/ART99/PDFs/art99_1.pdf

17. ASRM 2000

www.cdc.gov/nccdphp/drh/ART00/PDF's/ART2000.pdf

18. Trounson A, Wood C. In vitro fertilization results, 1979-1982, at Monash University, Queen Victoria,and Epworth Medical Centres.J In Vitro Fert Embryo Transf. 1984 Mar; 1(1):42-7.

19. Steptoe PC, Edwards RG, Walters DE. Observations on 767 clinical pregnancies and 500 births after human in-vitro fertilization. Hum Reprod. 1986 Feb; 1(2):89-94.

20. Speroff L, Glass RH, Kase NG. Assisted Reproduction. In: Mitchell C ed. Clinical Gynecologic Endocrinology and infertility. USA Williams \& Wilkins. 1994:931-46.

21. Porter RN, Smith W, Craft IL, Abdulwahid NA, Jacobs HS. Induction of ovulation for invitro fertilisation using buserelin and gonadotropins. Lancet. 1984 Dec 1;2(8414):1284-5.

22. Hughes EG, Fedorkow DM, Daya S, Sagle MA, Van de Koppel P, Collins JA. The routine use of gonadotropin-releasing hormone agonists prior to in vitro fertilization and gamete intrafallopian transfer: a meta-analysis of randomized controlled trials. Fertil Steril. 1992 Nov;58(5):888-96.

23. Loumaye $\mathrm{E}$. The control of endogenous secretion of LH by gonadotrophin-releasing hormone agonists during ovarian hyperstimulation for in-vitro fertilization and embryo transfer. Hum Reprod. 1990 May;5(4):357-76.

24. Rutherford AJ, Subak-Sharpe RJ, Dawson KJ, Margara RA, Franks S, Winston RM. Improvement of in vitro fertilisation after treatment with buserelin, an agonist of luteinising hormone releasing hormone. Br Med J (Clin Res Ed). 1988 Jun $25 ; 296(6639): 1765-8$.

25. Macnamee MC, Howles CM, Edwards RG, Taylor PJ, Elder KT. Short-term luteinizing hormone-releasing hormone agonist treatment: prospective trial of a novel ovarian stimulation regimen for in vitro fertilization. Fertil Steril. 1989 Aug;52(2):264-9.

26. Diedrich K, Diedrich C, Santos E, Zoll C, al-Hasani S, Reissmann T, Krebs D, Klingmuller $\mathrm{D}$. Suppression of the endogenous luteinizing hormone surge by the gonadotrophin-releasing hormone antagonist Cetrorelix during ovarian stimulation. Hum Reprod. 1994 May;9(5):788-91.

27. The European Middle East Orgalutran Study Group. Comparable clinical outcome using the GnRH antagonist ganirelix or a long protocol of the GnRH agonist triptorelin for the prevention of premature LH surges in women undergoing ovarian stimulation. Hum Reprod. 2001 Apr; 16(4):644-51. 28. Al-Inany H, Aboulghar M, GnRH antagonist in assisted reproduction: a Cochrane
review. Hum Reprod $200217(4): 874-85$. 
29. Germond M, Dessole S, Senn A, Loumaye E, Howles C, Beltranut V. Successful in-vitro fertilisation and embryo transfer after treatment with recombinant human FSH. Lancet. 1992 May 9;339(8802): 1170.

30. Devroey $P$, van Steirteghem A, Mannaerts B, Bennink HC. Successful in-vitro fertilisation and embryo transfer after treatment with recombinant human FSH. Lancet. 1992 May $9 ; 339(8802): 1170$.

31. Out HJ, Mannaerts BM, Driessen SG, Bennink HJ. A prospective, randomized, assessorblind, multicentre study comparing recombinant and urinary follicle stimulating hornone (Puregon versus Metrodin) in in-vitro fertilization. Hum Reprod, 1995 Oct;10(10):253440.

32. Westergaard LG, Erb K, Laursen SB, Rex S, Rasmussen PE. Human menopausal gonadotropin versus recombinant follicle-stimulating hormone in normogonadotropic women down-regulated with a gonadotropin-releasing hormone agonist who were undergoing in vitro fertilization and intracytoplasmic sperm injection: a prospective randomized study. Fertil Steril. 2001 Sep;76(3):543-9.

33. Daya S, Gunby J. Recombinant versus urinary follicle stimulating hormone for ovarian stimulation in assisted reproduction. Hum Reprod. 1999 Sep; 14(9):2207-15.

34. Al-Inany $\mathrm{H}$, Afnan M. Models of cost-effectiveness of recombinant FSH versus urinary FSH. Hum Reprod. 2002 Jun;17(6):1671-3.

35. Lenz S, Lauritsen $\mathrm{JG}_{\mathrm{G}} \mathrm{Kj}$ jellow $\mathrm{M}$. Collection of human oocytes for in vitro fertilisation by ultrasonically guided follicular puncture. Lancet. 1981 May 23;1(8230):1163-4.

36. Wikland $M$, Enk L, Hamberger L. Transvesical and transvaginal approaches for the aspiration of follicles by use of ultrasound. Ann N Y Acad Sci. 1985;442:182-94.

37. Palermo G, Joris H, Devroey $\mathbf{P}$, Van Steirteghem AC. Pregnancies after intracytoplasmic injection of single spermatozoon into an oocyte. Lancet. 1992 Jul 4;340(881.0):17-8.

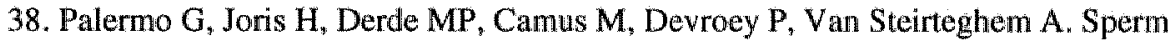
characteristics and outcome of human assisted fertilization by subzonal insemination and intracytoplasmic sperm injection. Fertil Steril. 1993 Apr:59(4):826-35.

39. Van Steirteghem AC, Nagy Z, Joris H, Liu J, Staessen C, Smitz J, Wisanto A, Devroey P. High fertilization and implantation rates after intracytoplasmic sperm injection. Hum Reprod. $1993 \mathrm{Jul} ; 8(7): 1061-6$.

40. Payne D, Flaherty SP, Jeffrey R, Warnes GM. Mathews CD. Successful treatment of severe male factor infertility in 100 consecutive cycles using intracytoplasmic sperm injection. Hum Reprod. 1994 Nov; $9(11): 2051-7$.

41. Mansour RT, Aboulghar MA, Serour GI, Amin YM, Ramzi AM. The effect of sperm parameters on the outcome of intracytoplasmic sperm injection. Fertil Sterill. 1995 Nov;64(5):982-6. 
42. Schoysman R, Vanderzwalmen P, Nijs M, Segal L, Segal-Bertin G, Geerts L, van Roosendaal E, Schoysman D. Pregnancy after fertilisation with human testicular spermatozoa. Lancet. 1993 Nov 13;342(8881):1237.

43. Schoysman $R$, Vanderzwalmen $P$, Nijs $M$, Segal-Bertin $G$, van de Casseye $M$. Successful fertilization by testicular spermatozoa in an in-vitro fertilization programme. Hum Reprod. 1993 Aug;8(8):1339-40.

44. Silber SJ, Nagy ZP, Liu J, Godoy H, Dewroey P, Van Steirteghem AC. Conventional invitro fertilization versus intracytoplasmic sperm injection for patients requiring microsurgical sperm aspiration. Hum Reprod. 1994 Sep;9(9): 1705-9.

45. Tournaye H, Devroey P, Liu J, Nagy Z, Lissens W, Van Steirteghem A. Microsurgical epididymall sperm aspiration and intracytoplasmic sperm injection: a new effective approach to infertility as a result of congenital bilateral absence of the vas deferens. Fertil Steril. 1994 Jun; $61(6): 1045-51$.

46. Mansour RT, Aboulghar MA, Serour GI, Falımi 1, Ramzy AM, Amin Y. Intracytoplasmic sperm injection using microsurgically retrieved epididymal and testicular sperm. Fertil Steril. 1996 Mar;65(3):566-72.

47. Mansour RT, Kamal A, Fahmy I, Tawab N, Serour GI, Aboulghar MA. Intracytoplasmic sperm injection in obstructive and non-obstructive azoospermia. Hum Reprod. 1997 Sep; 12(9): 1974-9.

48. Craft I, Bennett V, Nicholson N. Fertilising ability of testicular spermatozoa. Lancet. 1993 Oct $2 ; 342(8875): 864$.

49. Devroey $P$, Lit J, Nagy Z, Goossens A, Tournaye H, Camus M, Van Steirteghem A, Silber S. Pregnancies after testicular sperm extraction and intracytoplasmic sperm injection in non-obstructive azoospermia. Hum Reprod. 1995 Jun; 10(6): 1457-60.

50. Aboulghar MA, Mansour RT, Serour GI, Amin YM. The role of intracytoplasmic sperm injection (ICSI) in the treatment of patients with borderline semen. Hum Reprod. 1995
Now: 10 (11):2829-30.

51. Aboulghar MA, Mansour RT, Serour GI, Sattar MA, Amin YM. Intracytoplasmic sperm injection and conventional in vitro fertilization for sibling oocytes in cases of unexplained infertility and borderline semen. J Assist Reprod Genet. 1996 Jan; 13(1):38-42.

52. Hershlag $A$, Paine $T$, Kvapil $G$, Feng $H$, Napolitano B. In vitro fertilizationintracytoplasmic sperm injection split: an insemination method to prevent fertilization
failure. Fertil Steril. 2002 Feb; $77(2): 229-32$.

53. Nagy $2 \mathrm{P}$, Verheyen $\mathrm{G}_{\text {, Liu }} \mathrm{J}$, Joris $\mathrm{H}$, Janssenswillen $\mathrm{C}$, Wisanto $A$, DevroeyP, Van Steirteghem AC. Results of 55 intracytoplasmic sperm injection cycles in the treatment of male-immunological infertility. Hum Reprod. 1995 Jul; 10(7):1775-80. 
54. Lanzendorf S, Maloney M, Ackerman S, Acosta A, Hodgen G. Fertilizing potential of acrosome-defective sperm following microsurgical injection into eggs. Gamete Res. 1988 Apr; 19(4):329-37.

55. Lundin K, Sjogren A, Nilsson L, Hamberger L. Fertilization and pregnancy after intracytoplasmic microinjection of acrosomeless spermatozoa. Fertil Steril. 1994 $\operatorname{Dec} ; 62(6): 1266-7$.

56. Bourne H, Liu DY, Clarke GN, Baker HW. Normal fertilization and embryo development by intracytoplasmic sperm injection of round-headed acrosomeless sperm. Fertil Steril. 1995 Jun;63(6):1329-32.

57. Stalf T, Sanchez R, Kohn FM, Schalles U, Kleinstein J, Hinz V, Tielsch J, Khanaga O, Turley $\mathrm{H}$, Gïps $\mathrm{H}$, et al. Pregnancy and birth after intracytoplasmic sperm injection with spermatozoa from a patient with tail stump syndrome. Hum Reprod. 1995 Aug; 10(8):2112-4.

58. Kahraman S, Tasdemir M, Tasdemir I, Vicdan K, Ozgur S, Polat G, Islk AZ, Biberoglu K, Vanderzwalmen P, Nijs M, Schoysman R. Pregnancies achieved with testicular and ejaculated spermatozoa in combination with intracytoplasmic sperm injection in men with totally or initially immotile spermatozoa in the ejaculate. Hum Reprod. 1996 Jun; 11(6):1343-6.

59. Nijs M, Vanderzwalmen $P$, Vandamme B, Segal-Bertin $G$, Lejeune B, Segall L, van Roosendaal E, Schoysman R. Fertilizing ability of immotile spermatozoa after intracytoplasmic sperm injection. Hum Reprod. 1996 Oct;1 1(10):2180-5.

60. Gook DA, Schiewe MC, Osborn SM, Asch RH, Jansen RP, Johnston WI. Intracytoplasmic sperm injection and embryo development of human oocytes cryopreserved using 1,2-propanediol. Hum Reprod. 1995 Oct;10(10):2637-41.

61. Kazem R, Thompson LA, Srikantharajah A, Laing MA, Hamilton MP, Templeton A. Cryopreservation of human oocytes and fertilization by two techniques: in-vitro fertilization and intracytoplasmic sperm injection. Hum Reprod. 1995 Oct; 10(10):2650-4.

62. Cha KY, Han SY, Chung HM, Choi DH, Lim JM, Lee WS, Ko J, Yoon TK. Pregnancies and deliveries after in vitro maturation culture followed by in vitro fertilization and embryo transfer without stimulation in women with polycystic ovary syndrome. Fertil Steril. 2000 May; 73(5):978-83.

63. Russell JB, Knezevich KM, Fabian KF, Dickson JA. Unstimulated immature oocyte retrieval: early versus midfollicular endometrial priming. Fertill Steril. 1997 Apr;67(4):616-20.

64. Trounson A, Anderiesz C, Jones GM, Kausche A, Lolatgis N, Wood C. Oocyte maturation. Hum Reprod. 1998 Jun; 13 Suppl 3:52-62.

65. Aboulghar MA, Mansour RT, Serour GI, Amin YM, Kamal A. Prospective controlled randomized study of in vitro fertilization versus intracytoplasmic sperm injection in the 
treatment of tubal factor infertility with normal semen parameters. Fertil Steril. 1996 Nov;66(5):753-6.

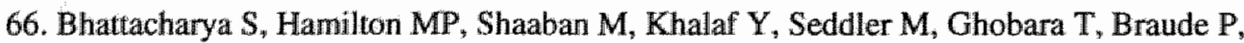
Kennedy $R$, Rutherford A, Hartshorne $G$, Templeton A. Conventional in-vitro fertilisation versus intracytoplasmic sperm injection for the treatment of non-male-factor infertility: a randomised controlled trial. Lancet. 2001 Jun 30;357(9274):2075-9.

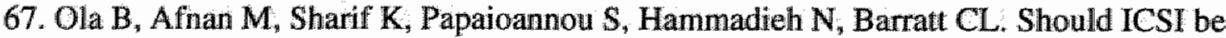
the treatment of choice for all cases of in-vitro conception? Considerations of fertilization and embryo development, cost effectiveness and safety. Hum Reprod. 2001 $\operatorname{Dec}_{\#} 16(12): 2485-90$.

68. Oehninger S, Veeck L, Lanzendorf S, Maloney M, Toner J, Muasher S. Intracytoplasmic sperm injection: achievement of high pregnancy rates in couples with severe male factor infertility is dependent primarily upon female and not male factors. Fertil Steril. 1995 Nov; $64(5): 977-81$.

69. Schoolcraft WB, Schlenker T, Adler A, Alikani M. A model for the incorporation of intracytoplasmic sperm injection into a private practice in vitro fertilization program. Fertil Steril. 1996 Feb;65(2):258-61.

70. Tarlatzis BC. Report on the activities of the ESHRE Task Force on intracytoplasmic sperm injection. European Society of Human Reproduction and Embryology. Hum Reprod. 1996 Dec; 1 1 Suppl 4:160-85.

71. van Rumste MM, Evers JL, Farquhar CM, Blake DA. Intra-cytoplasmic sperm injection versus partial zona dissection, subzonal insemination and conventional techniques for oocyte insemination during in vitro fertilisation. Cochrane Database Syst Rev. 2000;(2):CD001301.

72. Edwards RG, Brody SA. Human fertilization in the laboratory. In : Edwards RG, Brody SA eds. Principles \& Practice of Assisted Human Reproduction. Philadelphia:WB Saunders, 1995:351-413.

73. Davidson A, Vermesh M, Lobo RA, Paulson RJ. Mouse embryo culture as quality control for human in vitro fertilization: the one-cell versus the two-cell model. Fertil Sterill, 1988 Mar;49(3):516-21. 
Chapter 2

Aims of the study 
The aim of this work is to review the different research projects that have been done by our group in more than one aspect of IVF in an attempt to optimize IVF results. The research is focused on the following areas:

a) The diagnosis and management of the presence of fluid in the uterine cavity in association with hydrosalpinges before starting an IVF cycle.

b) Performing a dummy embryo transfer before the actual transfer to choose the most suitable kind of catheter, measure the length and direction of the uterine cavity, and to diagnose any unanticipated difficulty in the cervix.

c) Studying different factors that may affect the embryo transfer technique such as: the kind of catheter, the presence of cervical mucus, and the presence of air bubbles.

d) Experimenting with the technique of intracytoplasmic sperm injection and investigating the following: 1- the effect of different sperm parameters on the outcome of ICSI. 2- the use of micro-surgically retrieved epididymal and testicular sperm. 3- performing ICSI without cytoplasmic aspiration. 4- the use of ICSI in obstructive and non-obstructive azoospermia.

e) Modification of the technique of multifetal reduction in cases of high order multiple pregnancy in an attempt to improve the outcome. 


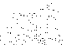




\section{Chapter 3}

Fluid accumulation of the uterine cavity before embryo transfer: a possible hindrance for implantation

Ragaa T. Mansour, Mohamed A. Aboulghar, Gamal I. Serour, Raafat Riad

Journal of in Vitro Fertilization and Embryo Transfer, Vol. 8, No. 3, 1991 


\section{Abstract}

Accumulation of fluid in the uterine cavity was recorded in three cases during vaginal ultrasound (US) monitoring for in vitro fertilization (IVF) cycles. The three patients had hydrosalpinges and tuboovarian cystic masses. They all had a common complaint of intermittent vaginal discharge. Attempts at aspirating the fluid to empty the cavity was done in two cases but the fluid recollected. This condition possibly renders the uterine cavity hostile to the transferred embryos and careful consideration should be taken to diagnose it. 


\section{INTRODUCTION}

Several factors affect the implantation rate after in vitro fertilization and embryo transfer (IVF-ET). The endometrial thickness and intrauterine environment are important factors. Ultrasound (US) reflectivity of the endometrium and its thickness as a possible parameter for an intrauterine environment favorable for implantation has been studied (1). Changes in the texture and thickness of the endometrium have been observed during follicular maturation in spontaneous and stimulated cycles (2). However, the presence of intrauterine fluid accumulating in its cavity before ET was not observed.

We record three cases showing accumulation of fluid in the uterine cavity before $\mathrm{ET}$.

\section{CASE REPORTS}

\section{Case I}

A 27-year old woman complaining of primary infertility came to the Egyptian IVF-ET Center for treatment. She gave a history of peritonitis following hysterosalpingography. She underwent a laparotomy 2 years later and it showed extensive pelvic adhesions and bilateral hydrosalpinges. She was counseled for IVF-ET, and on routine pelvic US examination she was found to have multiple pelvic cystic masses. She also gave a history of vaginal discharge of brownish viscid fluid persistent for many years. The amount of discharge was marked in the second half of the cycle. On clinical examination, the discharge was seen pouring from the cervix. Culture and sensitivity of the discharge were done on more than one occasion and revealed no growth. She received a prophylactic antibiotic course as part of our routine policy. Transwaginal aspiration of the pelvic cysts was done and she received gonadotropin releasing hormone analogue (GnRHa) and human menopausal gonadotropin (hMG) 
according to our previously described protocol (3). Transvaginal US ovum pickup resulted in retrieval of six oocytes. It was noted during the ovum pickup that the uterine cavity was distended with fuid $(7 \times 35 \mathrm{~mm})$ (Fig. la). Attempt at transcervical aspiration of the fluid was done using a Craft ET catheter (R 57.536, Rocket of London, Watford, Herts, England) and 3 $\mathrm{ml}$ of dark-brown viscid fluid was emptied. However, before the ET, the uterine cavity was redistended with fluid which was reaspirated immediately before ET and four embryos at the four-cell stage were transferred. Serum hCG 2 weeks later was less than $10 \mathrm{mIU} / \mathrm{ml}$.

\section{Case II}

A 30-year-old woman complaining of primary infertility for 5 years was counseled for entry into our IVF program. She had bilateral hydrosalpinges as evidenced from previous hysterosalpingography and laparoscopy. She also complained of brownish vaginal discharge for 3 years. General and pelvic examination revealed no abnormality except for the discharge, which was found to be coming from the uterus. Culture revealed no growth. Aspiration of the hydrosalpinges, prophylactic antibiotics, and ovarian stimulation for IVF were similar to those for case I. On the day of ovum pickup, the endometrial cavity was noted to be distended with fluid $(17 \times 21 \mathrm{~mm})$ as shown in Fig. 1b. Ovum pickup resulted in retrieval of eight oocytes. Embryo transfer was done 2 days later, replacing four embryos. The uterine cavity was still distended by fluid as during ovum pickup. Serum hCG 2 weeks later was less than $10 \mathrm{mIU} / \mathrm{ml}$.

\section{Case III}

A 37-year-old woman with primary infertility for 10 years presented with intermittent brownish vaginal discharge of variable amounts for 8 years. Her general and pelvic examination revealed no abnormalities except for a brownish discharge coming from the 
cervix. Laparoscopy diagnosed the presence of bilateral hydrosalpinges and extensive pelvic adhesions. Vaginal US showed multiple cysts. Attempts at aspirating these pelvic cystic masses was done through transvaginal US and $125 \mathrm{ml}$ of fluid was aspirated. The patient was followed up for 2 months after the aspiration and she noted that the vaginal discharge stopped. She was counseled for IVF-ET and ovarian stimulation was induced using GnRHa and hMG. During US monitoring of follicular growth, the uterine cavity was noticed to be distended with fluid $(20 \times 30 \mathrm{~mm})$ as shown in Fig. 1c, starting from day 10 of the cycle, reaching its maximum on the day of ovum pickup. Transvaginal US ovum pickup resulted in the retrieval of 12 oocytes. Aspiration of the uterine fluid was done, with removal of $5 \mathrm{ml}$ of yellowish clear fluid. Embryo transfer was done 2 days later, replacing four embryos. Pregnancy was not achieved in this cycle. At the time of the transfer the cavity was redistended with fluid but to a lesser degree.

Follow up of the three cases for 6 months following their IVF attempts revealed that the intrauterine fluid accumulated in all cycles. However, the volume of the fluid was slightly less than that accumulated during the IVF cycle. Curettage for endometrial and endocervical biopsies revealed no pathological findings. 


\section{DISCUSSION}

The presence of pelvic inflammatory cystic masses and hydrosalpinges is a common finding in infertile patients selected for IVF (3). It was also noted that hydrosalpinges may enlarge during stimulation (4). Passage of some fluid into the uterine cavity is likely to occur in some cases. Intermittent hydrosalpinx is a pathological condition in which passage of the fluid from the distended tube into the uterine cavity occurs at different intervals, resulting in copious amount of vaginal discharge (5). The amount could be very minimal to be detected clinically but its effect in rendering the uterine environment hostile to the transferred embryos should be seriously considered. Vaginal ultrasound revealed that the uterine cavity was distended with fluid in these three recorded cases. All of them were diagnosed to have hydrosalpinges and tuboovarian masses and they all had a common complaint of persistent vaginal discharge, which was especially marked during the second half of the cycle. The fluid was not directly related to superstimulation because it was present during the subsequent natural cycles. This finding drove our attention to careful US monitoring of IVF patients who are diagnosed to have hydrosalpinges or tuboovarian masses to spot any fluid in the uterine cavily. The treatment of this condition is rather a difficult one. Transvaginal US aspiration of the fluid in hydrosalpinges and tuboovarian masses before the IVF cycle may be of help (3). Unfortunately, in these three cases the lluid recollected and the discharge recurred. Closing the cornual end of both sides could be worthwhile through laparoscopy or laparotomy after a neosalpingostomy is performed. Bilateral salpingectomy could be done if Peasible. 


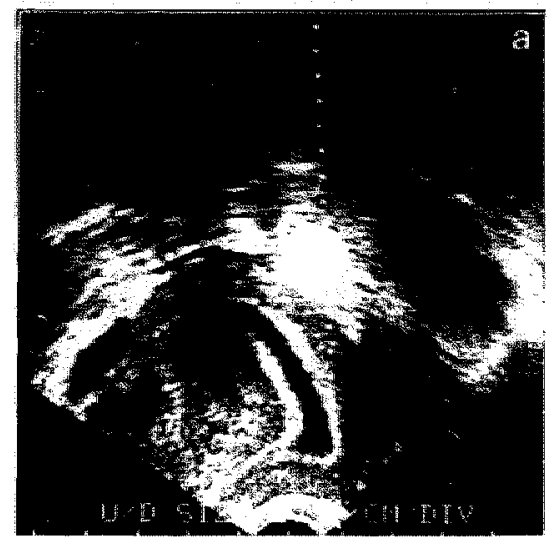

Figl (a) Uterine cavity distended with

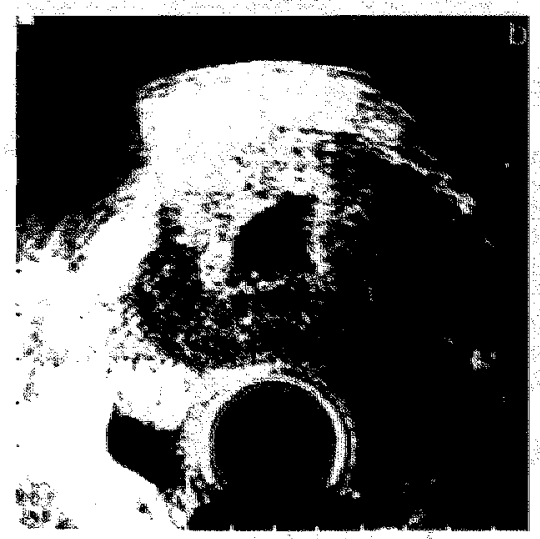

Fig 1 (b) Uterine cavily in case 2.

fluid in case 1.

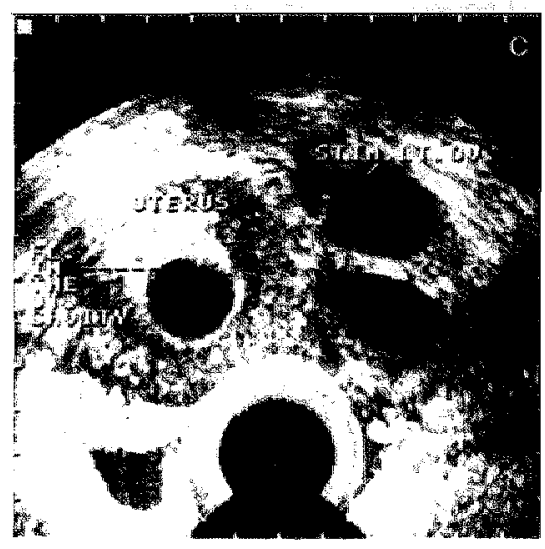

Fig 1 (c) Uterine cavity in case 3. 


\section{REFERENCES}

1. Gonen $X$, Casper RF, Jacobson $W$, Blankier J. Endometrial thickness and growth during ovarian stimulation; a possible predictor of implantation in in vitro fertilization. Fertil Steril. 1989 sep, $2(3), 446-50$.

2. Smith B, Porter R, Ahuja K, Craft I. Ultrasonic assessment of endometrial changes in stimulated cycles in an in vitro fertilization and embryo transfer program. J In Vitro Fert Embryo Transf, 1984 Dec; $1(4): 233-8$.

3. Aboulghar MA, Manisour RT, Serour GI, Sattar MA, Awad MM, Amin Y. Transvaginal ultrasonic needle guided aspiration of pelvic inflammatory cystic masses before ovulation induction for in viltro fertilization. Fertil Steril. 1990 Feb;53(2):311-4.

4. Hill GA, Herbert CM, Fleischer AC, Webster BW, Maxson WS, Wentz AC. Enjargement of hydrosalpinges during ovarian stimulation protocols for in vitro fertilization and embryo replacement. Fertil Steril. 1986 Jun;45(6):883-5.

5. Peel J: Infections of fallopian tubes and ovaries. In Textbook of Gynecology. London, William Heinmann, 1960 , pp 174-177 
Chapter 4

Dummy embryo transfer: a technique that minimizes the problems of embryo transfer and improves the pregnancy rate in human in vitro fertilization

Ragaa Mansour, Mohamed Aboulghar, Gamal Serour

FERTILITY AND STERILITY Vol. 54, No.4, October 1990 
Abstract

Three hundred thirty-five patients selected for in vitro fertilization (IVF) were randomly divided into two groups. Group $A(n=167)$ was subjected to dummy embryo transfer (ET) before the start of IVF treatment to choose the most suitable catheter for each patient. Group $\mathrm{B}(\mathrm{n}=168)$ started their IVF treatment without dummy ET. Embryo transfer technique was difficult in 50 cases $(29.8 \%)$ in group $B$, whereas no difficulty was met in group A. Pregnancy rate and implantation rate $(22.8 \%, 7.2 \%)$ in group A were significantly higher than in group $\mathrm{B}(13.1 \%, 4.3 \%)$. The lower pregnancy rate in group $\mathrm{B}$ is due to the very low pregnancy rate $(4 \%)$ in difficult ET cases. Dummy ET is a simple procedure that determines the most suitable ET catheter for each patient and avoids unexpected difficult and failed ET. Fertil Steril 54:678, 1990 


\section{INTRODUCTION}

The different factors influencing the pregnancy rate after in vitro fertilization and embryo transfer (IVF-ET) have been studied by many investigators in an endeavor to improve

results. ${ }^{1,2}$ One of the most important factors that determine the outcome of IVF is the technique of ET. This last step of the IVF treatment has been examined by few investigators ${ }^{2-4}$.

Most gynecologists involved in IVF programs have certainly noticed the very wide difference in the degree of difficulty in passing the ET catheter through the cervix. Soft ET catheters are preferred over more rigid ones because the latter would be more likely to induce cervical and endometrial laceration. ${ }^{4}$ However, passing soft catheters through the cervical canal is often difficult and sometimes impossible. Failed ET and replacing the embryos using a different catheter is very frustrating and might have many adverse effects on the embryos.

Since December 1987 we have been doing a "dummy ET" for patients before starting their IVF treatment to evaluate exactly the passage of the ET catheter through the cervical canal, the length and the direction of the uterine cavity, and to determine the most suitable kind of ET catheter to be used for every patient. This study compares the IVF outcome in patients for whom dummy ET was done and those who underwent IVF treatment without performing dummy ET. 


\section{MATERIALS AND METHODS}

During the period between December 1987 and October 1989,335 patients selected for IVF were divided into two groups in a controlled, randomized study on an alternate basis. Group $A(n=167)$ was subjected to dummy ET before the start of IVF treatment. Group $B(n=$ 168) started their IVF treatment without dummy ET. The clinical characteristics of the two groups are summarized in Table 1. Our protocol for human IVF has been described previously".

\section{Duwmy ET}

After counseling the patient for IVF, the gynecologist performed the dummy ET by introducing a Wallace catheter (1816 N, H.G.; Wallace LTD., Cholchester, Englland), It is a soft silicon catheter with an external diameter of $1.6 \mathrm{~mm}$ and an end opening, fitted in a more rigid outer Teflon sleeve. If the Wallace catheter did not pass easily, a Craft Catheter $R$ 57.536; Rocket of London, Watford Herts, England) was used. It is a Teflon catheter with an end opening fitted in an introducing cannula that is rigid but malleable. In difficult cases, when neither the Wallace catheter nor the Craft catheter passed easily, a metal cannula was used to pass through the cervical canal. We use a $20-\mathrm{cm}$ metal cannula with internal and extemal diameters of 1.6 and $1.9 \mathrm{~mm}$, respectively. The cannula curves gently to follow the curvature of the cervical canal. In few cases, when the introduction of the metal cannula was difficult due to very stenosed internal os or anatomical distortion of the cervix, dilatation under anesthesia up to Hegar 12 was done. All the catheters used for the dummy ET were used previously for ET and resterilized. 


\section{ET Techique}

Embryo transfer was usually done 50 to 60 hours after oocyte pickup. Before the procedure, the patients were given $10 \mathrm{mg}$ Diazepam (Valium; F. Hoffmann-La Roche \& Co. LTD, Basle, Switzerland) intravenously. All transfers were done in the dorsal position. The ectocervix and the cervical canal up to the internal os were cleaned of cervical mucus, using a fine sterile cotton swab soaked with culture medium (Ham's F-10; Gibco Laboratories, Grand Island, NY). Meanwhile, the best four embryos were selected for the transfer and were put together in one organ tissue culture dish (Falcon 3037, Cockeysville, MD) containing Hams F-10 media supplemented with $15 \%$ heat-inactivated serum. The choice of the ET catheters was as follows:

Group A included 167 patients. The transfer was performed using a Wallace catheter, a Craft catheter, or the metal cannula chosen for each patient according to the previous evaluation of the dummy ET.

Group $\mathrm{B}$ included 168 patients who did not previously have dummy transfer. The transfer was done using either Wallace or Craft catheter. The opinion of the gynecologist about the transfer was recorded as (1) easy when the Wallace or Craft catheter passed immediately through the cervix without resistance and (2) difficult when the gynecologist had to use manipulations and strong push to pass the Wallace or the Craft catheter or when they fail to be passed completely and the metal cannula had to be used. The use of a tenaculum to hold the cervix or the occunence of bleeding was not necessarily considered as difficult transfer. The subjective evaluation of the procedure by the patient was not taken into consideration as there is a wide range of pain perception among patients. This group was divided randomly on an alternate basis into two subgroups.

Group $\mathrm{B}_{1}$ included 85 cases. The transfer was done using the Wallace catheter. In difficult cases, the metal cannula was used to negotiate the cervical canal, and the Wallace catheter 
was threaded into it. If the Wallace catheter was kinked or plugged with mucus, the embryos were replaced in a new one.

Group $B_{2}$ included 83 cases. The transfer was done using the Craft catheter. In difficult cases, the metal cannula was used, and the Craft catheter was passed through it. In case of kinking or plugging of the Craft by mucus or blood, the embryos were replaced in a new one.

In all kinds of catheters, the loading was in the following sequence: 15 to $20 \mu \mathrm{L}$ of medium, $10 \mu \mathrm{L}$ of air, the embryos were loaded in 15 to $20 \mu \mathrm{L}$ of transfer medium and withdrawn from the tip of the catheter by aspirating $10 \mu \mathrm{L}$ of air. The tip of the catheter was placed approximately $0.5 \mathrm{~cm}$ from the fundus, and the embryos were gently injected into the uterine cawity. The catheter was immediately checked for retained embryos, blood, or mucus. The length of the uterine cavity was previously measured with ultrasound (US) in group B and directly during the dummy ET in group A. After the transfer, the patients remained in bed for about 4 hours, and they usually stayed overnight in the center and were discharged the next morning. The $\mathrm{X} 2$ test was used for statistical analysis.

\section{RESULTS}

The dummy transfer showed that the Wallace catheter passed easily in 110 cases $(65 \%)$. In the remaining 57 patients, the Craft catheter passed easily in 46 cases $(80.7 \%)$. However, in 11 cases, neither the Wallace catheter nor the Craft catheter were easily introduced and the metal cannula had to be used. This last group included two cases in which the metal cannula did not pass due to severe stenosis and anatomical distortion of the cervical canal, and dilatation under anesthesia up to Hegar 12 was done. 
When the ET procedures were done for group $\mathrm{A}$, guided by the previous evaluation of the dummy ET, there was no difficulty met. In group B, there were 118 cases of easy ET and 50 cases of difficult ones. The difficult transfers were met in $32(37.6 \%)$ of ET procedures using the Wallace catheter (group $B_{1}$ ) and in 18 cases $(21.7 \%$ ) of ET procedures using the Craft catheter (group $\mathrm{B}_{2}$ ) as shown in Table 2 .

The total number of ET procedures was 167 in group A that resulted in 38 pregnancies $(22.8 \%)$, whereas in group $B$ there were 168 procedures that resulted in 22 pregnancies (13.1\%). The difference was statistically significant $(\mathrm{P}=0.02)$. There was no significant difference between the pregnancy rates in the subgroups $\mathbb{B}_{1}$ and $\mathbf{B}_{2}$ (Table 2). The total number of embryos transferred in group A were 651 embryos, resulting in 47 implantations $(7.2 \%)$, whereas in group $\mathbb{B}, 604$ embryos were transferred, resulting in 26 implantations $(4.3 \%)$. The difference is statistically significant $(\mathrm{P}=0.027)$.

The overall pregnancy rate in all cases of easy ET in both groups was $20.4 \%$, which is significantly higher than the pregnancy rate in cases of difficult $\mathrm{ET}(4 \%), \mathrm{p}=0.005$. Difficult ET resulted in a significantly lower pregnancy rate compared with easy ET perforined using the Wallace catheter, the Craft catheter, or the metal cannula $(P=0.025)$. In all cases of easy ET, 1,061 embryos were transferred, resulting in 71 implantations $(6.7 \%)$. In difficult ET 187 embryos were transferred, resulting in 2 implantations $(1 \%)$. The difference is highly significant $(\mathrm{P}=0.003)$ as shown in Table 3.

Easy ET, using the Wallace catheter, resulted in a slightly higher pregnancy rate when compared with easy ET using other catheters. The difference, however, was not statistically significant. 


\section{DISCUSSION}

There is a marked discrepancy between oocyte retrieval, fertilization, and cleavage rates that surpass the $90 \%$ range and the pregnancy rate in IVF. There are some mechanical factors that might account for lack of implantation. ${ }^{6}$ Careful study of the technique of ET may achieve improvement of the results because minor variations of the transfer technique may impact on the chance of implantation. ${ }^{7}$ Our study showed that the pregnancy and implantation rates in group $\mathrm{A}(22.8 \%, 7.2 \%)$ are significantly higher than in group $\mathrm{B}(13.1 \%, 4.3 \%)$. Both groups were comparable in all aspects except that ET procedures were easy in all cases of group A due to individual selection of the most suitable catheter for each patient, which was done according to the previous evaluation of the dummy ET. In group B, difficult ET procedures occurred in $29.8 \%$ of cases. The lower pregnancy rate in group B is due to the very low pregnancy rate $(4 \%)$ in difficult ET cases. In these cases, the passage of the catheter was difficult and manipulations had to be used that often resulted in kinking of the catheter or failure of the transfer. In case of failure, the embryos had to be replaced using another more rigid catheter. This certainly exposes the embryos to adverse effects and subjects the gynecologist and the embryologist to a lot of stress. The better pregnancy rate in cases of easy ET corresponds with earlier published data. ${ }^{2,3}$

The other possible value of the dummy ET is the exact measurement of the length of the uterine cavity from the funclus to the external os, which we found more accurate than the US measurement that does not follow exactly the curvature of the uterus. Lack of consideration of high fundal placement of embryos may be partially responsible for the higher rate of spontaneous abortion generally observed with IVF-ET. ${ }^{8}$ Also, the dummy ET discovers the anatomically distorted cervical canals and abnormally stenosed ones that might benefit from dilatation under anesthesia before the IVF treatment cycle. In some patients, the pelvic 
adhesions pull the uterus acutely toward one side, and the dummy ET is useful to recognize the direction of the cervical canal.

Our results showed that difficult ET procedures had significantly lower pregnancy and implantation rates $(4 \%, 1 \%)$ compared with easy ET $(20.4 \%, 6.7 \%)$. Soft ET catheters are generally preferred over more rigid ones. This work suggests that the best pregnancy rate. was achieved when the softest catheter (Wallace) was used and passed easily through the cervical canal. Unfortunately, these soft catheters resulted in the highest rate $(37.6 \%)$ of difficult ET procedures with its consequences of lowering the pregnancy rate. Therefore, soft catheters are preferred but only when its easy passage through the cervix is assured through the dummy ET.

Most IVF programs aim at the choice of the most suitable catheter to be used for their patients to achieve the best results. The choice should be individualized for each patient by performing the dummy ET, which is a very simple procedure that avoids the occurrence of unexpected difficult and failed embryo transfers. 
Tablo 1 Chinical Characteriutice of the Patients

\begin{tabular}{|c|c|c|c|}
\hline & \multirow[b]{2}{*}{ Group A } & \multicolumn{2}{|c|}{ Grows 1} \\
\hline & & $\mathbf{B}_{\mathbf{y}}$ & $B_{2}$ \\
\hline $\begin{array}{l}\text { No of patients } \\
\text { Agie (mean } \pm \text { SIY) } \\
\text { Indication for IVF }\end{array}$ & 39.9874 .05 & $3447 \pm 124$ & $8291 \pm 5$ \\
\hline $\begin{array}{l}\text { Tubal: } \\
\text { Tubal + male } \\
\text { Tnidometrosis } \\
\text { Tubal + owulatory } \\
\text { Dumakion of infertility } \\
\text { in yean } \\
\text { (inuean } \pm \text { SD) }\end{array}$ & $\begin{array}{r}145 \\
111 \\
4 \\
7\end{array}$ & $\begin{array}{r}74 \\
6 \\
2 \\
3\end{array}$ & $\begin{array}{r}7 \\
5 \\
3 \\
2\end{array}$ \\
\hline
\end{tabular}

- BD, estandard deviation.

Table 2 Results of ET in Group A (Previous Dummy ET) and Group B (No Previous Durnmy ET)

\begin{tabular}{|c|c|c|c|c|c|}
\hline & $\begin{array}{l}\text { "Fothal no. } \\
\text { of } E \text { " }\end{array}$ & $\begin{array}{l}\text { No. of embryas } \\
\text { per transfier }\end{array}$ & $\begin{array}{c}\text { No of } \\
\text { pregnancies }\end{array}$ & Pregnancy rate: & $\begin{array}{l}\text { No. of } \\
\text { difficult ET }\end{array}$ \\
\hline & & & \multicolumn{3}{|c|}{ 管 } \\
\hline Group A & 167 & $3.9 \pm 1.2$ & 38 & $22.8^{*}$ & - \\
\hline Group $\mathrm{B}$ & 168 & $3.6 \pm 1.9$ & 22 & $13.1^{6}$ & $50(29.8)^{\circ}$ \\
\hline $\mathbf{B}_{1}$ & 85 & $3.7 \pm 1.5$ & 10 & 18.8 & $32(37.6)$ \\
\hline $\mathrm{B}_{2}$ & 83 & $3.5+2.9$ & 12 & 14.5 & $18(21.7)$ \\
\hline
\end{tabular}

- Values are mearu $\pm \mathrm{SD}$.

t $P=0,02 ; x^{2}$ w 5.32 with 1 degree of treedon.

"Values in parentheses are percents

Table 3 Implantation Rate in Different Groups

\begin{tabular}{|c|c|c|c|c|}
\hline & No. of ET? & $\begin{array}{l}\text { Total no. of } \\
\text { embryos trminserred }\end{array}$ & $\begin{array}{l}\text { No. of } \\
\text { implantations }\end{array}$ & $\begin{array}{l}\text { Implantation } \\
\text { rate }\end{array}$ \\
\hline & & & & 路 \\
\hline Group $A$ & 167 & 651 & 47 & $7.2^{\mathrm{m}}$ \\
\hline Group 3 & 168 & 60.4 & 26 & $4.3^{\mathrm{m}}$ \\
\hline 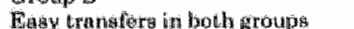 & 285 & 1061 & 71 & $6.7^{\text {s }}$ \\
\hline 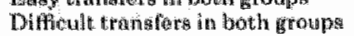 & 30 & 187 & 2 & $1^{\text {tit }}$ \\
\hline
\end{tabular}

"P $P$ a. $0.2 \%$

${ }^{B} P=0,000$. 


\section{REFERENCES}

1. Trounson $A O$ : Factors influencing the success of fertilization and embryonic growth in vitro. In Human Conception in Vitro, Edited by RG Edwards, JM Purdy. New York, Academic Press, 1982, p 201

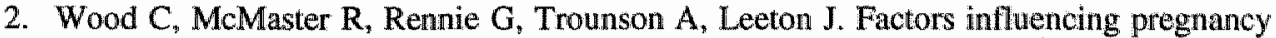
rates following in vitro fertilization and embryo transfer. Fertil Steril. 1985 Feb;43(2):245-50.

3. Englert Y, Puissant F, Camus M, Van Hoeck J, Leroy F. Clinical study on embryo transfer after human in vitro fertilization. J In Vitro Fert Embryo Transf. 1986 Aug; 3(4):243-6.

4. Wisanto A, Janssens R, Deschacht J, Camus M, Devroey P, Van Steirteghem AC. Performance of different embryo transfer catheters in a human in vitro fertilization program. Fertil Steril. 1989 Jul;52(1):79-84.

5. Aboulghar M, Mansour RT, Serour GI, Sattar MA, Awad MM, Amin Y: Transvaginal ultrasonic needle guided aspiration of pelvic inflammatory cystic masses before ovulation induction for in vitro fertilization. Fertil Steril 53:311, 1990

6. Garcia JE: Conceptus transfer. In In Vitro Fertilization, Norfolk, Vol. 1, Edited by HW Jones, GS Jones, GD Hodgen, Z Rosenwaks. Baltimore, Williams \& Wilkins, 1986, p 215

7. Meldrum DR, Chetkowski R, Steingold KA, de Ziegler D, Cedars MI, Hamilton M. Evolution of a highly successful in vitro fertilization-embryo transfer program. Fertil Steril. 1987 Jul;48(1):86-93.

8. Seppala M. The world collaborative report on in vitro fertilization and embryo replacement: current state of the art in January 1984. Ann N Y Acad Sci. 1985;442:55863. 


\section{Chapter 5}

Dummy embryo transfer using methylene blue dye

Ragaa T. Mansour, Mohamed A. Aboulghar, Gamal I. Serour, Yehia M. Amin

Human Reproduction vol. 9 no.7 pp.1257-1259, 1994 
Abstract

The aim of this prospective work was to evaluate different catheters and techniques used for embryo transfer. Studies were performed on 105 IVF patients before the start of treatment cycles. Each patient was used as her own control to study the expulsion of methylene blue (MB) dye after dummy embryo transfer. Group $\mathrm{A}(\mathrm{n}=35)$ underwent the test twice, before and after aspiration of the cervical mucus. Group $B(n=30)$ underwent the test twice with and without the presence of two air bubbles in the embryo transfer catheter. Group $C(n=40)$ underwent the test twice using two different catheters, the Wallace and the Craft catheters. The results showed that the dye was extrudled at the external os in $57 \%$ of the cases when the cervical mucus was not aspirated compared to $23 \%$ when the mucus was aspirated $(\mathrm{P}=0.01)$. The dye was extruded in $33 \%$ of the cases with air bubbles in the catheter as compared to $27 \%$ when no air was present $(\mathrm{P}>0.05)$. When the Wallace catheter was used expulsion occurred in $25.5 \%$ compared to $77.5 \%$ when the Craft catheter was used. We concluded that using soft catheters and complete aspiration of cervical mucus significantly reduced the expulsion of the dye. The presence of air bubbles did not affect rate of expulsion of the dye. 


\section{INTRODUCTION}

The technique of embryo transfer is one of the most critical steps affecting the success tate after in-vitro fertilization (IVF). We previously reported that performing a dummy embryo transfer for patients before starting their IVF treatment significantly improved the pregnancy rate (Mansour et at., 1990). The possibility of embryo expulsion after what was thought to be a successfull transfer has been the concern of different investigators (Kerin et at., 198., Poindexter et at., 1986; Schulman, 1984). Were the embryos transferred to the uterus? And if they were, did they stay there or were they expelled? This study was designed to answer some of these questions. The aim of the present work was to evaluate different catheters and different techniques for dummy embryo transfer in which methylene blue (MB) dye was used in place of the embryo column.

\section{MATERIALS AND METHODS}

This prospective study was done on 105 IVF patients before the start of their treatment cycles. It was done 4-5 days after the detection of the luteinizing hormone (LH) surge in urine, which is approximately the time of embryo transfer in the subsequent IVF cycle. The patients signed a consent to undergo this test as a rehearsal of their actual embryo transfer with the aim of improving the IVF results. Each patient was used as her own control to study the rate of expulsion of MB after dummy embryo transfer in relation to three factors. 


\section{Group A: the effect of cervical mucus}

A dummy MB test was done twice on 35 patients using the Wallace embryo transfer catheter (catalogue number $1816 \mathrm{~N}$; H.G. Wallace Ltd, Colchester, UK). It is a soft sillicon catheter with an external diameter of $1.6 \mathrm{~mm}$ and an end opening, fitted in a more rigid outer Teflon Sleeve. The catheter was loaded with MB as shown in Figure la, and the transfer itself was done by the same gynaecologist using two different techniques: (i) wiping the cervical mucus from the surface of the cervix onlly and (ii) complete aspiration of the mucus from the cervicall canal using a tuberculin syringe and a prewiously used re-sterilized Wallace catheter. In both methods the catheter was gently introduced without grasping the cervix with a tenaculum, and a volume of $20-25 \mu \mathrm{MB}$ dye was injected.

\section{Group B: the effect of air bubbles}

The Wallace catheter was used twice on 30 patients loading the catheter with two different methods: (i) loading no air in the catheter as shown in Figure la, and (ii) using air bubbles in the catheter before and after the MB as shown in Figure $\mathrm{lb}$. The total volume was the same in both conditions and the transfer was done as described above.

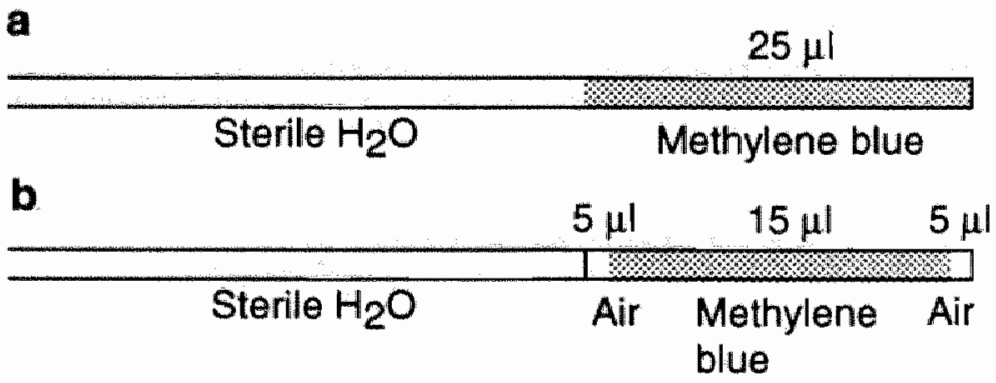

Fig. 1. Loading of the catheter for dummy embryo transfer. (a) Methylene blue only; (b) methylene blue and air bubbles. 


\section{Group C: the effect of different catheters}

A dummy MB test was done twice for 40 patients using two different catheters: (i) the Wallace catheter and (ii) the Craft catheter (R 57.536; Rocket of London, Watford, Herts, UK). It is a Teflon catheter, that is more rigid than the Wallace catheter, with an end opening and fitted in an introducing catheter that is more rigid but malleable.

In both kinds of catheters, the loading was done as shown in Figure la, and the transfer was done by the same gynaecologist as described previously. In all groups the catheter was gradually withdrawn and the cervix was observed for a few minutes to visualize the dye at the external os; a positive result was recorded if the dye was extruded or a negative one if the dye was not extruded. Cases with difficult transfers or the ones with bloody spots at the external os were excluded from the study.

\section{Statistical analysis}

McNemar's test was used.

\section{RESULTS}

In group A, the dye was visualized at the external os in 20 cases (57\%) when the cervical mucus was not aspirated compared to eight cases $(23 \%)$ when the mucus was aspirated ( $\mathrm{P}=$ $0.01)$.

In group B, the dye was extruded in eight cases (27\%) when no air was loaded in the catheter compared to 10 cases $(33 \%)$ when air was present $(\mathrm{P}>0.05)$. 
In group $\mathrm{C}$, the dye was extruded at the external os in nine cases $(22.5 \%)$ when the Wallace catheter was used compared to 31 cases $(77.5 \%)$ when the Craft catheter was used (P< 0.001 ). Extrusion of the dye occurred in $42 \%$ of all cases of dummy embryo transfer in the three groups using different techniques.

\section{DISCUSSION}

Embryo transfer technique is one of the most important factors affecting IVF results. The assurance that the embryos are successfully transferred to the uterus and that they remain in the uterine cavity is an essential prerequisite for successful IVF results.

The subject of embryo transfer has been described in detail by Betteridge and Rieger (1993), including the synchronization of reproductive cycles and techniques. Embryo transfer is being done routinely through the cervix and there are only a few reports on the use of the transfundal surgical route (Parsons et al., 1987; Kato et al., 1993). Therefore, it is essentially a blind technique following which there is no certainty that the embryos are even within the uterine cavity. The mere introduction of the embryo transfer catheter through the cervical canal may initiate uterine contraction. A forceful expulsion of a droplet of fluid was noticed at the external os up to 5-10 min after embryo transfer (Schulman, 1984). Consequently the transierred embryos are probably being partially or totally lost. Poindexter et al. (1986) collected $15 \%$ of the transferred embryos after expulsion from the external os, on the vaginal speculum, and the outer surface of the catheter. In fact, the lost fraction is probably $>15 \%$ as it is difficult to find the extruded embryos. It has been shown that stimulation of the cervix causes the release of oxytocin, thus increasing uterine contractions, and that an injection of oxytocin induces uterine contractions at all stages of the oestrous cycle in the cow (Harper et 
al., 1961). In an early study on cow, a technique dependent on the use of 'artificial ova' consisting of resin spheres impregnated with radioactive gold was used. At varying times after the insertion of the spheres, the uterus, cervix and vagina were checked for radioactivity. It was found that after $1.5 \mathrm{~h}$, a large proportion of the spheres had been expelled from the uterus altogether (Harper et al, 1961). In a similar study in humans by Knutzen et al. (1992), using radio-opaque dye mimicking embryo transfer, it was found that the dye remained primarily in the uterine cavity in only $58 \%$ of cases, and it was concluded that the remainder of the patients would have lost their opportunity for pregnancy as a result of the embryo transfer procedure. The role of embryo transfer and its associated difficulties on the outcome of human IVF were examined to assess any effects of the smooth muscle rellaxant, glyceryl trinitrate (Shaker et al., 1993). In an attempt to avoid embryo expulsion and ectopic pregnancy, Feichtinger et al. (1992) used a two-component fibrin sealant in human embryo transfer. Their technique resulted in a significant reduction in ectopic pregnancy rate. Our study showed that the dye was visualized at the external os in $42 \%$ of all cases. This means that the uterus extruded the dye, at least partially, which was transferred using the same volume and technique as in actual embryo transfer. Consequently, it is possible that the embryos may be extruded partially or totally at the time of embryo transfer. The rate of extrusion was significantly less when using soft catheters compared to rigid ones. Therefore, soft catheters are generally preferred over more rigid ones, as shown previously by Wisanto et al. (1989). Still with the use of the soft catheters, there was extrusion of the dye in $25.5 \%$ of cases. There was no significant difference between the presence or absence of two air bubbles as long as the volume was not increased.. Removing the cervical mucus before embryo transfer significantly reduced the appearance of the dye at the external os. Due to its high elastic nature, the cervical mucus probably stretches with the embryo transfer catheter during the introduction and goes back outside during withdrawal of the catheter trapping the 
MB with it. Therefore, we think it is of importance to clear the cervical mucus completely before embryo transfer, taking into consideration that it may take up to $10 \mathrm{~min}$.

We conclude that using soft catheters for embryo transfer and complete aspiration of cervical mucus significantly reduced the expulsion rate of the dye. The presence of air bubbles did not have a significant effect provided that it did not increase the volume injected. Obserwations from this study and from previous work, showing that allmost $40 \%$ of all patients might have lost their chance of pregnancy at the time of embryo transfer, should alarm physicians and scientists working in the field, and stimulate extensive research to ensure safe transfer of the embryos to the uterine cavity and to prevent factors which might cause their expulsion. 


\section{REFERENCES}

Betteridge KJ, Rieger D. Embryo transfer and related techniques in domestic animals, and their implications for human medicine. Hum Reprod. 1993 Jan;8(1):147-67.

Feichtinger W, Strohmer $\mathbb{H}$, Radner KM, Goldin M. The use of fibrin sealant for embryo transfer: development and clinical studies. Hum Reprod. 1992 Jul; 7(6):890-3.

Harper,M.J., Bemett,J.P. and Rowson,L.E. (1961) A possible explanation for the failure of non-surgical ovum transfer in the cow. Nature, 190, 789-790.

Kato O, Takatsuka R, Asch RH. Transvaginal-transmyometrial embryo transfer: the Towako method; experiences of 104 cases. Fertil Steril. $1993 \mathrm{Jan} ; 59(1): 51-3$.

Kerin JF, Jeffrey R, Warnes GM, Cox LW, Broom TJ. A simple technique for human embryo transfer into the uterus. Lancet. 1981 Oct 3;2(8249):726-7.

Knutzen V, Stratton CJ, Sher G, McNamee PI, Huang TT, Soto-Albors C. Mock embryo transfer in early luteal phase, the cycle before in vitro fertilization and embryo transfer: a descriptive study. Fertil Steril. 1992 Jan;57(1):156-62.

Mansour R, Aboulghar M, Serour G. Dummy embryo transfer: a technique that minimizes the problems of embryo transfer and improves the pregnancy rate in human in vitro fertilization. Fertil Steril. 1990 Oct;54(4):678-81.

Parsons JH, Bolton VN, Wilson L, Campbell S. Pregnancies following in vitro fertilization and ultrasound-directed surgical embryo transfer by perurethral and transwaginal techniques. Fertil Steril. 1987 Oct;48(4):691-3.

Poindexter AN 3rd, Thompson DJ, Gibbons WE, Findley WE, Dodson MG, Young RL. Residual embryos in failed embryo transfer. Fertil Steri1. 1986 Aug;46(2):262-7.

Schulman JD. Delayed expulsion of transfer flüd after IVF/ET. Lancet. 1986 Jan $4: 1(8471): 44$.

Shaker AG, Fleming R, Jamieson ME, Yates RW, Coutts JR. Assessments of embryo transfer after in-vitro fertilization: effects of glyceryl trinitrate. Hum Reprod. 1993 Sep;8(9):1426-8.

Wisanto,A., Janssens, R., Deschacht,J., Camus,M., Devroey,P. and Van Steirteghem,A.C. (1989) Performance of different embryo transfer catheters in a human in vitro fertilization program. Fertil. Steril., 52, 79-84. 


\section{Chapter 6}

The effect of sperm parameters on the outcome of intracytoplasmic sperm injection

Ragaa T. Mansour, Mohamed A. Aboulghar, Gamal I. Serour, Yehia M. Amin, Abdel Mageed Ramzi

Fertility and Sterility Vol. 64, No.5, November, 1995 


\section{Abstract}

Objective: To investigate the influence of sperm parameters on the fertilization and preginancy tates in intracytoplasmic sperm injection (ICSI).

Design: A retrospective analysis of 130 cycles of ICSI performed for the treatment af male factor infertility.

\section{Setting: The Egyptian IVF-ET Center.}

Participants: One hundred thirty couples with the diagnosis of male factor infertility or with previous failed fertilization in conventional IVF or sub zonal sperm injection.

Intervention: Ovam pick-up and ICSI.

Main Outcome Measure: Fertilization and pregnancy rates in relation to different semen parameters.

Results: A total of 1,433 oocyles were retrieved and 1,071 metaphase II oocytes were injected. Normal fertilization occurred in 620 oocytes $(58 \%)$. Embryo transfer was done for $128(98.5 \%)$ patients, and a total of $46(35 \%)$ clinical pregnancies were achieved. There was no statistically significant difference in the fertilization or pregnancy rates between patients who had previously failed fertilization in conventional TVF, patients with subfertile semen, patients with semen between 1 and $10 \times 10^{6} / \mathrm{mL}$, and patients with semen $<1 \times 10^{6} / \mathrm{mL}$. There was also no significant difference in the fertilization and pregnancy rates between patients with $<95 \%$ or $>95 \%$ teratozoospermia.

Conclusion: In ICSI, the fertilization and pregnancy rates are not affected by different semen parameters as long as morphologically well-shaped live sperms could be used for the injection. Fertil Steril 1995;64:982-6 


\section{INTRODUCTION}

Different modalities of assisted reproduction for the treatment of male factor infertility including conventional IVF were tried for several years with \ittle success (1). Various techniques of micromanipulation have been developed to assist fertilization, including partial zona dissection and subzonal insemination (SUZI) (2,3). Palermo et al. (4) reported the first successful pregnancy after intracytoplasmic sperm injection (ICSI) for the treatment of male factor, and in a large series Van Steirteghem et al. (5) reported a higher success rate using ICSI as compared with SUZI.

After this report, most IVF centers, including ours, shifted to the use of the ICSI technique as the only method of assisted fertilization. The introduction of ICSI opened the door for the treatment of male factor infertility irrespective of the severity of the condition. The aim of the present work was to study the effect of different sperm parameters on the fertilization and pregnancy rates after ICSI.

\section{MATERLALS AND METHODS}

A series of 130 ICSI cycles was performed for the treatment of infertility due to male factor with different degrees of severity. The mean age of the femalle partners was $35 \pm 4$ (mean \pm SD) years (range 23 to 41 ). The mean duration of infertility was $8.3 \pm 3.9$ years (range 3 to 19). Couples were counseled extensively about the technigue and signed a consent form prepared by our ethical committee. The initial semen evaluation was done on at least two samples before the treatment cycle and one or both samples were cryopreserved. Semen was 
considered abnomal if the count was $<20 \times 10^{6} / \mathrm{mL}$, motility $<40 \%$ according to the World Health Organization (WHO) criteria (6), and normal morphology $<14 \%$ according to Kruger et al:'s (7) strict criteria.

The patients were divided into four groups according to semen parameters. Group $1(\mathrm{n}=28)$ included patients who had previous total failure of fertilization, at least twice, in regular IVF with normal semen parameters, including 5 patients with previous failure or poor fertilization after SUZI. Group $2(n=21)$ included patients who had subfertile semen that was just below the WHO criteria. They had a count of 10 to $20 \times 10^{6} / \mathrm{mL}$, motility $<40 \%$, and abnormal forms $>40 \%$. Group $3(\mathrm{n}=32)$ consisted of patients who had a count from 1 to $10 \times 10^{6} / \mathrm{mL}$, motility $<30 \%$, and abnormal forms $>60 \%$. Group $4(\mathrm{n}=49)$ included patients who had a count $<1 \times 10^{6} / \mathrm{mL}$, including 28 patients with only a few motile sperms in the whole ejaculate. In this latter subgroup the actual counts were not evaluated so as not to lose any motile sperms in the counting chambers. These patients were routinely asked to provide a second and, if possible, a third sample. We used our routine long GnRH analogue and hMG protocol for the induction of ovulation as described before (8).

\section{Oocyte Handling}

The oocytes were denuded of their surrounding cumulus cells ( 2 hours after ovum pick-up) wing hyaluronidase $80 \mathrm{TU} / \mathrm{mL}$ in $\mathrm{N}$-2-hydroxyethylpiperazine-N"2-ethanesulfonic acid (HEPES)-buffered Earle's Balance Salt Solution (EBSS; cat no.1200; Medicult, Copenhagen, Denmark) for 10 to 15 seconds, and then the oocytes were transterred to Ham"s F-10 (GIBCO Laboratory, Grand Island, NY) for complete removal of the corona cells by repeated aspiration in a finely pulled pipette. The oocytes were then rinsed and incubated in Ham's F-10 medium/10\% patient serum under mineral oil (Squibb, Princeton, NJ) untill the 
time of injection ( 2 to 3 hours after pick-up) that was done only for oocytes that extruded their first polar bodies, metaphase II (MII).

\section{Semen Processing}

Semen samples were usually collected before or at the time of ovum pick-up, and when necessary the husband was asked to collect a second sample a few hours later. Five milligrams of alpha chemotrypsin (cat. no. C-4129; Sigma Chemical Company, St. Louis, $\mathrm{MO}$ ) in $2 \mathrm{~mL}$ Ham"s F-10 was added to the semen sample. After complete liquefaction, the semen was washed twice with Ham's F-10, and the final pellet was resuspended in $0.2 \mathrm{~mL}$ medium and layered carefully in the surrounding ring of a Tea tube (9), filled with Ham's F10, and incubated untill the time of injection. Sperm suspension was aspirated from the central cone of the Tea tube, and the count was adjusted from 2 to $6 \times 10^{6} / \mathrm{mL}$. Approximately $2 \mu \mathrm{L}$ from this sperm suspension was added to the polyvinylpyrrolidone (PVP) droplet. In cases of severe oligoasthenospermia, the micropipettor was used to aspirate $2 \mu \mathrm{L}$ from the bottom of the central cone of the Tea tube to be added directly to the PVP droplet. We always have been able to retrieve enough sperms for the microinjection using this technique of sperm processing, and we have never used Percoll gradient. In some cases of very severe oligospermic samples, a microdroplet from the pellet itself had to be wsed to search for a motile sperm and transfer it to the PVP droplet using the microinjection pipette.

\section{Microinjection Procedure}

The cover of an organ tissue culture dish (Falcon 3037; Becton Dickinson Labware, Lincoln Park, NJ) was used as the injection dish. A microdroplet of $10 \mu \mathrm{L}$ PVP $10 \%$ (cat. no.1089; 
Medicult; Copenhagen, Denmark) was put in the middle and was surrounded by eight microdropletef of EBSS/HEPES (cat. no. 1034; Medicult) under oil.

The oocytes were put individually in the EBSS/ HEPES droplets, and the sperms were put in the PVP droplet as described above. The micromjection procedure was done using an inverted phase microscope (diaphot TMD; Nikon, Tokyo, Japan) with a heated stage (Swemed Laboratory, Frolunda, Sweden) and equipped with a Hoffman condenser (Modulation Optics Ince. Greenvale, NY), and micromanipulation was set (Narishige Inc., Tokyo, Japan). The procedure was allowed to be followed on a monitor (model KX-14CPI; Sony, Tokyo, Japan) connected to a video camera (Panasonic color CC TV camera model WVCL 300/6; Matsushita Communication Industrial Co., Tokyo, Japan) that was attached to the microscope. The injection micropipettes were ready made (Humagen Fertility Diagnostics, Charlottesville, VA); they had an inner diameter of approximately equal to 7 $\mu \mathrm{m}$, a bevel of $45^{\circ}$, and a spike. The holding pipettes were from Cook (calt. no. K- HPIP1000; Eight Mile Plains, Queensland, Australia).

The microinjection pipette was lowered in the PVP microdroplet, and one sperm was chosen (the best available motile and morphologically well shaped) and was immobilized by touching its tail near the midpiece with the injection micropipet. The immobilized sperm was aspirated, tail first, into the injection pipette. After securing the oocyte in position with the holding pipette (polar body at 6 or 12 o clock position), the injection pipette was introduced at the 3 o'clock position through the zona pellucida, oolemma, and deeply into the cytoplasm, and the sperm was injected slowly and the pipette was withdrawn. We never tried to aspirate the cytoplasm. After injection, the oocytes were rinsed and incubated under oil in Ham's F$10110 \%$ serum.

The next morning, the oocytes were examined for evidence of fertilization and transferred to fresh media (Ham's F-10/20\% patient serum). Embryo transfer was done on day 2 after the 
pick-up, using a Wallace catheter (cat. no.1816, N.H.G. Wallace Limited, Cholchester, England) or a Labotect catheter (Labotect, Bovender-Gottingen, Germany) if the Wallace catheter could not be introduced. Luteal phase support was given routinely in the form of 2,500 IU hCG every 4th day. Cases that were considered at high risk of developing ovarian hyperstimulation syndrome were given a daily $P$ injection (100 $\mathrm{mg}, \mathrm{P}$ USP; STERIS, Phoenix, AZ). Serum ( $\beta$-hCG test was done 2 weeks after the ET to dilagnose pregnancy, and ultrasonic examination was done after 2 to 3 weeks for patients with a positive test. Clinical pregnancy was diagnosed by the presence of a gestational sac with fetal echoes and pulsations. Chï-square test was used for statistical analysis. $\mathrm{P}<0.05$ was considered significant.

\section{RESULTS}

A total of 130 cycles were performed, and 1,433 oocytes were retrieved. Out of: 1,433 oocytes retrieved, $1,071(74.7 \%)$ were at the metaphase II $_{w} 172(12 \%)$ were at the metaphase I, $143(10 \%)$ were at the prophase, and $47(3.3 \%)$ were fractured and ill formed. Out of 1,071 oocytes at the metaphase II that were injected, $1,028(96 \%)$ were intact after the injection and when examined the next morning. Normal fertilization (two pronuclei) occurred in 620 oocytes $(58 \%)$, 3 PN were observed in $10(1 \%)$, and $1 \mathrm{PN}$ was observed in $32(3 \%)$. Twentysix oocytes were already at the two-cell stage 18 to 20 hours after the injection. Cryopreservation was done for 133 normally fertilized oocytes (21.5\%), and cleavage arrest occurred for $39(8 \%)$ of the normally fertilized oocytes. Out of the 130 ovum pick-up cycles, $128(98.5 \%)$ reached the ET stage with an average of 3.5 embryos per transfer. A total of 46 
(35\%) clinical pregnancies were achieved, including $12(26 \%)$ multiple pregnancies. A total of 10 abortions $(21 \%)$ occurred in this series.

The number of oocytes retrieved, number of metaphase II oocytes that were injected, number of oocytes fertilized, and the clinical pregnancies in all groups are shown in Table 1 . The fertilization rates were $52 \%, 58 \%, 59 \%$, and $61 \%$ in groups $1,2,3$, and 4 , respectivelly. The clinical pregnancy rates were $36 \%, 38 \%, 34 \%$, and $35 \%$ in groups $1,2,3$, and 4 , respectivelly. There was no statistically significant difference in fertilization and clinical pregnancy rates between the four groups of patients irrespective of the semen parameters. There was no significant difference in the pregnancy wastage between all groups. As shown in Table 2, there was no statistically significant difference in the fertilization and pregnancy rates between patients with $\geq 95 \%$ abnormal forms $(n=41)$ and patients with $<95 \%$ abnormal forms $(n=89)$.

In 122 of 130 patients, enough numbers of motile morphologically well-shaped sperms have been identified and used for microinjection. Eight patients had 100\% teratozoospermia, and abnormal forms were the only available sperms for the injection. Two patients had $100 \%$ amorphous heads, and there was a complete failure of fertilization. In 6 patients, with $100 \%$ midpiece abnormalities, 54 metaphase II oocytes were injected and normal fertilization was achieved in $31(57 \%)$. Fertilization was achieved in all 6 patients, and 4 of them became pregnant. Two pattents aborted and the two other pregnancies are ongoing.

\section{DISCUSSION}

In conventional IVF it was reported that embryos resulting from poor semen had less quality and were associated with low pregnancy rate (10). Before the introduction of ICSI, it had 
been shown that sperm characteristics influenced the outcome of assisted fertilization techniques and that sperm of mostly teratozoospermic semen appeared to be unable to produce functionally normal embryos either because of metabolic errors or genetic aberrations (11). Palermo et al. (12) investigated the relation between the sperm parameters and the outcome of SUZI and ICSI and found out that none of the single sperm parameters, such as concentration, progressive motility, or morphology, correlated with the outcome of assisted fertilization. On the other hand, they found a correlation between the number of progressive motile sperms with normal morphology in the whole ejaculate and the fertilization and pregnancy rates. They also demonstrated that embryos obtained from men with extensive teratozoospermia implanted at a significantly lower rate than embryos from men with less severe teratozoospermia; however, they commented that these findings required confirmation on a larger number of pregnancies.

The present study using ICSI for the treatment of male factor infertility showed that there was no correlation between the sperm motility, density, or percentage of abnormal forms and the fertilization and pregnancy rates so long as motile morphologically well-shaped sperm could be found for the microinjection. Our data support other recent publications that showed no relation between semen parameters and the ICSI results. Cohen et al. (13) reported that in ICSI there was no significant correlation between the percentage of normal sperm forms, fertilization, and implantation. They were also not able to correlate fertilization and implantation with sperm concentration or motility. The same finding was also demonstrated by Payne et al. (14), who reported that there was no significant difference in the fertilization or pregnancy rates between patients who had only occasional motile spermatozoa in the ejaculate, semen that was too poor for routine IVF, or had failed routine IVF and/or SUZI. 
In agrement with several recent reports $(12-14)$, our data demonstrated that patients who had previous failed fertilization with conventional IVF or SUZI had a similar success rate as compared with other groups. Rowlands et al. (15) reported that true idiopathic fertilization Pailure must be consistent and not a haphazard event that may rectify itself in subsequent cycles. It is our routine policy that patients with normal semen and only one cycle of previous failure of fertilization in conventional IVF not to be allocated directly for our ICSI program. In their next IVF cycle, the retrieved oocytes for each patient are randomly divided between conventional IVF and ICSI. This will confirm the diagnosis and at the same time will rescue the cycle with embryos resulting from the ICSI group. In this study, the first group consisted of patients that had at least two cycles of previous failure of fertilization.

Our results show that there was no significant difference in fertilization and pregnancy rates in patients with severe teratozoospermia as compared with less-severe forms (Table 2). This could be explained by the fact that we were able to inject morphologically well-shaped live sperm in all but eight patients with $100 \%$ teratozoospermia. It is believed that the outcome of ICSI is not affected by the different sperm parameters if a well-shaped motile sperm could be isolated and injected, and the number finally needed for injection in ICSI is very small.

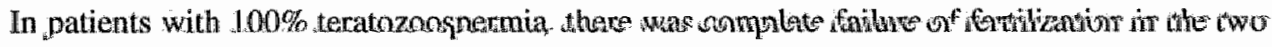
patients with amorphous spetm head. On the other hand, there was an excellent fertilization and pregnancy rate in patients with midpiece deformities. Midpiece deformity is probably due to the presence of cytoplasmic droplet that seems to have no deleterious effect on the fertilizing ability of the spermatozoa as long as the head is mormal. At the time being, in patients with $100 \%$ teratozoospermia, it is recommended to choose sperm for injection with midpiece abnormalities rather than head defects if at all possible. However, the data on absolute teratozoospermia are too small to confirm this finding. Lunden et al. (16) reported recently the first delivery from patients with $100 \%$ acrosomeless sperm (rounded heads). 
This shows that even in patients with $100 \%$ abnormal forms, pregnancy and delivery of healthy babies is possible after the use of ICSI.

A Percoll gradient was not used in this study to select spermatozoa used for injection. The sperm selection method used in this study, which is routinely used in our ICSI program, is unusual when compared with the majority of other ICSI programs. It may have an interesting implication in the comparison of embryo cleavage, quality, implantation, and normality of the babies borm. This experience may clarify the different outcomes in studies that use a sperm selection by Percoll where silica gel particles may have been injected into the egg during ICSI.

In conclusion, our results show that the excellent success rate of ICSI, which was reported, recently is reproducible. It also shows that different sperm parameters do not affect the fertilization, pregnancy rates, or the outcome of pregnancy as long as a morphologically well-shaped motile sperm is used for the injection. Further studies on patients with total teratozoospermia are ongoing to evaluate the fertilization and pregnancy rates and the outcome in this group.

Table 1 Fertilization and Prequancy Ratel in All Groups

\begin{tabular}{|c|c|c|c|c|c|}
\hline Grousp & $\begin{array}{c}\text { Noto. } \\
\text { phtients. }\end{array}$ & 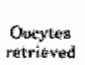 & 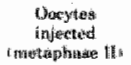 & 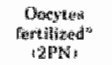 & 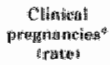 \\
\hline 1 & 28 & 302 & 252 & $182(52) \div$ & $10(36)$ \\
\hline 2 & 21 & 233 & 167 & $96(58)$ & $8(38)$ \\
\hline 3 & 32 & 347 & 256 & $151(59)$ & $11(34)$ \\
\hline 4 & 49 & 551 & 396 & $241(61)$ & $17(35)$ \\
\hline Total & 1,30 & 1,433 & 1,071 & $B 20(58)$ & $46(35)$ \\
\hline
\end{tabular}

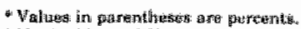

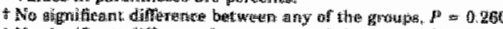

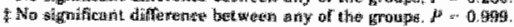


Table 2 Fertilization and Pregriancy Rates in Rielation to Abnormal Eorm Fiate

\begin{tabular}{|c|c|c|c|c|}
\hline 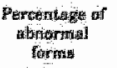 & Pow & 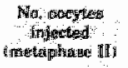 & 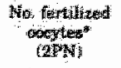 & 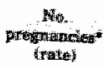 \\
\hline$>950$ & 斗薄, & 348 & $2060(159)$ & $15(36 ; 6)$ \\
\hline$\angle 90 \%$ & 89 & 722 & $41.6(57,3)$ & $31(346,8)$ \\
\hline
\end{tabular}

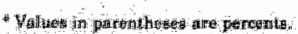

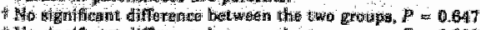

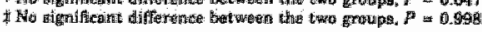




\section{REFERENCES}

1. Ron-el R, Nachum H, Herman A, Golan A, Caspi E, Soffer Y. Delayed fertilization and poor embryonic development associated with impaired semen quality. Fertil Steril. 1991 Feb;55(2):338-44.

2. Malter HE, Cohen J. Partial zona dissection of the human oocyte: a nontraumatic method using micromanipulation to assist zona pellucida penetration. Fertil Steril. 1989 $\operatorname{Jan} ; 51(1): 139-48$.

3. Laws-King A, Trounson A, Sathananthan H, Kola I. Fertilization of human oocytes by microinjection of a single spermatozoon under the zona pellucida. Fertil Steril. 1987 Oct:48(4):637-42.

4. Palermo G, Joris H, Devroey P, Van Steirteghem AC. Pregnancies after intracytoplasmic injection of single spermatozoon into an oocyte. Lancet. $1992 \mathrm{Jul} 4 ; 340(8810): 17-8$.

5. Van Steirteghem AC, Liu J, Joris $H$, Nagy Z, Janssenswillen C, Tournaye $H$, Derde $M P_{\text {, }}$ Van Assche E, Devroey P. Higher success rate by intracytoplasmic sperm injection than by subzonal insemination. Report of a second series of 300 consecutive treatment cycles. Hum Reprod. 1993 Jul;8(7):1055-60.

6. World Health Organization. Laboratory manual for the examination of human semen and semen-cervical mucus interaction. 3rd ed. New York: Cambridge University Press, 1993.

7. Kruger TF, Menkveld R, Stander FS, Lombard CJ, Van der Merwe JP, van Zyl JA, Smith K. Sperm morphologic features as a prognostic factor in in vitro fertilization. Fertil Sterill. 1986 Dec;46(6): 1118-23.

8. Aboulghar MA, Mansour RT, Serour GI, Amin YM. The prognostic value of successful in-vitro fertilization in subsequent trials. Hum Reprod. 1994 Oct;9(10):1932-4.

9. Lucena E, Lucena C, Gomez M, Ortiz JA, Ruiz J, Arango A, Diaz C, BeuermanC. Recovery of motile sperm using the migration-sedimentation technique in an in-vitro fertilization-embryo transfer programme. Hum Reprod. 1989 Feb;4(2):163-5.

10. Parinaud J, Mieusset $R$, Vieitez G, Labal $B$, Richoilley $G$. Influence of sperm parameters on embryo quality. Fertil Sterill. 1993 Nov;60(5):888-92.

11. Cohen J, Talansky BE, Malter H, Alikani M, Adler A, Reing A, Berkeley A, Graf M, Davis $\mathrm{O}$, Liu $\mathrm{H}$, et al. Microsurgical fertilization and teratozoospermia. Hum Reprod. $1991 \mathrm{Jan} ; 6(1): 118-23$.

12. Palermo G, Joris $H$, Derde MP, Camus M, Dewroey $P$, Van Steirteghem A. Sperm characteristics and outcome of human assisted fertilization by subzonal insemination and intracytoplasmic sperm injection. Fertil Steril. 1993 Apr;59(4):826-35. 
13. Cohen J, Alikani M, Munne $\mathrm{S}$, Palermo G. Micromanipulation in clinical management of fertility disorders. Semin Reprod Endocrinol 1994;12:151-6.

14. Payne D, Faherty SP, Jeffrey R, Warnes GM, Matthews CD. Successful treatment of severe male factor infertility in 100 consecutive cycles using intracytoplasmic sperm injection. Hum Reprod. 1994 Nov; $9(1$ 1):2051-7.

15. Rowlands DJ, McDermott A, Hull MG. The prognosis for assisted conception treatment after unexpected failure of fertilization in vitro: a comparative study. Hum Reprod. 1994 Dec;9(12):2287-90.

16. Lundin K, Sjogren A, Nilsson L, Hamberger L. Fertilization and pregnancy after intracytoplasmic microinjection of acrosomeless spermatozoa. Fertil Steril. 1994 Dec;62(6):1266-7. 


\section{Chapter 7}

Intracytoplasmic sperm injection using microsurgically retrieved epididymal and testicular sperm

Ragaa T. Mansour, Mohamed A. Aboulghar, Gamal I. Serour, Ibrahim Fahmi, Abdel Maguid Ramzy, Yehia Amin

FERTILITY AND STERILITY Vol. 65, No.3, March 1996 
Abstract

Objective: To evalluate treatment of couples who are infertile due to unreconstructable obstruetive azoospermia with microsurgical epididymal sperm aspiration or testicular sperm and intracytoplasmic sperm injection (ICSD).

Design: Prospective.

Setting: The Egyptian IVF-ET Center in association with Cairo University:

Patients" 'Twenty-three couples who are infertile due to obstructive azoospermia in which reconstructive microsurgery failed or was not possible.

Interventions: Microsurgical epididymal or testicular sperm retrieval and ICSI in 24 cycles. Main Outcome Measures: Fertilization and pregnancies.

Results: All 24 cycles had successful fertilization and reached the ET stage. In microsurgical epididymal sperm aspiration cases, fertilization rate per metaphase II oocyte was $63 \%$ (109/ 172). Six patients became pregnant, including one set of twins and one set of triplets. One pregnancy resulted from the use of cryothawed epididymal sperm. In testicular sperm aspiration cases, the fertilization rate was 59\% (32/54) and four clinical pregnancies resulted. Conclusion: The use of microepididymal sperm aspiration or testicular sperm aspiration in conjunction with ICSI provide a highly precise and efficient procedure for achieving pregnancy in cases of unreconstructable obstructive azoospermia. Fertil Steril 1996; 65:56672 


\section{INTRODUCTION}

Patients with obstructive azoospermia due to congenital absence of the vas deferens or those who failed reconstructive surgery were considered hopelessly infertile. Recently, IVF in conjunction with microsurgical sperm aspiration, first described in 1984 by Pryor et al. (1) and in 1985 by Temple-Smith et al. (2), provided new hope for those patients. Pregnancy and live birth after microepididymal sperm aspiration and IVF was reported by Silber et al. $(3,4)$ in 1988 and 1990 . The fertilization and pregnancy rates after microepididymal sperm aspiration and IVF were low and epididymal sperm appeared to have impaired fertilizing ability with conventionall IVF (5). The introduction of intracytoplasmic sperm injection (ICSI) (6) made IVF so efficient and precise to the extent that very low numbers of spermatozoa, regardless of their motility pattern, are required to fertilize the oocytes retrieved for the procedure. The combination of both microepididymal sperm aspiration and ICSI proved to be a highly successful technique that significantly improved the results as reported by Tournaye et al (7). Silber et al. (8) demonstrated clearly that ICSI could achieve better results than conventional IVF with microsurgically retrieved epididymal or testicular sperm. In some cases, the epididymis is absent or fibrosed, and a testicular biopsy is needed

to extract spermatozoa. Recently, fertilization and pregnancies were reported after the use of testicular sperm in conjunction with ICSI (9). The aim of the present work was to report our experience with the first 24 cycles of ICSI using microsurgically retrieved epididymal or testicular sperm. 


\section{MATERIALS AND METHODS}

A total of 23 couples with infertility due to obstructive azoospermia were considered for microsurgical sperm retrieval in conjunction with ICSI. Eight men had bilateral congenital absence of the vas deferens. Alloplastic spermatocele had been implanted in one of them but aspiration from this artificial spermatocele was negative for sperm. Two cases had single testis with unilateral congenital absence of the vas in one patient and acquired vasal obstruction in the second patient. Three men had unilateral absent vas with contralateral ductal obstruction for which previous attempts of reconstructive surgery had failed. Eight patients had acquired obstructive azoospermia and previous epididymovasostomy trials had failed due to multiple obstructions. One patient had a previous vasectomy operation for contraception and failed reconstructive surgery twice. One patient had unilateral orchidlopexy, the other testis was normal. His semen showed severe oligospermia $(<1 \mathrm{X}$ $10^{6} / \mathrm{mL}$ ). Bilateral testicular biopsy showed germinal aplasia at the site of orchidopexy and normal spermatogenesis on the other testis. Incomplete obstruction was diagnosed and the patient was appointed for ICSI. On ovum pick-up day, semen analysis showed azoospermia. Testicular sperm retrieval was done as an emergency to avoid canceling the ICSI procedure. The female partners had regular ovulatory eycles and normal pelvic and general examinations. There was no history suggestive of previous pelvic infection or pelvic surgery. An infertility work-up and tubal patency test were not done routinely for them. Patient characteristics are shown in Tables 1 and 2.

Counseling was done for each of the couples with congenital absence of the vas deferens to inform them about the possibility of having offspring with cystic fibrosis (CF). They were told that if the wives were CF negalive, then the risk of having offspring with CF was approximately $0.3 \%(10)$. None of the patients agreed to be tested because they considered the risk to be minimal. 


\section{Ovarian Stimulation and Oocyte Retrieval}

The wives received $200 \mu \mathrm{g} / 8 \mathrm{~h}$ Suprefact nasal spray (Hoechst AG, Frankfurt am Main, Germany) 10 days before menstruation and until the day of hCG injection. Human menopausal gonadotropin (Humegon; Organon, Oss, The Netherlands) was given (2 to 3 weeks after the start of Suprefact) $150 \mathrm{IU} / \mathrm{d}$ IM for 5 days, and then the dose was modified according to the response. When two or more follicles reached $>18 \mathrm{~mm}$ in mean diameter, 10,000 IU hCG was given IM and ovum pick-up was scheduled 36 hours later.

\section{Microsurgical Epididymal Sperm Aspiration}

The procedure was performed under general anesthesia in an ambulatory surgicenter as an outpatient procedure. Via a small scrotal longitudinal incision, the tunica vaginalis was identified and incised; subsequently, the epididymis was delivered into the operative field. At this point, the procedure was performed under the operating microscope at $10 \mathrm{x}$ to $40 \mathrm{x}$ magnification as a modification of the technique described by Silber et al. (3). The aspiration was attempted at the lowest possible level within the epididymis. The epididymal capsule was incised using microscissors and epididymal fascia was dissected. Meticulous hemostasis was achieved using a bipolar microcoagulator on low-voltage setting. A single epididymal tubule was isolated and punctured using the microscissors. The fluid coming out from the open tubule was aspirated with a tuberculin syringe containing $0.1 \mathrm{~mL}$ of HEPES Earl's buffered salt solution (EBSS, cat. no.1034; Medicult, Copenhagen, Denmark) attached to a 25-gauge angiocatheter. The fluid was examined microscopically within the operating room for the presence of motile sperms. If the aspirated fluid contained no motile sperm, another tubule in a more proximal site was incised. When the aspirate contained motile sperms it was transferred to a 5-mL. Falcon tube containing $1 \mathrm{~mL}$. HEPES-buffered EBSS media. The same 
syringe was used for continued aspiration at the same site until a sufficient number of sperm was obtained. The epididymal sheath was closed with interrupted $8-0$ nyton sutures. This closure of the tunica epididymis would decrease the amount of postoperative scarring and adhesions, thus allowing repeat microepididymal sperm aspiration to take place if necessary. In seven cases, testicular biopsies were taken because the epididymis was fibrosed or absent. The closure of the tunica vaginalis, dartos, and skin was carried out in a standard fashion.

The Fralcon tubes (Becton Dickson, Plymouth, United Kingdom) containing the aspirated epididymal sperms or the testicular biopsies were put in an isolated container to prevent exposure to sunlight or extremes of temperature. The container was carried to our IVF center and the delivery time ranged from approximately 0.5 to 1 hour.

\section{Epididymal Sperm Processing}

The epididymal sample was washed with HEPES EBSS and centrifuged for 7 minutes at 400 $\mathrm{Xg}$. The pellet was resuspended in $0.2 \mathrm{~mL}$ media and layered carefully in the surrounding ring of a Tea tube (11) that was filled with Ham's F-10 medium (GIBCO Laboratory, Grand Island, NY) and $10 \%$ patient serum. The tube was incubated at $5 \% \mathrm{CO}_{2}$ at $37^{\circ} \mathrm{C}$ until use. After completing the microinjection, the rest of the sperm was cryopreserved in all cases for possible future use.

\section{Testicular Biopsy Processing}

The biopsy was morselized in a petri dish (Falcon cat. no.3001, Becton Dickson) under the dissecting microscope using two needles. The morselized tissues were incubated in $1.5 \mathrm{~mL}$ Ham's F-10 medium for approximately 2 hours in a $5-\mathrm{mL}$ Falcon tube. The contents of the 
tube then were mixed and allowed to settle for 1 minute and the deposited pieces of testicular tissue were removed.

The tube was centrifuged for 5 minutes at $400 \mathrm{Xg}$ and the pellet was resuspended in $0.2 \mathrm{~mL}$ Ham's F-10 medium. Two or three microdroplets were used from this resuspended pellet to be put near the PVP microdroplet in the injection dish. Using the injection micropipette, a search was done for a motile sperm, which was aspirated from among Sertoll cells, red blood cells, and debris and transferred to the polyvinylpyrrolidone (PVP) droplet. It was immobilized, aspirated tail first, and injected into the oocyte. During sperm immobilization by touching the sperm near the midpiece, cytoplasmic droplets and some debris around the midpiece and tail were removed.

\section{Oocyte Handling}

The oocytes were denuded of their surrounding cumulus cells 2 hours after owum pick-up using $80 \mathrm{IU} / \mathrm{mL}$ hyaluronidase (catalog no.1200; Medicult) for 10 seconds, and then the oocytes were transferred to Ham's F-10 for complete removal of the corona cells by repeated aspiration in a finely pulled pipette. The oocytes then were rinsed and incubated in Ham's F10 and $10 \%$ patient serum under mineral oil (Squibb, Princeton, NJ) until the time of injection. Intracytoplasmic injection was done only for oocytes that extruded their first polar bodies.

\section{Microinjection Procedure}

The injection dish used was the cover of a Falcon dish (cat. no.3037; Becton Dickinson; Plymouth, United Kingdom). A microdroplet of $10 \mu \mathrm{L}$ PVP 10\% (cat. no.1089; Medicult) was put in the middle and was surrounded by eight microdroplets of HEPES EBSS under oil. The oocytes were put individually in each droplet. Approximately $2 \mu \mathrm{L}$ from the bottom of 
the Tea twbe was added to the PVP droplet and checked under the microscope. If no sperm were found, a microdroplet from the resuspended pellet itself was put near the PVP.The microinjection procedure was done using an inverted-phase microscope (Nikon diaphot TMD; Nikon, Tokyo, Japan) with a heated stage (Swemed, Frolunda, Sweden) and equipped with Hoffman condenser (Modulation Optics Inc. Greenvale, NY) and micromanipulation set (Narishige Inc: Tokyo, Japan). The procedure was allowed to be followed on a monitor (model no. KX-14CPI, Sony, Tokyo, Japan) connected to a video camera (Panasonic color CC TV camera model no. WVCL 300/6; Matsushita Communication Industrial Co., Tokyo, Japan) that was attached to the microscope. The injecting micropipettes were ready made (Humagen Fertility Diagnostics, Charlottesville, V A) and the holding pipettes were from Cook (cat. no. K-HPIP-1000; Cook, Eight Mile Plains, Queensland, Australia). The microinjection pipette was lowered in the PVP microdroplet and one sperm was chosen (the best available motile and morphologically well-formed sperm) and was immobilized by touching its tail near the midpiece with the injecting micropipet. The immobilized sperm was aspirated, tail first, into the injecting pipette. After securing the oocyte in position with the holding pipette (polar body at 6 or 12 o'clock position), the injecting pipette was introduced at the 3 o'clock position through the zona pellucida, oolemma, and deeply into the cytoplasm. The sperm then was injected slowily and the pipette was withdrawn. No attempt was made to aspirate the cytoplasm. After injection, the oocytes were rinsed and incubated ander oil in Ham's F-10 and $10 \%$ patient serum. The next morning, the oocytes were examined for evidence of fertilization and transferred to fresh media (Ham"s F-10 and $20 \%$ patient serum). The rate of cleavage and morphological appearance of embryos were observed. Embryo transfer was done on day 2 after the pick-up, using the Wallace catheter (cat. no. $1816 \mathrm{~N}_{*}$ H.G. Wallace Limited, Cholchester, United Kingdom) or the Labotect catheter (Labotect, Bovender-Gottingen, Germany) if the Wallace catheter could not be introduced. Luteal phase 
support was given routinely in the form of $2,500 \mathrm{IU}$ hCG every 4 th day. Cases that were considered at high risk of developing ovarian hyperstimulation syndrome were given a daily. P injection (100 mg, P USP, STERIS, Phoenix, AZ). A serum $\beta$-hCG test was done 2 weeks after ET to diagnose pregnancy, and an ultrasound examination was done after 2 to 3 more weeks for patients with a positive test. Clinical pregnancy was diagnosed by the presence of a gestational sac.

\section{RESULTS}

A total of 23 patients with infertility due to obstructive azoospermia underwent 24 cycles of microsurgical sperm retrieval in combination with ICSI. The total number of metaphase II oocytes injected was 226 and normal fertilization (two pronuclei [2PN]) was evident in 141 oocytes (62\%). All patients reached the ET stage with an average of 3.7 embryos per transfert. Ten clinical pregnancies resulted in this series, achieving a clinical pregnancy rate of $42 \%$. Three healthy babiles were born, one abortion occurred in the first trimester, and the rest of the pregnancies are ongoing.

Tables 3 and 4 summarize the results of microepididymal sperm aspiration and testicular sperm aspiration cases respectively. Table 5 illustrates a comparison between microepididymal sperm aspiration and testicular sperm aspiration results. There was no significant difference in the fertilization and pregnancy rates between both groups $(\mathrm{P}>0.05)$. In 17 cycles, the spermatozoa were aspirated microsurgically from the epididymis. The epididymal samples aspirated contained large numbers of spermatozoa in most of the cases, ranging between 0.3 and $200 \times 10^{6} / \mathrm{mL}$, with an average of $30 \times 10^{6} / \mathrm{mL}$. The initial sperm motility ranged between $\mathbb{1} \%$ and $25 \%$ with an average of $6 \%$ and forward grade 1 and 2 (World Health Organization standards) (12). The abnormal forms ranged from $65 \%$ to $100 \%$ 
according 10 strict criteria (13). The abnormality was mostly in the midpiece because of the presence of a cytoplasmic droplet whereas the morphology of the sperm head was mostly normal. In seven cases the epididymis was either absent or completely fibrosed and testicular biopsies were taken. The sperm retrieved ranged from very few spermatozoa to $2 \times 10 \% / \mathrm{mL}$, with an average of $5 \%$ motility and forward grade $1+$ or barely twitching in place.

Cryopreservation was done for $452 \mathrm{PN}$ oocytes in eight cycles. Three pregnant patients have a total of 22 cryopreserved embryos for future use. All patients had the rest of the aspirated epididymal and testicular spermatozoa cryopreserved. Cryothawed epididymal spermatozoa was used in one case and resulted in successful fertilization and an ongoing pregnancy.

\section{DISCUSSION}

Men with surgically unreconstructable obstructive azoospermia are relatively common among infertile patients. In Egypt, congenital absence of the vas deferens accounts for $\geq 10 \%$ of the cases of obstruction (14). Retroperitoneal vasal obstruction, multiple obstructions, and failed attempts of epididymovasostomy are other common examples of unreconstructable causes of infertility (15). Using epididymal or testicular sperm in patients with obstructive azoospermia to fertilize their wive's oocytes in vitro is a great achievement and a highly valued procedure espechally in countries, like ours, where no sperm donation is allowed. The procedure is not easy and requires a collaboration between an experienced IVF team and a urologic or andrological microsurgeon.

Recently, the new therapy involving the surgical retrieval of sperm combined with assisted conception has given new hope to those previously considered "sterile" malles. Pryor et al. (1), in 1984, first reported pregnancy with the use of surgically aspirated sperm for IVF. They aspirated spernatozoa from the vas deferens of a man after vasovasostomy failed to 
correct a tuberculous obstruction of the vas. In 1985, Temple-Smith et al. (2) reported a pregnancy after IVF using microsurgically aspirated sperm from the epididymis. In 1988 , Silber et al. (3) reported pregnancies using microsurgically aspirated spermatozoa from the epididymis of men who were azoospermic because of congenital absence of the vasa deferentia. Mictosurgical epididymal sperm aspiration was tried with conventional IVF, partial zona dissection, and sub zonal sperm injection with overall fertilization and pregnancy rates of $19 \%$ and $27.5 \%$, respectively (5). Combined microepididymal sperm aspiration and ICSI proved to be a highly successful approach, achieving fertilization and pregnancy rates of $58 \%$ and $35.7 \%$, respectively (7). When the epididymis was absent or fibrosed, no spermatozoa could be retrieved and testicular biopsies were taken to extract spermatozoa. Successful fertilization and pregnancies have been reported using testicular sperm for ICSI (9). Because of the consistently very good results using epididymal and testicular spermatozoa with ICSI in comparison to conventional IVF, ICSI may be mandlatory for all patients with congenital absence of the vas deferens or with irreparable obstructive azoospermia (8). The present study confirmed that ICSI, using micro surgically retrieved epididymal or testicular sperm, is a highly successful technique, achieving fiertillization and pregnancy rates of $62 \%$ and $42 \%$, respectively.

Malurational changes occur during the transport of the spermatozoa in the epididymis. Sperm are immotile or ineffectively motile at the time they enter the caput. However, the fertilizing capacity of the sperm aspirated from the caput that had not traversed the complete epididymis was confirmed by Silber et al. (3) when they succeeded in obtaining a pregnancy from sperm aspirated from the caput in a case of congenital absent vas. Based on the current understanding of sperm maturation, Jow et al. (16), in 1993 , suggested that sperm may acquire motility in an obstructed system through prolonged confinement within the reproductive tract, direct contact with refluxed epididymal factors, and retrograde migration 
of sperm after contact with epididymal environment. Furthermore, chronic obstruction also may cause adaptation of the testicular epithelium, which allows acquisition of intratesticular sperm motility and maturation of fertilizing capacity to occur. It is plausible that a combination of these factors would indeed be necessary to account for these observations.

Epididymal samples usually have a high count but very low motility" in this study the count ranged between 0.3 and $200 \times 10^{6} / \mathrm{mL}$ with an average of $30 \times 10^{6} / \mathrm{mL}$ and the motility had an average of $6 \%$ forward grade 1 and 2 . Such semen characteristics usually are associated with poor fertilization in conventional IVF and the use of micromanipulation improved the chances of fertilization of these spermatozoa with impaired ability (5). The most precise and efficient form of micromanipulation is ICSI. The number and the motility of sperm does not affect the success rate in terms of fertilization or pregnancy with the use of ICSI as shown in this study and as reported previously $(17,18)$.

Marmar et al. (19), in 1993, reported that a mobile program, in which sperm collection and egg retrieval performed in two centers away from each other, is feasible. In their study, they were able to transfer processed semen to other centers; the farthest shipment was 90 miles with no impact on sperm survival. In the present study we transferred sperms aspirated in HEPES media directly to the IVF center without processing or incubation; the transport time ranged from 0.5 to 1 hour depending on the traffic. This success with specimen transport may encourage other centers that do not have urologic surgical services within an IVF unit to pursue offering this treatment.

In this study, a good fertilization rate was achieved in the absence of cytoplasmic aspiration at the time of sperm injection. This methodological aspect is different from that of many other ICSI investigators who consider cytoplasmic aspiration to be essential to good fertilization. It is our routine policy in all ICSI cases, not to aspirate the cytoplasm (18). The injection needle is introduced deeply into the cytoplasm and piercing of the oolemmal 
membrane usually occurs when the tip of the needle is near the 9 o'clock position. Piercing of the oolemmal membrane is assured when a yield of the pulled membrame is felt and the sperm is released away from the tip of the pipette without increasing the pressure of the injection. A good fertilization rate of $62 \%$ using this technique indicates that aspirating the cytoplasm is not essential for activating the oocyte.

Sperm processing used in our ICSI cases is also different from that of other ICSI investigators, as we never used Percoll gradient and we use only a Tea tube for separating motile spermatozoa. Spermatozoa of testicular and epididymal origin usually have a very slow forward grade and sometimes only shake in place. In most of these cases no motile spermatozoa are expected to be separated using the Tea tube, and a microdroplet from the resuspended pellet itself is used to search for a motile sperm using the injecting pipette.

This sperm processing method without the use of Percoll may prove to have an interesting implication for embryo cleavage, quality, implantation, and normality of infants born when compared with other ICSI programs. This experience may clarify the different outcomes in studies that use a sperm selection by Percoll in which silica gel particles may have been injected into the egg during ICSI.

In conclusion, we reported our first 24 cycles of ICSI using testicular and epididymal sperm. It is a highly successful technique in cases of obstructive azoospermia. Fertilization rate was $62 \%$ and 10 clinical pregnancies resulted. 


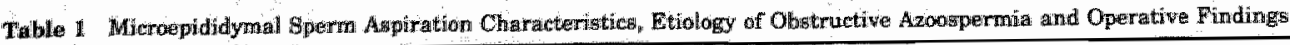

\begin{tabular}{|c|c|c|c|c|c|}
\hline $\begin{array}{l}\text { Patifent } \\
\text { no. }\end{array}$ & $\begin{array}{l}\text { Hubandls: } \\
\text { age }\end{array}$ & $\begin{array}{l}\text { Whife:s } \\
\text { age }\end{array}$ & $\begin{array}{l}\text { Infortility } \\
\text { period }\end{array}$ & $\begin{array}{l}\text { Etiology of obstructive } \\
\text { a:oospermia }\end{array}$ & Operative findings \\
\hline & $y$ & y & $y^{\prime}$ & & \\
\hline 1 & 35 & 89 & 6 & $\begin{array}{l}\text { Bilateral congenital absence of } \\
\text { wast defereng (CAVD) }\end{array}$ & Mild adhesions, right epididymis full \\
\hline 2 & 40 & 35 & 12 & $\begin{array}{l}\text { Right CAVD, Left absent testis } \\
\text { Lef CAVD multiple obstruetions }\end{array}$ & $\begin{array}{l}\text { Right massive adhesions, thick epididymal capsule } \\
\text { Left massive adthesions, thick epididymal capsule }\end{array}$ \\
\hline & & & & in the right vate & \\
\hline 4 & 3 & 35 & 4 & $\begin{array}{l}\text { Bilateral CAVD, previous } \\
\text { Implantation of alloplastic } \\
\text { spermetocele on the right side }\end{array}$ & $\begin{array}{l}\text { Epididymal head and body were present } \text { minimal } \\
\text { adheations }\end{array}$ \\
\hline 6 & 36 & 31 & 12 & $\begin{array}{l}\text { Right CAVD with collaped right } \\
\text { epididymis, acquired left } \\
\text { obstruction. }\end{array}$ & $\begin{array}{l}\text { Left vas totally obstructed, moderate adhesions } \\
\text { aspiration from epididymal head }\end{array}$ \\
\hline 6 & 49 & 36 & 12 & $\begin{array}{l}\text { Bilateral acquired multiplue } \\
\text { obsistructions }\end{array}$ & Dense adhesions, multiple obstructions. \\
\hline 7 & 34 & 34 & 12 & Bilateral CAVD & Epididymall head and body was preaent, mild adhesions \\
\hline 8 & 45 & 35 & 14 & Bilateral CAVD & $\begin{array}{l}\text { Masivive adhesions from previous ourgery, thich } \\
\text { epididymal eapsule }\end{array}$ \\
\hline 9 & 32 & 31 & 9 & Acquired multiple obustractions & $\begin{array}{l}\text { Left massive adhesions thick and wascular epididymal } \\
\text { capsule; aspiration. was tried at two different sites in } \\
\text { the head }\end{array}$ \\
\hline 10 & 38 & 33 & 8 & Acquired multiple obstmetions & Massive adhesions, maltiple obstructione \\
\hline 11 & 86 & 30 & 8 & $\begin{array}{l}\text { Right CA.VD lef acquired } \\
\text { obstruetion }\end{array}$ & Massive adhesions \\
\hline 12 & 52 & 38 & 18 & Bilateral CAVD & No adhesions, puncture of the epididymal heart \\
\hline 13 & 30 & 31 & 5 & $\begin{array}{l}\text { Atwophic right testis after } \\
\text { orehitis, acquired left multiple } \\
\text { abstructions }\end{array}$ & Marked adliusions, loculated hydrocele \\
\hline 14 & 45 & 37 & 15 & $\begin{array}{l}\text { Acquired bilateral onstumetions, } \\
\text { failled right } \\
\text { epididymovasostomy }\end{array}$ & Moderate adhesions, epididymal head was foll \\
\hline 16 & 45 & 38 & 14 & Bilateral CAVD & No adhesions, epadidymal head was full \\
\hline 16 & 43 & 34 & 12 & Bilateral CAMD & Mo adhesions \\
\hline
\end{tabular}

Table 2 Testicutar Sperm Aspiration Patient Characteristics and Eitiology of Obstruction

\begin{tabular}{|c|c|c|c|c|c|}
\hline $\begin{array}{l}\text { Pationt } \\
\text { now }\end{array}$ & $\begin{array}{l}\text { Husband'a } \\
\text { suge }\end{array}$ & $\begin{array}{l}\text { Wife's } \\
\text { age }\end{array}$ & $\begin{array}{l}\text { Infertility } \\
\text { period }\end{array}$ & Btitology of obstruetive axoospermia & Operative findings: \\
\hline & $y$ & $y$ & y & & \\
\hline 1 & 武1. & 28 & 7 & $\begin{array}{l}\text { Single teistide, acquíred opididymal } \\
\text { obstruction: }\end{array}$ & Npididymis completely fibro:ed \\
\hline 2 & 40 & 31 & 10 & $\begin{array}{l}\text { Acquired obstraction }{ }_{\text {f }} \text { failed right } \\
\text { epididymowasestomy }\end{array}$ & Extenstive fibrosis, empty epidiöymis \\
\hline 3 & 43 & 3 & 13 & Acquired obstruetion & $\begin{array}{l}\text { Complotely fibrosed epididymis } \\
\text { (bilateral) }\end{array}$ \\
\hline 4 & 28 & 21 & 7 & $\begin{array}{l}\text { Acquired obstruetion, previous billateral } \\
\text { epididymovasostomy }\end{array}$ & Massive adhesions, empty epididymita \\
\hline 5 & 49 & 36 & 9 & $\begin{array}{l}\text { Vasectomy for contraception, failed } \\
\text { reconstructiwe surgery twice }\end{array}$ & $\begin{array}{l}\text { Masgive adhesions, no epididymal } \\
\text { Lissues }\end{array}$ \\
\hline 6 & 43 & 40 & 10 & $\begin{array}{l}\text { Right orchidopexy operated upon at } 16 \text { yedrs: } \\
\text { partial obstruction. At day of ICSI, semen } \\
\text { A2O; teaticular sperm aspiration was done } \\
\text { to obtain spermacotom }\end{array}$ & $\begin{array}{l}\text { Massive adhesions, wery vascular empty } \\
\text { epididymis }\end{array}$ \\
\hline 7 & 32 & 28 & 5 & Bilateral congenital absence of vas defierens & Totral absence of the epididymis \\
\hline
\end{tabular}




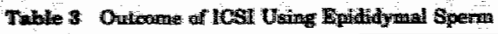

\begin{tabular}{|c|c|c|c|c|c|c|c|c|c|c|c|}
\hline \multirow[b]{3}{*}{ Prationt nax. } & \multicolumn{6}{|c|}{ Characteristics of the aspinated semen } & \multirow{3}{*}{$\begin{array}{l}\text { Na. of } \\
\text { ancyted } \\
\text { injected } \\
\text { CAII) }\end{array}$} & \multirow{3}{*}{ 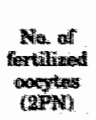 } & \multirow{3}{*}{ 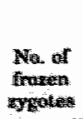 } & \multirow{3}{*}{ 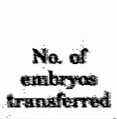 } & \multirow[b]{3}{*}{ Prognaniag } \\
\hline & \multirow[b]{2}{*}{ Coumati } & \multicolumn{4}{|c|}{ Forwand graiat } & \multirow{2}{*}{ 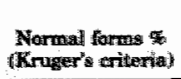 } & & & & & \\
\hline & & 1 & 2 & 3 & 4 & & & & & & \\
\hline & $\times$ M & & & & & \% & & & & & \\
\hline$\sqrt{1}$ & 200 & 5 & - & - & $-m$ & 10 & 8 & 4 & . & 4 & . \\
\hline 2 & 踢 & $\mathbf{2}$ & - & - & $\operatorname{mon}$ & 5 & 3 & s & - & 19. & 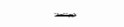 \\
\hline 8 & 15: & 15 & - & - & 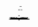 & (a) & 20 & 12 & "ir & 5 & - \\
\hline 4 & 25 & 5 & - & - & - & 20 & 8 & 2 & - & 2 & Ohemideal \\
\hline 5 & 30 & 15 & - & - & - & 15 & 15 & 20 & 8 & 晹 & You (Twint \\
\hline 5 & 40 & 1 & - & - & - & 10 & 3 & 2 & س & 9 & - \\
\hline 7 & 80 & 2 & - & - & - & 19 & 7 & 1 & - & 1 & تصيس \\
\hline 8 & 5 & $\mathbf{1}$ & man & $m$ & - & 25 & 1 & 1 & $\therefore$ & $i$ & $Y_{\text {fog }}$ \\
\hline 9 & 100 & 10 & 5 & - & - & B & 2 & 17 & 12 & 4 & Yes (Triples \\
\hline 10 & 20 & 10 & - & - & - & 3 & 15 & 7 & $\therefore$ & 5 & $=$ \\
\hline 11 & 1幙 & 16 & 15 & - & - & a & 13 & 7 & 2 & 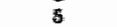 & $\therefore$ \\
\hline 2 inepent cyelan & 10 & 1 & 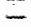 & - & - & 5 & 4 & 3 & - & 3 & Ies \\
\hline 12 & 10 & 1 & - & - & - & 0 & 5 & 4 & - & 3 & Yos \\
\hline 18 & 3 & 1 & ست & - & - & 10 & 16 & 10 & 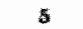 & 5 & Yes \\
\hline 14 & 10 & 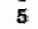 & - & سي- & $-m$ & 0 & 12 & 8 & 3 & 4 & - \\
\hline 15 & 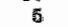 & 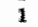 & - & - & لعست. & (1) & 17 & 12 & 6 & $\sqrt{5}$ & - \\
\hline 16 & 0.3 & 1 & - & - & تיب & 10 & 8 & 60 & - & 6 & -im \\
\hline
\end{tabular}

Trable 4 Oratoume of ICsil Using Testicular Sparm

\begin{tabular}{|c|c|c|c|c|c|c|c|c|c|c|c|}
\hline \multirow[b]{3}{*}{$\begin{array}{l}\text { Patulent: } \\
\text { not. }\end{array}$} & \multicolumn{6}{|c|}{ Testicular sperm retrieved } & \multirow[b]{3}{*}{$\begin{array}{l}\text { Nia of oovylte } \\
\text { infected inII) }\end{array}$} & \multirow[b]{3}{*}{ 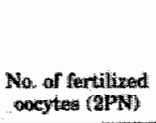 } & \multirow[b]{3}{*}{$\begin{array}{l}\text { Fintertin } \\
\text { 4yisolueas }\end{array}$} & \multirow[b]{3}{*}{ 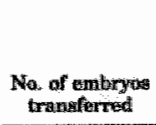 } & \multirow[b]{3}{*}{ Pregatantity } \\
\hline & \multirow[b]{2}{*}{ Coutust } & \multicolumn{4}{|c|}{ Forward gradio } & \multirow[b]{2}{*}{ Normal formas } & & & & & \\
\hline & & 1 & 2 & 3 & 4 & & & & & & \\
\hline & $x .10$ & & & & $\therefore$ & 㤠 & & & & & \\
\hline 1 & 1 & 1 & - & - & - & 10 & 5 & 3 & - & 3 & Yow \\
\hline 2 & 0.2 & 5 & $m$ & - & - & 5 & 9 & 5 & $=$ & 5 & Yos \\
\hline 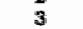 & 0.05 & - & - & $=$ & - & 10 & 4 & $\mathbb{1}$ & $n-m$ & 1 & Chemical \\
\hline 4 & 0.5 & 100 & - & - & - & 0 & 6 & 4 & $=$ & 4 & Chomical \\
\hline 5 & 1 & 5 & - & - & $\mathrm{m}$ & 0 & 17 & 1W & 5 & 5 & Yo: \\
\hline 6 & 0 & $\mathbf{i}$ & - & - & - & 1 & 3 & 2 & onse & 2 & 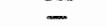 \\
\hline 7 & 1 & i & תמב. & $\mathrm{m}$ & - & 0 & 10 & 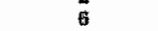 & - & 5 & Ye \\
\hline
\end{tabular}

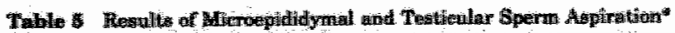

\begin{tabular}{|c|c|c|c|c|c|c|}
\hline & wot of & 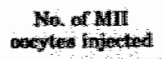 & 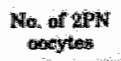 & 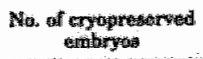 & 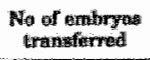 & 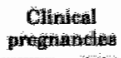 \\
\hline 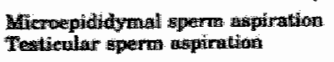 & $\frac{17}{7}$ & 172 & 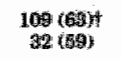 & 40 & ois & $\begin{array}{l}405) \\
467)\end{array}$ \\
\hline Torsal & 24 & 296 & $141 \mathrm{R} B \mathrm{z}$ & 40 & s & $104+2$ \\
\hline
\end{tabular}




\section{REFERENCES}

1. Pryor J, Parsons $J$, Goswamy $\mathbb{R}_{*}$ Malson $P$, Vaid $P_{t}$ Wilson L, Whitehead M. In-vitro fertilisation for men with obstructive azoospermia. Lancet. 1984 Sep 29;2(8405):762.

2. Temple-Smith PD, Southwick GJ, Yates CA, Trounson AO, de Kretser DM. Human pregnancy by in vitro fertilization (IVF) using sperm aspirated from the epididymis. I In Vütro Fert Embryo Transf. 1985 Sep;2(3):119-22.

3. Silber $\mathrm{SJ}$, Balmaceda J, Borrero $\mathrm{C}$, Ord T, Asch R. Pregnancy with sperm aspiration from the proximal head of the epididymis: a newtreatment for congenital absence of the vas deferens. Fertil Steril. 1988 Sep;50(3):525-8.

4. Silber $S J_{,}$Ord $T$, Balmaceda J, Patrizio P, Asch RH. Congenital absence of the vas deferens. The fertilizing capacity of human epididymal sperm. N Engl J Med. 1990 Dec $27 ; 323(26): 1788-92$.

5. Schlegel PN, Berkeley AS, Goldstein M, Cohen J, Alikani M, Adler A, Gilbert BR, Rosenwaks Z. Epididymal micropuncture with in vitro fertilization and oocyte micromanipulation for the treatment of unreconstructable obstructive azoospermia. Fertil Steril. 1994 May;61(5):895-901.

6. Palermo G, Joris $\mathbb{H}$, Devroey $P$, Van Steirteghem AC. Pregnancies after intracytoplasmic injection of single spermatozoon into an oocyte. Lancet 1992;340:17-8.

7. Tournaye H, Devroey P, Liu J, Nagy Z, Lissens W, Van Steirteghem A. Microsurgical epididymal sperm aspiration and intracytoplasmic sperm injection: a new effective approach to infertility as a result of congenital bilateral absence of the vas deferens. Fertil Steril. 1994 Jun;61(6): 1045-51.

8. Silber $S^{\prime} J$, Nagy ZP, Liu J, Godoy H, Devroey P, Van Steirteghem AC. Conventional invitro fertilization versus intracytoplasmic sperm injection for patients requiring microsurgical sperm aspiration. Hum Reprod. 1994 Sep; $9(9): 1705-9$.

9. Silber SJ, Van Steirteghem AC, Litu J, Nagy Z, Tournaye H, Devroey P. High fertilization and pregnancy rate after intracytoplasmic sperm injection with spermatozoa obtained from testicle biopsy. Hum Reprod. 1995 Jan; 10(1):148-52.

10. Patrizio P, Asch RH, Handelin B, Silber SJ. Aetiology of congenital absence of vas deferens: genetic study of three generations. Hum Reprod. 1993 Feb;8(2):215-20.

11. Lucena E, Lucena C, Gomez M, Ortiz JA, Ruiz J, Arango A, et al Recovery of motile sperm using the migration-sedimentation technique in an in-vitro fertilization-embryo transfer. Hum Reprod 1989;4:163-5.

12. World Health Organization. WHO laboratory manual for the examination of human semen and sperm cerwical mucus interaction. 3rd ed. New York: Cambridge University Press, 1993:13-80. 
13. Kruger TF, Acosta AA, Simmons KF, Swanson RJ, Matta JF, Oehninger S. Predictive value of abnormal sperm morphology in in vitro fertilization.. Fertil Steril. 1988 Jan;49(1):112-7.

14. EI-Itreby AA, Girgis SM. Congenital absence of the vas deferens in male sterility, Int J Fertil 1961;6:409-16.

15. Girgis SM, Etriby AN, Ibrahim AA, Kahil SA. Testicular biopsy in azoospermia. A review of the last ten years" experiences of over 800 cases. Fertil Steril. 1969 MayJun;20(3):467-77.

16. Jow WW, Steckel J, Schllegel PN, Magid MS, Goldstein M. Motile sperm in human testis biopsy specimens. J Androl. 1993 May-Jun; 14(3): 194-8.

17. Payne D, Flaherty SP, Jeffrey R, Wamers GM, Mattews CD. Successful treatment of severe male factor infertility in 100 consecutive cycles using intracytoplasmic sperm injection. Hum Reprod 1994;9:2051-7.

18. Mansour RT, Aboulghar MA, Serour GI, Amin YM, Ramzi AM. The effect of sperm parameters on the outcome of intracytoplasmic sperm injection. Fertil Steril. 1995 Nov;64(5):982-6.

19. Marmar JL, Corson SL, Batzer FR, Gocial B, Go K. Microsurgical aspiration of sperm from the epididymis: a mobile program. J Urol. 1993 May;149(5 Pt 2):1368-73. 


\section{Chapter 8}

Successful intracytoplasmic sperm injection without performing cytoplasmic aspiration

Ragaa T. Mansour, Mohamed A. Aboulghar, Gamal I. Serour, Nevine A. Tawab, Yehia Amin, Mehany A. Sattar

FERTILITY AND STERILITY Vol. 66, No. 2, August 1996 
Abstract

Objective: To compare the effect of cytoplasmic aspiration versus no aspiration before intracytoplasmic spern injection (ICSI) on the rate of oocyte damage, fertilization rate, and embryo quality.

Design: A randomized prospective study on sibling oocytes.

Setting: The Egyptian IVF-ET Center, Cairo, Egypt.

Participants: Fifty-eight patients who were infertile due to male factor who underwent 60 ICSI cycles.

Intervention: Intracytoplasmic sperm injection was performed on randomly allocated metaphase II oocytes with cytoplasmic aspiration in group I and without cytoplasmic aspiration in group II before sperm injection.

Main Outcome Measure: Fertilization rate, oocyte damage rate, and embryo quality.

Results: Normal fertilization rate per injected oocyte was $61.4 \%$ in group I compared with $62.5 \%$ in group II. The damage rate per injected oocyte was $16.8 \%$ in group I as compared with $4.6 \%$ in group II. Grade I embryos were $24.5 \%$ in group I compared with $48.5 \%$ in group II.

Conclusilon: Cytoplasmic aspiration before sperm injection in ICSI is not essential for oocyte activation. It did not improve the rate of normal fertilization. On the other hand, it increased the damaged oocyte rate and the rate of cytoplasmic fragments. Fertil Steril ${ }^{3}$ 1996;66:256-9 
The development of intracytoplasmic sperm injection (ICSI) technique in humans was reported first by Lanzendorf et al. (1) in 1988. In their work, they proved that the human oocyte was capable of surviving the injection and supporting the formation of male and female pronuclei. The first four human pregnancies using ICSI that were reported first by Palermo et al. (2) in 1992 was a breakthrough in the field of assisted fertilization. High fertilization and pregnancy rates, comparable to those reported in nonmale factor patients were achieved in patients with severe male factor infertility (3) and obstructive azoospermia (4) with the use of ICSI. Therefore, most IVF centers, including our own, have shifted to the use of ICSI technique as the only method for assisted fertilization (5).

Cytoplasmic aspiration was considered an integral part of the ICSI procedure and an essential step for activation of the oocyte (6). It even was reported recently that vigorous aspiration of the oocyte cytoplasm is a crucial factor for the success of ICSI (7). On the contrary, in our ICSI program, the injection always has been done routinely without cytoplasmic aspiration, and we have achieved high fertilization and clinical pregnancy rates. The aim of the present study was to compare ICSI, with and without performing cytoplasmic aspiration, on sibling oocytes to see the outcome on the rate of oocyte damage, normal fertilization, and quality of embryos. 


\section{MATERTALS AND METHODS}

\section{Patients}

Fifty-eight patients who underwent 60 ICSI cycles at the Egyptian IVF-ET center are included in this study. The mean age of the female partners was $32.4 \pm 4.2$ years and the mean duration of infertility was $8.5 \pm 2.5$ years. All patients had male factor infertility. The initial semen evaluation was done on at least two occasions before the treatment cycle. They had a sperm count $<10 \times 10^{6} / \mathrm{mL}$, motility $<30 \%$, and abnormal forms $>60 \%$. Ovulation induction was done using GnRH agonist analogue, long protocol, and hMG (8). Oocyte pick-up was done 36 hours after hCG injection (9) through ultrasonic transvaginal route. Semen processing and details of ICSI was described previously (5).

\section{Microinjection Procedure}

After securing the oocyte in position with the holding pipette (polar body at 6 or 12 o'clock position), the injection pipette was introduced at 3 o'clock position through the zona pellucida, oolemma, and deeply into the cytoplasm. In group I, a negative pressure was appliced whit the cyoplasm was whthriwn inside the injecting pipette approximately one quarter of the diameter of the oocyte then the sperm was injected slowly and the pipette was

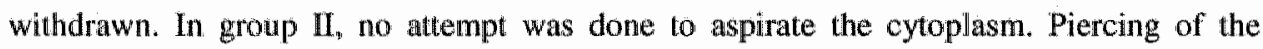
oolemmal membrane was assured when a yield of the pulled membrane at the periphery of the oocyte was felt and the sperm was released away from the tip of the pipette without increasing the pressure of the injection. If the pressure inside the injecting pipette was low at the moment of piercing the oolemma, the spermatozoon and minimal cytoplasm may fllow into the tip of the pipette. After injection, the oocytes were rinsed and incubated under oil in Ham's F-10 (GIBCO Laboratory, Grand Island, NY) supplemented with $10 \%$ patient serum. 
The next morning, the oocytes were examined for evidence of fertilization and transferred to fresh media (Ham"s F-10 supplemented with $20 \%$ patient serum). Assessment of the embryos was performed by adopting a modified morphological criteria classification (10) as follows: grade 1, good quality, blastomeres uniform in size and shape, ooplasm with no granularity, no anucleate fragments; grade 2, intermediate quality, blastomeres uneven in size and shape, ooplasm slightly granular, anucleate fragments affecting $<25 \%$ of blastomeres; and grade 3, poor quality blastomeres uneven in size and shape, ooplasm extremely granular, anucleate fragments affecting $>25 \%$ of blastomeres.

Embryo transfer was done on day 2 after the pickup with the best morphologically looking embryos from both groups. Luteal phase support was given routinely in the form of 2,500 IU of hCG every 4th day. Patients that were considered at high risk of developing ovarian hyperstimulation syndrome were given daily $\mathrm{P}$ injection. Serum $\beta$-hCG test was done 2 weeks after ET to diagnose pregnancy, and an ultrasonic examination was done after 2 to 3 more weeks for patients with a positive test. Clinical pregnancy was diagnosed by the presence of a gestational sac with fetal echoes. Statistical analysis was done using $\mathrm{X}^{2}$ test. 


\section{RESULTS}

Fifty-eight patients underwent 60 ICSI cycles. A total of 580 oocytes were retrieved, 460 oocytes were at metaphase II (79\%). In group I (cytoplasmic aspiration), of 220 oocytes injected, 37 oocytes were damaged (16.8\%) and 135 oocytes (61.4\%) showed normal (two pronuclei) fertilization. In group II (no cytoplasmic aspiration), out of 240 oocytes injected 11 oocytes were damaged (4.6\%) and 150 oocytes $(62.5 \%)$ showed normal fertilization (Table 1). The rate of damaged oocytes was significantly higher in group I as compared with group II $\left(X^{2}=18.38, p=0.001\right)$. However, there was no statistically significant difference in the fertilization rate between the two groups $\left(X^{2}=0.06, p=0.802\right)$.

The number and quality of embryos in each group is shown in Table 2. There was a statistically significant higher percentage of grade I embryos in group II; the rate of grade III embryos was significantly higher in group $1\left(X^{2}=17.08, p=0.001\right)$.

Seventy-five embryos were cryopreserved from both groups. Clinical pregnancy was diagnosed in 21 patients (35\%), including 17 singletons and 4 twins.

\section{DISCUSSION}

In this study, we compared the ICSI procedure with cytoplasmic aspiration before sperm injection versus no aspiration on sibling oocytes. There was no statistically significant difference in the fertilization rate between the two groups. These results would question the hypothesis of the importance of cytoplasmic aspiration in inducing oocyte activation. The high fertilization and cleavage rate in the oocytes injected without cytoplasmic aspiration indicate that there are other factors that induce oocyte activation. Puncturing the oocyte cytoplasm with a pipette for injection in itself was considered a cause for oocyte activation 
(11). Edwards and Van Steirteghem (12) suggested that the calcium contained in the medium with which the sperm is injected into the oocyte may be the impulse initiating oocyte activation by triggering calcium-induced calloium release, a mechanism known to work in some species. Hoshi et al. (13) used calcium ionophore because they thought that increased $\mathrm{Ca}^{2+}$ in the ooplasm has a positive effect on oocyte activation. Electroporation also has been used to accelerate the flow of $\mathrm{Ca}^{2+}$ into the ooplasm $(11,14)$. Tesarik et al. (15) reported that the activation of human oocytes after ICSI does not occur as a result of the injection procedure, and they stated that elevated calcium concentrations in the medium in which ICSI is performed is not needed and even may be an overload. In their experiment, they concluded that activation of the oocyte occurs as a result of the release of spermactivating factor. In a recent study by the same author (7), it was suggested that vigorous aspiration of the oocyte cytoplasm may facillitate fertilization after ICSI by increasing the oocyte $\mathrm{Ca}^{2+}$ load at the time of injection, by establishing a more intimate contact of the injected sperm head with oocyte intracellular $\mathrm{Ca}^{2+}$ stores or by a conjunction of these mechanisms. Cytoplasmic aspiration also was considered an essential step for oocyte activation by other investigators (6). Our results clearly demonstrated that cytoplasmic aspiration is not at all an essential factor for oocyte activation. More likely, the oocyte is activated from the release of sperm factors as reported by Dale and De Felice in 1990 (16). Fishel et al. (17) demonstrated a highly significant increase in fertilization rate in ICSI when sperm tail plasma membrane was damaged. They suggested that damaging the sperm plasma membrane release a sperm cytosolic component for egg activation.

Our results suggest that cytoplasmic aspiration might be a way of making sure that the oolemmal membrane is pierced rather than a factor in oocyte activation. Until recently, the detailed methodology of penetration into the ooplasm in performing ICSI was not described clearly in the literature. Palermo et al. (6) reported that the oolemma may be particularly soft 
and elastic depending upon the time spent by the oocyte in vivo or in vitro, rendering it difficult to penetrate. We believe that one of the main reasons for the low fertilization rate in ICSI by some inwestigators in early reports was probably that the oolemmal membrane was not perforated in all oocytes and that the sperm was deposited outside the cytoplasm. Therefore, the function of cytoplasmic aspiration is to ensure that the oolemmal membrane is pierced rather than its role for oocyte activation. Fishel et al. (17) clearly described their technique of piercing the oolemma. They stated that the oolemma often invaginated and created an artificial furrow in the ooplasm, simulating penetration of the oolemma. In most instances they had to manipulate the colemma either by tiny sharp thrusts of the microneedle once the latter had traversed $>75 \%$ of the diameter of the oocyte or to aspirate the oolemma (which is very stretchable) into the microneedle or a combination of both. We always have been ablle to pierce the oolemmal membrane without any attempt of cytoplasmic aspiration. Piercing of the oolemmal membrane was confirmed when a yield of the pulled membrane was felt above and below the introduced injection pipette accompanied with a release of the sperm away from the tip of the injection pipette without increasing the injection pressure. If the pressure inside the injecting pipette was low, at the moment of piercing the oolemma, the spermatozoon and minimal cytoplasm may flow into the tip of the pipette.

The rate of oocyte damage in our study was significantly higher in group I (16.8\%) as compared with group $\Pi(4.6 \%)$, indicating that cytoplasmic aspiration increases the rate of oocyte damage at least in our hands. Palermo et al. (6) reported that the mechanical damage from the injection procedure was $7.1 \%$ as compared with higher rates of damage reported in earlier studies. They suggested that the reduction of oocyte damage rate was most likely a result of avoiding the area of polar granularity during insertion of the injection pipette, therefore avoiding the place where possibly the germinal vesicle breakdown takes place and where the chromosomes and mitotic spindles are located. Fishel et all. (17) demonstrated a 
highly significant decrease in cytoplasmic fragmentation when a permanently immobilized spermatozoon is utilized for ICSI, suggesting that immobilization might prevent disruption the ooplasm by an active sperm tail. The technique of cytoplasmic aspiration before sperm injection may produce mechanical disruption of the cytoplasmic structures, including the spindle. Moreover, the process of cytoplasmic aspiration might result in an increased volume of the fluid injected inside the cytoplasm during the deposition of the sperm. Nevertheless, it should be mentioned that the higher incidence of oocyte damage observed in this study with cytoplasmic aspiration compared with injection only may have been due to the fact that the former technique is not the routine technique in our lab.

The results of this work has shown a statistically significant higher percentage of grade I embryos in the group with no cytoplasmic aspiration as compared with the group with cytoplasmic aspiration. The implantation rate of embryos resulting from each technique was not evaluated because ET was done using a mixture of the best quality embryos from both groups.

Using this technique of no aspiration of the cytoplasm as a routine in our ICSI program, we have achieved a fertilization rate of $61 \%$ and a clinical pregnancy rate of $35 \%$ in a series of 350 ICSI cases (18). In two other reports using the same technique, similar fertilization and pregnancy rates were achieved $(5,19)$. To the best of our knowledge, this is the first report in the literature that demonstrates that cytoplasmic aspiration in ICSI procedure is nol: essential for oocyte activation. High fertilization rate and high quality embryos were achieved without cytoplasmic aspiration. 
Table 1 Fertilization and Damaged Oocyte Rates

\begin{tabular}{lcc}
\hline & $\begin{array}{c}\text { Group I } \\
\text { cytoplasmic } \\
\text { aspiration }\end{array}$ & $\begin{array}{c}\text { Group II } \\
\text { no cytoplasmic } \\
\text { aspiration }\end{array}$ \\
\hline $\begin{array}{l}\text { No. of injected oocytes } \\
\text { (metaphase II) }\end{array}$ & 220 & 240 \\
No. of damaged oocytes* & $37(16.8)$ & $11(4.6) \dagger$ \\
No. of two pronuclear oocytes & $135(61.4)$ & $150(62.5) \ddagger$ \\
\hline
\end{tabular}

* Values in parentheses are percentages.

$\dagger x^{2}=18.38, P=0.001$.

$\ddagger \chi^{2}=0.06, P=0.802$.

Table 2 Cleavage and Embryo Quality

\begin{tabular}{lcc}
\hline & $\begin{array}{c}\text { Group I } \\
\text { cytoplasmic } \\
\text { aspiration }\end{array}$ & $\begin{array}{c}\text { Group II } \\
\text { no cytoplasmic } \\
\text { aspiration }\end{array}$ \\
\hline $\begin{array}{l}\text { No. of two pronuclear oocytes } \\
\text { No. of cryopreserved embryos }\end{array}$ & 135 & 150 \\
$\begin{array}{l}\text { Oocytes arrested at two } \\
\text { pronuclear stage }\end{array}$ & 33 & 42 \\
$\begin{array}{l}\text { No. of cleaved embryos* } \\
\text { Grading*t }\end{array}$ & 8 & 5 \\
$\quad$ Grade I & $94(92)$ & $103(95)$ \\
Grade II & $23(24.5)$ & $50(48.5)$ \\
Grade III & $34(36.2)$ & $36(35)$ \\
\hline
\end{tabular}

* Values in parentheses are percentages.

$+\chi^{2}=17.08, P=0.001$. 


\section{REFERENCES}

1. Lanzendorf SE, Maloney MK, Veeck LL, Slusser J, Hodgen GD, Rosenwaks Z. A preclinical evaluation of pronuclear formation by microinjection of human spermatozoa into human oocytes. Fertil Steril. 1988 May;49(5):835-42.

2. Palermo GD, Joris $H$, Devroey $P$, Van steirteghem AC. Pregnancies after intracytoplasmic injection of single spermatozoon into an oocyte. Lancet 1992;340:17-8.

3. Van Steirteghem AC, Nagy Z, Joris H, Liu J, Staessen C, Smitz J, Wisanto A, Devroey P. High fertilization and implantation rates after intracytoplasmic sperm injection. Hum Reprod. 1993 Jul;8(7):1061-6.

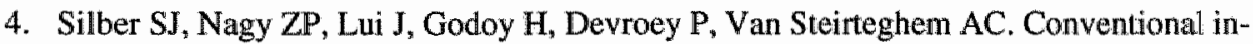
vitro fertilization versus intracytoplasmic sperm injection for patients requiring microsurgical sperm aspiration. Hum Reprod 1994;9:1705-9.

5. Mansour RT, Aboulghar A, Serour GI, Amin YM; Ramzi AM. The effect of sperm parameters on the outcome of intracytoplasmic sperm injection. Fertil Steril $1995 ; 64 ; 982$ 6.

6. Palermo GD, Cohen J, Alikani M, Adler A, Rosenwaks Z. Intracytoplasmic sperm injection: a novel treatment for all forms of male factor infertility. Fertil Steril. 1995 Jun;63(6): 1231-40.

7. Tesarik J, Sousa M. Key elements of a highly efficient intracytoplasmic sperm injection technique: $\mathrm{Ca} 2+$ fluxes and oocyte cytoplasmic dislocation. Fertil Steril. 1995 Oct; $64(4): 770-6$.

8. Aboulghar MA. Mansour RT, Serour GI, Amin MY. The prognostic value of successful in vitro fertilization on subsequent trials. Hum Reprod 1994;9:1932.

9. Mansour RT, Aboulghar MA. Serour GI. Study of the optimum time for human chorionic gonadotropin-ovum pickup interval in in witro fertilization. I Assist Reprod Genet. 1994 Oct; 11(9):478-81.

10. Erenus M, Zouwes C, Rajamahendran P, Leung S, Fluker M, Gomel V. The effect of embryo quality on subsequent pregnancy rates after in vitro fertilization. Fertil Steril. 1991 Oct;56(4):707-10.

11. Hoshi K, Yanagida K, Yazawa H, Katayose H, Sato A. Intracytoplasmic sperm injection using immobilized or motile human spermatozoon. Fertil Steril. 1995 Jun;63(6): 1241-5.

12. Edwards $\mathrm{RG}$, Van Steirteghem AC. Intracytoplasmic sperm injections (ICSI) and human fertilization: does calcium hold the key to success? Hum Reprod. 1993 Jul;8(7);988-9.

13. Hoshi K, Yanagida K, Sato A. Pretreatment of hamster oocytes with Ca2+ ionophore to facilitate fertilization by ooplasmic micro-injection. Hum Reprod. $1992 \mathrm{Jul} ; 7(6): 871-5$. 
14. Rickords LF, White KL, Wiltbanik JN. Effect of microinjection and two types of electrical stimuli on bovine sperm-hamster egg penetration. Mol Reprod Dev. 1990 $0 \mathrm{ct} ; 27(2): 163-7$.

15. Tesarik J, Sousa M, Testart J. Human oocyte activation after intracytoplasmic sperm injection. Hum Reprod. 1994 Mar;9(3):511-8

16. Dale B, De Felice $\mathbb{L} J$. Soluble sperm factors, electrical events and egg activation. In: Dale B, editor, Mechanism of fertilization: plants to humans. Nato ASI Series. Vol. H45. Berlin: Springer-Verlag. 1990:475-87.

17. Fishel S, Lisi F, Rinaldi L, Green $S$, Hunter A, Dowell K, Thomton S. Systematic examination of immobilizing spermatozoa before intracytoplasmic sperm injection in the human. Hum Reprod. 1995 Mar; 10(3):497-500.

18. Aboulghar MA, Mansour RT, Serour GI, Amin YM. The role of intracytoplasmic sperm injection (ICSD) in the treatment of patients with borderline semen. Hum Reprod. 1995 Nov; $10(11): 2829-30$.

19. Mansour RT, Aboulghar MA, Serour GI, Fahmi I, Ramzy AM, Amin Y. Intracytoplasmic sperm injection using microsurgically retrieved epididymal and testicular sperm. Fertil Steril. 1996 Mar;65(3):566-72. 


\section{Chapter 9}

Intracytoplasmic sperm injection in obstructive and non-obstructive azoospermia

Ragaa T. Mansour, Ahmed Kamal, Ibrahim Fahmy, Neviene Tawab, Gamal I. Serour, Mohamed A. Aboulghar

Human Reproduction Vol.9 pp.1974-1979, 1997 


\section{Abstract}

We compared the results of intracytoplasmic sperm injection (ICSI) in: (i) obstructive versus non-obstructive acoospermia, (ii) obstructive azoospermia using epididymal versus testicular spermatozoa and (iii) acquired versus congenital obstructive azoospermia due to congenital absence of the vas deferens (CAVD). A retrospective analysis was done of 241 consecutive ICSI cycles done in 103 patients with non-obstructive azoospermia and 119 patients with obstructive azoospermia. In the obstructive group, 135 ICSI cycles were performed. Epididymal spermatozoa were used in 44 cycles and testicular spermatozoa in 91 cycles. In the non - bstructive group, 106 cycles were performed. The fertilization and pregnancy per cycle rates were 59.5 and $27.3 \%$ respectively using epididymal spermatozoa, 54.4 and $31.9 \%$ respectively using testicular spermatozoa in obstructive cases, and 39 and $11.3 \%$ respectively in non-obstructive cases. The fertilization and pregnancy per cycle rates were 56.6 and $37 \%$ respectively in acquired obstructive cases, and 55.2 and $20.4 \%$ respectively in CAVD. In conclusion, ICSI using spermatozoa from patients with acquired obstructive azoospermia resulted in significantly higher fertilization and pregnancy rates as compared to CAVD and non-obstructive cases. 


\section{INTRODUCTION}

Surgically unreconstructable obstruction of the male genital tract is a relatively common aetiology of azoospermia among infertile men (Girgis et al., 1969). Patients with obstructive azoospermia due to congenital absence of the vas deferens (CAVD), or those who had suffered failure of reconstructive surgery, have historically been considered hopelessly infertile. Recently, new therapy involving surgical retrieval of spermatozoa combined with assisted reproduction has given new hope to those patients previously considered 'sterile" males. The reported fertilization and pregnancy rates after the combination of microsurgical epididymal spermatozoa aspiration (MESA) and standard in-vitro fertilization (IVF) are poor, not exceeding 20 and $11 \%$ respectively (Pryor et al., 1984; Temple-Smith et al., 1985; Silber: et al., 1988, 1990; Schlegel et al., 1994).

The introduction of intracytoplasmic sperm injection (ICSI; Palermo et al., 1992) has improved the results significantly, and high fertilization and pregnancy rates have been reported after the combination of MESA and ICSI (Silber et al., 1994; Tournaye et al., 1994; Hovatta et al., 1995; Mansour et al., 1996a).

In some patients with obstructive azoospermia, MESA fails to retrieve any spermatozoa, either due to fibrosis or complete absence of the epididymis. Because neither sperm motility nor morphology significantly influences the results of ICSI (Van Steirteghem et al., 1993; Mansour et al. 1995), it seems a logical approach to use testicular spermatozoa in cases when it is impossible to retrieve any spermatozoa from the ejaculate or the epididymis. Until recently, the fertilizing capacity of testicular spermatozoa was unexplored. It was reported in 1993 that the use of testicular spermatozoa in ICSI for cases of obstructive azoospermia could achieve fertilization and pregnancy (Craft et al., 1993; Schoysman et al., 1993a,b). Following that, different programmes reported the use of testicular spermatozoa with ICSI (Devroey et 
al., 1994; Bourne al., 1995; Craft and Tsirigotis, 1995; Nagy et al., 1995; Silber et al., 1995; Fahmy et al., 1996; Mansour et al $\left.{ }_{a,} 1996 \mathrm{a}, \mathrm{b}\right)$. Recently, the indications for testicular sperm extraction (TESE) and ICSI were expanded to include cases with non-obstructive azoospermia due to severe impairment of spermatogenesis (Devroey et al, 1995; Gil-Salom et al., 1995, Tournaye et al., 1995; Kahraman et al., 1996a,b; Silber et al., 1996; Tournaye et al., 1997).

Different investigators have studied fertilization and pregnancy rates in ICSI, using epididymal and testicular spermatozoa (Hovatta et al., 1995; Nagy et al., 1995; Silber et al., 1995; Fahmy al. 1996), for patients with obstructive and non-obstructive azoospermia (Devroey et al., 1996; Kahraman et al., 1996) and congenital and acquired obstructive azoospermia (Chen et al., 1995).

The aim of this work was to compare the results of ICSI for (i) obstructive versus nonobstructive azoospermia, (ii) acquired obstructive azoospermia versus congenital obstruction due to CAVD, (iii) epididymal versus testicular spermatozoa in obstructive azoospermia.

\section{MATERIALS AND METHODS}

This retrospective analysis involved 241 consecutive ICSI cycles for azoospermic patients that were performed between September 1994 and September 1996. The routine andrological work-up of the male patients included conventional semen analysis, endocrinological profile, culture of urine and examination of expressed prostatic secretion. Other investigations, such as transrectall ultrasound and preoperative diagnostic testis biopsy, were performed whenever indicated. Karyotyping to exclude chromosomal abnormalities was routinely done for patients with very small testes $(<3-5 \mathrm{~cm})$. Patients with Klinefelter's syndrome were excluded 
from the study. Counseling was done for each of the couples with CAVD, informing them about the possibility of having an offspring with cystic fibrosis (CF). They were told that if the wife is $\mathrm{CF}$ negative then the risk of having an offspring with $\mathrm{CF}$ is $\simeq 0.3 \%$ (Patrizio et al., 1993).

All patients were counseled and signed a consent approved by our internal ethical committee. Ovarian stimulation was induced using a long protocol of gonadotrophin-releasing hormone agonist and human menopausal gonadotrophin (Aboulghar et al., 1994). Human chorionic gonadotrophin (HCG) was given (10 000 IU i.m.) when three or more follicles reached a mean diameter of $\geq 18 \mathrm{~mm}$. Ovum retrieval was scheduled $36 \mathrm{~h}$ after $\mathrm{HCG}$ injection.. Oocyte handling and details of microinjection have been described previously (Mansour et al., 1995).

\section{Sperm retrieval}

MESA was performed under general anaesthesia, as an outpatient procedure, as described before (Mansour et al., 1996a,b). Percutaneous sperm aspiration (PESA) was successfully performed in 25 patients (18 with CAVD and seven with acquired obstruction), using a 25 gauge butterfly needle filled with tissue culture medium, connected to a $1 \mathrm{ml}$ syringe under local infiltration anaesthesia (Craft et al., 1995). We attempted PESA in nine more cases, but the epididymal aspirates either failed or showed no motile spermatozoa, and TESE was done instead. Testicular biopsy was done under local anaesthesia, using a technique of testicular biopsy processing described previously (Fahmy et al., 1996). In some cases of nonobstructive azoospermia, an extensive search for spermatozoa was performed (up to $4 \mathrm{~h}$ ) and none was found. Then spermatids were looked for and used for injection. Ovall spermatids looked like the head of a spermatozoon with a dark elongated nucleus and a lighter area in the middle. Round spermatids were identified by their size, which is smaller than all other spermatogenic cells, and also by the shape of their nuclei, which are dark, nounded structures 
with a lighter area in the centre; they have a minimal cytoplasm, and a cytoplasmic membrane that can be identified easily. One of the criteria used to identify round spermatids was the spinning of the round spermatid at the tip of the pipette during aspiration, which has been described by Tesarik and Mendoza (1996). Normal size microinjection pipettes (inner diameter 5-7 $\mu \mathrm{m})$ were used to inject the elongated spermatids, and larger diameter pipettes $(8-10 \mu \mathrm{m})$ were used to inject the round spermatids. Trials of hitting the spermatid with the injection pipette were done in an attempt to break the cytoplasmic membrane.

\section{Statistical analysis}

The significance of differences in frequencies between groups were compared by the $\mathrm{X}^{2}$ test. Differences between means were tested by analysis of variance. All statistical tests were assessed at the $5 \%$ level of significance.

\section{RESULTS}

A total of 222 azoospermic patients underwent 241 consecutive ICSI cycles; 119 patients with obstructive azoospermia underwent 135 cycles. The spermatozoa were retrieved from the epididymis in 44 cycles (MESA, $n=18 ; \operatorname{PESA}, n=22 ;$ cryothawed MESA, $n=4$ ). TESE was done for 81 patients, who underwent 91 ICSI cycles (five cycles using cryothawed testicular spermatozoa). The aetiology of infertility and indications for surgical retrieval of spermatozoa are summarized in Table 1 .

Non-obstructive azoospermia due to severe impairment of spermatogenesis was observed in 103 patients who underwent 106 cycles of ICSI and TESE. Acconding to previous histopathological testicular biopsy reports, maturation arrest was diagnosed in 58 cycles. Partial or incomplete arrest, with some testicular tubules showing late spermatids, was 
diagnosed in 28 cycles. Nine cycles were diagnosed as complete arrest at primary spermatocytes. Twenty one cycles were diagnosed as complete arrest at early spermatids. Sertoli cell-only syndrome ( $\mathrm{SCO}$ ), where all the tubules were devoid of any spermatogenic cells, was diagnosed in 17 cycles. Mixed SCO, where some tubules showed some spermatogenic cells at various stages, was diagnosed in 25 cycles. In five patients, the histological finding of the previous biopsy showed generalized proportionate reduction of all spermatogenic cells (hypospermatogenesis). This is different from partial spermatogenic arrest, where there is a reduction of the number of late spermatids, while the numbers of other spermatogenic cells are normal. In one patient, the testicular biopsy report showed complete tubular hyalinization. It is worth mentioning that this particular patient had lepromatous leprosy. Table II illustrates the patients' characteristics in the obstructive and non-obstructive groups.

The overall fertilization rate was $50.1 \%$, and $213(88.4 \%)$ cycles reached the embryo transfer stage. Clinical pregnancy was achieved in 53 cases, with a clinical pregnancy rate of $25 \%$ per transfer and $22 \%$ per cycle. In the obstructive group, 135 cycles were performed, the fertilization rate was $56 \%$ and all cycles reached the embryo transfer stage. Clinical pregnancy was diagnosed in 41 cycles, achieving a clinical pregnancy rate per cycle of $30.4 \%$ (Table III).

Comparing the use of testicular and epididymal spermatozoa in the obstructive group, the fertilization rate and pregnancy rate per cycle were respectively 59.5 and $27.3 \%$ in the epididymal group and 54.4 and $31.9 \%$ in the testicular group. There was no statistically significant difference between the two groups.

When the obstructive group was re-analyzed according to the cause of obstruction, the fertilization and pregnancy rates were respectively 56.6 and $37 \%$ in the acquired obstruction group and 55.2 and $20.4 \%$ in the group with CAVD (Table IV). The fertilization rate was 
similar in both groups, but the pregnancy rate was significantly higher in the acquired obstructive group $(\mathrm{P}<0.05)$.

In the non-obstructive group, ICSI was performed in 106 cycles, and 79 cycles reached the embryo transfer stage $(74.5 \%)$. The fertilization rate was $39 \%$ and 12 clinical pregnancies were diagnosed, achieving a clinical pregnancy rate of $15.2 \%$ per transfer and $11.3 \%$ per cycle (Table III). The results of the non-obstructive group were re-analysed according to the type of spermatogenic cell used for injection (Table V). Spermatozoa could be found in the testicular biopsies in 60 cycles $(56.6 \%)$ and used for ICSI. The fertilization and pregnancy rates for these cycles were 39.7 and $18.3 \%$. In 11 cycles $(10.4 \%)$, the number of normal live spermatozoa was too few to inject all the retrieved oocytes, and spermatids were also injected, with a fertilization rate of $39 \%$ but no pregnancy resulted. In 15 cycles $(14.2 \%)$, no spermatozoa were found, and spermatids alone were used for injection. The fertilization rate was $38.1 \%$ per injected oocyte, and one pregnancy resulted. In 20 cycles (18.9\%), the oocytes were not injected due to failure to find either spermatozoa or spermatids. The relationship between the previous histopathological reports and the findings on the day of oocyte retrieval was investigated (Table V). Spermatozoa were retrieved in 22 out of $28(78.6 \%)$ cases previously diagnosed as partial spermatogenic arrest, in 19 out of $25(76 \%)$ mixed SCO, in 7 out of $2 \Perp(33 \%)$ complete arrest at early spermatids, in 4 out of $17(23.5 \%)$ classical SCO, and in 2 out of $9(22 \%)$ cases of complete arrest at primary spermatocytes. Spermatozoa were also retrieved from one case with hyalinization and five cases of hypospermatogenesis.

The fertilization and pregnancy rates were significantly higher in the obstructive group when compared to the non- obstructive group $(\mathrm{P}<0.05$; Table IIII).

In total 53 clinical pregnancies resulted from 241 cycles $(22 \%): 35$ singles, nine sets of twins, three sets of triplets, and one set of quadruplets; the other five patients miscarried in the first trimester $(9.4 \%)$. A total of 43 children were born, comprising two sets of triplets, 
eight sets of twins and 21 singles. The spermatid pregnancy resulted in the delivery of a healthy boy with normal karyotyping.

\section{DISCUSSION}

At the beginning of our ICSI programme for obstructive azoospermic patients, spermatozoa were retrieved using the MESA technique, as described by Silber et al. (1994) and Tournaye et al. (1994). When the epididymis was absent or fibrosed, testicular biopsy was performed to retrieve spermatozoa for ICSI. The fertilization and clinical pregnancy rates at our centre using epididymal spermatozoa were comparable to the results of ICSI combined with TESE (Mansour et al., 1996a,b). Due to the simplicity of the TESE technique we shifted to its routine use in cases of obstructive azoospermia, except in the presence of spermatocele or when the epididymis was found to be distended, where it is easier to obtain spermatozoa through PESA (as described by Craft et al., 1995; Collins et al., 1996; Hirsh et al., 1996; Tsirigotis et ai., 1996). Encouraged by the initial report on the use of ICSI in non-obstructive azoospermia (Devroey et al., 1995), ICSI and TESE have also been extended to nonobstructive azoospermia in our programme.

The results of this study demonstrate that ICSI, in combination with surgically retrieved spermatozoa, achieves good fertilization and pregnancy rates $(56$ and $30.4 \%$ ) in obstructive azoospermia, comparable to other successful programmes (Silber et al., 1994; Tournaye et al., 1994).

Our data show that testicular spermatozoa from cases with obstructive azoospermia used for ICSI achieve good fertilization and clinical pregnancy rate (54.4 and 31.9\%) which are comparable to those with epididymal spermatozoa (59.5 and $27.3 \%)$. These findings are in agreement with a previous study by Silber et al. (1995) that concluded that epididymal and 
testicular spermatozoa yield similar fertilization, cleavage and ongoing pregnancy rates with ICSI in cases of obstructive azoospermia. Also, these results are comparable to the fertilization rate and pregnancy rate $(61$ and $30.5 \%)$ obtained with ICSI using ejaculated spermatozoa in our centre (Mansour et al., 1996a,b). It has also been shown by Gil-Salom et al. (1995) that high fertilization, cleavage and pregnancy rates can be achieved with intracytoplasmic testicular sperm injection, reaching values comparable to those of ICSI using ejaculated spermatozoa:

In this study, we compared the results of ICSI in acquired obstructive azoospermia with those of azoospermia due to CAVD. The fertilization rate was not significantly different: 56.6 and $55.2 \%$ in the acquired obstruction and CAVD groups respectively. However, the pregnancy rate was significantly higher $(\mathrm{P}<0.05)$ in the acquired obstruction group $(37 \%)$ than in the congenital group $(20.4 \%)$. In a previous study by Chen et al. (1995) that compared acquired and congenital obstructive azoospermia, there was also no significant difference in the fertilization rate. However, contrary to our findings, they concluded that the congenital group seemed to have a stronger tendency to achieve pregnancy than the acquired obstruction group. It should be mentioned, however, that their study was of a small series.

It was reported recently that the fertilization rate and cleavage rates in patients with severe spermatogenic defects were simillar to those observed using testicular spermatozoa from men with normal spermatogenesis in obstructive azoospermia (Devroey et al., 1995; Tournaye et al. 1995). In a recent study, Devroey et al. (1996) emphasized that even in cases of the most severe testicular failure, such as Sertoli cell-only syndrome, patients now must be counseled that if a few spermatozoa are found, the chance of pregnancy for the couple is no different than that for a couple with normal spermatogenesis. Indeed, the results of our study demonstrated that the fertilizing ability of testicular spermatozoa obtained from obstructive azoospermic patients was sigmificantly higher than those obtained from non-obstructive 
cases: Even in the 60 cycles (out of the 106 cycles of non-obstructive azoospermia) in which enough spermatozoa were successfully retrieved to inject all the metaphase II oocytes, the fertilization and pregnancy rates were significantly lower than in the obstructive group. These results confirm a recent study by Kahraman et al. $(1996 \mathrm{a}, \mathrm{b})$ that denonstrated a significantly higher fertilization rate in the obstructive group as compared to the non-obstructive group. This may be due to the fact that, in non-obstructive azoospermia, there is severe impairment of spermatogenesis, and even testicular failure. One hypothesis is that it might have a genetic origin (Smith et al., 1979; Vogt et al., 1992; Martin-du-Pan and Casnpana, 1993; Chandley, 1995; Vogt et al, 1995). Non-obstructive azoospermic patients, and those with severe idiopathic oligozoospermia, may be suffering from a genetic defect or a genetically determined barrier to reproduction (Vogt, 1995). Therefore, it is not surprising that, despite succeeding in extracting live spermatozoa in non- obstructive cases of azoospermia, the fertilization and pregnancy rates are significantly lower than those of obstructive azoospermia.

Our study demonstrated that in $67 \%$ of the cycles involving non-obstructive azoospermia spermatozoa were found and used for ICSI, achieving a fertilization rate of $39 \%$. In 15 $(14.2 \%)$ cycles, no spermatozoa were found, and spermatids were used for the injection, with a resulting fertilization rate of $38 \%$. In 20 out of 106 cases $(19 \%)$, neither spermatozoa nor spermatids were found after an extensive search and the oocytes were not injected. Of interest to this study is the relationship between previous histopathological reports and the rate of sperm retrieval (Table IV), which was $78.6 \%$ in cases of partial spermatogenic arrest, $76 \%$ in mixed SCO, $33 \%$ in cases of complete arrest at early spermatids, $23.5 \%$ in classical $\mathrm{SCO}$, and in $22 \%$ in complete arrest at primary spermatocytes. In a recent study by Tournaye et al. (1997), spermatozoa were successfully recovered in some patients with tubular sclerosis (seven out of 18 ), SCO (55 out of 112 ) and maturation arrest ( 39 out of 76 ). In another study 
by Kahraman et al. (1996a,b), ICSI combined with TESE was done for 29 men with nonobstructive azoospermia, and enough spermatozoa could be retrieved for ICSI in 14 patients. It is clear from these data that even in non-obstructive azoospermia there are usually tiny foci of spermatogenesis that allow TESE with ICSI to be performed in cases that were previously considered absolutely hopeless. Therefore, testicular biopsy should not be avoided in an azoospermic patient only on the basis of elevated serum FSH concentrations, at least not until other markers more specific than FSH for the presence of mature spermatozoa within the testes are developed (Carreau, 1995; Martin-du-Pan and Bischof, 1995). Mulhall et al. (1997) demonstrated that $70 \%$ of $2 \mathbb{1}$ patients with testicular dysfunction and azoospermia had spermatozoa in testicular tissue analysis, and neither patient age nor FSH concentration was predictive of the ability to find spermatozoa. Previous studies on spermatogenesis based on histopathological diagnosis documented that some patients with absolute azoospermia may show some foci of spermatogenesis (Steinberger and Tjioe, 1968; Girgis et al., 1969; Clermont, 1972). Therefore, an extremely low rate of spermatogenesis in the testes will result in absolute azoospermia in the ejaculate, even though there are some spermatozoa being produced. A certain tiny threshold of sperm production is necessary before any spermatozoa appear in the ejaculate (Silber et $\left.\mathrm{Al}_{* n}, 1996\right)_{j}$.

In conclusion; ICSI with surgically retrieved spermatozoa achieved fertilization rates and pregnancy rates per cycle respectively of 56 and $30.4 \%$ in obstructive azoospermia and 39 and $11.3 \%$ in non-obstructive azoospermia. In obstructive azoospermia, the fertilization and pregnancy rates resulting from the thse of testicular spermatozoa were similar to those with epididymal spermatozoal, and the pregnancy rate in the acquired obstruction group was significantly higher than in the CAVD group. In $67 \%$ of cycles involving non-obstructive azoospermia it was possible to find spermatozoa for ICSI. The fertilization and pregnancy 
rates resulting from the use of testicular spermatozoa in obstructive cases were significantly higher than in non-obstructive cases. 
Table I. Aetrology of infertility in 241 intracytoplasmic sperm injection cycles for patienis with azoospermia

\begin{tabular}{|c|c|}
\hline Aetiology & No. of cyicless \\
\hline Obstructive & 135 \\
\hline Congenial absence of was deferens & 54 \\
\hline Bilaterai & 43 \\
\hline Unitgateral & U1 \\
\hline Acquired abstruction & 81 \\
\hline Non *bowatructive & 106 \\
\hline Hypospermalogetessis. & 5 \\
\hline Partial spematogenic arrest & 28 \\
\hline Complete spernialogence arrest (spermatid) & 21 \\
\hline Complete spermatogenic arrest (primary spernatocyte) & 9 \\
\hline Sertoli cell-only syndrome (mixedl) & $2 s$ \\
\hline Sertoll cell-only syndromie (classical) & 17 \\
\hline Hyalinization & $\mathbf{l}$ \\
\hline Total & 241 \\
\hline
\end{tabular}

Table II. Characteristics of patients with obstructive of non-obstructive azoospermita and of their partners. There were no statistically significant differences between the two groups

\begin{tabular}{|c|c|c|}
\hline & Obstructive & Nonmobstruetive \\
\hline Number of piatients & 119 & 103 \\
\hline \multicolumn{3}{|c|}{ Age of the male (years) } \\
\hline Range & $23-55$ & $25-60$ \\
\hline Ment: $\mathbf{n}$ SD & $40.4=6.3$ & $39.6 \pm 72$ \\
\hline \multicolumn{3}{|c|}{ Age of the female (years) } \\
\hline Range & $19-42$ & $23-44$ \\
\hline Mean $\pm S D$ & $32.9 \pm 4.7$ & $32.5 \pm 52$ \\
\hline \multicolumn{3}{|c|}{ Duration of unfertillity (years) } \\
\hline Range & $2-25$ & $2-27$ \\
\hline Mealu $\pm S D$ & $10.5 \pm 4.8$ & $9.2 \pm 5.6$ \\
\hline
\end{tabular}


Table IIL. Outcome of intracytoplasmic spern injection (ICSI) for patients with obstructive and nou-obstructive aroospennia

\begin{tabular}{|c|c|c|c|c|c|}
\hline & \multicolumn{3}{|l|}{ Obsintictive } & \multirow{2}{*}{$\begin{array}{l}\text { Non-obsinctive } \\
\text { testiotilar }\end{array}$} & \multirow[t]{2}{*}{ Total } \\
\hline & Epididymal" & Teaticular & Total & & \\
\hline No. af ICSI cycles & 44 & 91 & 135 & 1106 & 241 \\
\hline No. of injected oocytes (MII) & 471 & 9.55 & 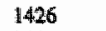 & 754 & 2180 \\
\hline Mo. af fentillued oocyles (2PN) & 280 & 519 & 799 & 294 & 1003 \\
\hline Fertilizution rate ( & 59.5 & 54.4 & $56^{\mathrm{b}}$ & $39^{6}$ & 50.1 \\
\hline $\begin{array}{l}\text { No. of ICSI cycles reaching } \\
\text { emiryo thansfer stage (a) }\end{array}$ & $44(100)$ & $91(100)$ & $135(100)$ & $79(74.5)$ & $213(88.4)$ \\
\hline $\begin{array}{l}\text { Mo. of ctunical pregnamcies } \\
\text { Clúnuctal pregnancy rate }\end{array}$ & 12 & 29 & 41 & 12 & 53 \\
\hline per cycle $(\$)$ & 27.3 & 31.9 & $30.4^{t}$ & $11.3^{\mathrm{b}}$ & 22 \\
\hline per venbryo transfer $(\%)$ & 27.3 & 31.9 & 30.4 & 15.2 & 24.9 \\
\hline
\end{tabular}

There were no significant differences between the testicular and epididymal groups of the obstructive azocospermila cycles.

Wialues with the same superscript were significantly different $(P<0.05)$.

MII = metaphase If: $\mathbf{P N}=$ pronuclear.

Table IV. Results of intracytoplasmic sperm injection (ICSI) in acquired obstructive awoospermia, congenital absence of the vas deferens (CAVD) and nom-obstructive azoospermia

\begin{tabular}{|c|c|c|c|}
\hline \multirow{2}{*}{$\because \quad \because$} & \multicolumn{2}{|c|}{ Obstructive } & \multirow[b]{2}{*}{ Non-obstructive } \\
\hline & Acquired & CAVD & \\
\hline $\begin{array}{l}\text { No. of ICSI cycles } \\
\text { No. of injected oocytes (MII) } \\
\text { No. of fertilized oocytes (2PN) } \\
\text { Fertilization trate (\%) } \\
\text { No. of ICSI cycles reaching } \\
\text { ermbryo transfer stage ( } \%) \\
\text { No. of clinical pregnancies } \\
\text { Clinical prignancy rate } \\
\text { per cycle (\%) } \\
\text { per transfer (\%) }\end{array}$ & $\begin{array}{c}81 \\
839 \\
475 \\
56.6^{\circ} \\
81 \\
(100) \\
30 \\
\\
37^{\circ} \\
37\end{array}$ & $\begin{array}{c}54 \\
587 \\
324 \\
55.2^{4} \\
54 \\
(100) \\
11 \\
20.4^{d} \\
20.4^{d}\end{array}$ & $\begin{array}{l}60 \\
549 \\
218 \\
319.7^{b} \\
55 \\
(91.7) \\
11 \\
20.0^{4} \\
21.8^{d}\end{array}$ \\
\hline
\end{tabular}

Orily enses in which enough spermatozoa were found for the injection wiere included, b.e. 60 out of 106 total.

b.edivevalues within rows with different superseripts werte significantly different $(P<0.05)$. 
Table V. Type of germ cell injected and outcome in noo-obstructive azoospermia

\begin{tabular}{|c|c|c|c|}
\hline $\begin{array}{l}\text { Type of cell } \\
\text { injected }\end{array}$ & $\begin{array}{l}\text { No. of cycles } \\
\text { (क) }\end{array}$ & $\begin{array}{l}\text { Fertilization rate } \\
\text { (\$) }\end{array}$ & $\begin{array}{l}\text { Pregnancy rate } \\
\text { per cycle (\%) }\end{array}$ \\
\hline Spermatiozoa & $60(56.6)$ & 39.7 & 18.3 \\
\hline $\begin{array}{l}\text { Spermatiozos } \\
+ \text { spentuatids }\end{array}$ & $11(10.4)$ & 39 & - \\
\hline Spermatids & $15(14.2)$ & 38.1 & 6.7 \\
\hline None & $20(18.9)$ & - & - \\
\hline Total & 106 & 39 & 11.3 \\
\hline
\end{tabular}

Tible VI. Relationship between the histopathological testicular biopsy nepon and the type of injected germ cell in the non-obstructive azoospermia grons

Spermatogenic cell used on the day of oocyte retrieval

\begin{tabular}{|c|c|c|c|c|c|}
\hline \multirow{2}{*}{ Histopathlology of previlous biopsy repert. } & \multirow[b]{2}{*}{ No. of cycles } & & & & \\
\hline & & Spermatozoa & Spennatozoa + spermatids & Spermatids & Notat \\
\hline Hyalinization & 1 & 1 & - & - & - \\
\hline Sertoll cell-only (classical) & 17 & 4 & - & 2 & 11 \\
\hline Sertoli cell-only (mixed) & 25 & 19 & 2 & a & 3 \\
\hline Complete arrest at primary spermitocytes & 9 & 2 & - & 2 & $\mathrm{~s}$ \\
\hline Complete arnest at early spermatids & 2I & 7 & 6 & 7 & 1 \\
\hline Partial spermatogenic anest & 28 & 22 & 3 & 3 & - \\
\hline Hypospermatogenesis & 5 & 5 & - & - & - \\
\hline Total & 106 & 60 & 11 & 15 & 20 \\
\hline
\end{tabular}




\section{REFERENCES}

Aboulghar MA, Mansour RT, Serour GI, Amin YM. The prognostic value of successful in-vitro fertilization in subsequent trials. Hum Reprod. 1994 Oct;9(10):1932-4.

Bourne H, Watkins W, Speirs A, Baker HW. Pregnancies after intracytoplasmic injection of sperm collected by fine needle biopsy of the testis. Fertil Steril. 1995 Aug;64(2):433-6.

Carreau S. Human Sertoli cells produce inhibin in vitro: an additional marker to assess the seminiferous epithelium development. Hum Reprod. 1995 Aug;10(8):1947-9.

Chandley, A.C. (1995) The genetic basis of male infertility. Reprod. Med. Rev., 4, 1-8.

Chen CS, Chu SH, Soong YK, Lai YM. Epididymal sperm aspiration with assisted reproductive techniques: difference between congenital and acquired obstructive azoospermia? Hum Reprod. 1995 May; 10(5):1104-8.

Clermont Y. Kinetics of spermatogenesis in mammals: seminiferous epithelium cycle and spermatogonial renewal. Physiol Rev. 1972 Jan;52(1):198-236.

Collins GN, Critchlow ID, Lau MW, Payne SR. Open versus closed epididymal sperm retrieval in men with secondarily obstructed vasal systems--a preliminary report. $\mathrm{Br} J$ Urol. 1996 Sep; $78(3): 437-9$.

Craft I, Tsirigotis M. Simplified recovery, preparation and cryopreservation of testicular spermatozoa. Hum Reprod: 1995 Jul; 10(7):1623-6.

Craft I, Bennett V, Nicholson N. Fertilising ability of testicular spermatozoa. Lancet. 1993 Oct $2 ; 342(8875): 864$.

Craft I, Tsirigotis M, Bennett V, Taranissi M, Khalifa Y, Hogewind G, Nicholson N. Percutaneous epididymal sperm aspiration and intracytoplasmic sperm injection in the management of infertility due to obstructive azoospermia. Fertil Steril. 1995 May; $63(5): 1038-42$.

Devroey P, Liu J, Nagy Z, Tournaye H, Silber SJ, Van Steirteghen AC. Normal fertilization of human oocytes after testicular sperm extraction and intracytoplasmic sperm injection. Fertil Steril. 1994 Sep;62(3):639-41.

Devroey P, Liu J, Nagy Z, Goossens A, Tournaye H, Camus M, Van Steirteghem A. Silber S. Pregnancies after testicular sperm extraction and intracytoplasmic sperm injection in non-obstructive azoospermia. Hum Reprod. 1995 Jun; 10(6): 1457-60.

Devroey P, Nagy P, Tournaye H, Liu J, Silber S, Van Steirteghem A. Outcome of intracytoplasmic sperm injection with testicular spermatozoa in obstructive and non obstructive azoospermia. Hum Reprod. 1996 May;11(5): 1015-8. 
Fahmy, I. Mansour, R., Aboulghar, M.A. et al. (1996) Intracytoplasmic injection of surgically retrieved sperm and spermatids in patients with obstructive and non-obstructive azoospermia. Middle East Fertil. Soc. J., 1, 134-141.

Gil-Salom M, Minguez $Y$, Rubio $C$, De los Santos MJ, Remohi J, Pellicer A. Efficacy of intracytoplasmic sperm injection using testicular spermatozoa. Hum Reprod. 1995 $\operatorname{Dec}_{*} 10(12) ; 3166-70$.

Girgis SM, Etriby AN, Ibrahim AA, Kahil SA. Testicular biopsy in azoospermia. A review of the last ten years" experiences of over 800 cases. Fertil Steril. 1969 MayJun; $20(3), 467-77$.

Hirsh AV, Dean NL, Mohan PJ, Shaker AG, Bekir JS. Natural spermatoceles in irreversible obstructive azoospermia--reservoirs of viable spermatozoa for assisted conception. Hum Reprod. 1996 Sep;11(9):1919-22.

Hovatta O, Moilanen J, von Smitten K, Reima I. Testicular needle biopsy, open biopsy, epididymal aspiration and intracytoplasmic sperm injection in obstructive azoospermia. Hum Reprod. 1995 Oct;10(10):2595-9.

Kahraman S, Ozgur S, Alatas C, Aksoy S, Balaban B, Evrenkaya T, Nuhoglu A, Tasdemir M, Biberoglu K, Schoysman R, Vanderzwalmen P, Nijs M. High implantation and pregnancy rates with testicular sperm extraction and intracytoplasmic sperm injection in obstructive and non-obstructive azoospermia. Hum Reprod. 1996 Mar; 11(3):673-6.

Kahraman S, Ozgur S, Alatas C, Aksoy S, Tasdemir M, Nuhoglu A, Tasdemir I, Balaban B, Biberoglu K, Schoysman R, Nijs M, Vanderzwalmen P. Fertility with testicular sperm extraction and intracytoplasmic sperm injection in non-obstructive azoospermic men. Hum Reprod. 1996 Apr;1 1(4):756-60.

Mansour RT, Aboulghar MA, Serour GI, Amin YM, Ramzi AM. The effect of sperm parameters on the outcome of intracytoplasmic sperm injection. Fertil Steril. 1995 Nov;64(5):982-6.

Mansour RI, Aboulghar MA, Serour GI, Fahmi I, Ramzy AM, Amin Y. Intracytoplasmic sperm injection using microsurgically retrieved epididymal and testicular sperm. Fertil Steril. 1996 Mar;65(3):566-72.

Mansour, R.T., Aboulghar, M.A., Serour, G.I. et al. (1996b) Intracytoplasmic sperm injection in six hundred and fifty consecutive cycles: the Egyptian IVF-ET experience. Middle East Fertil. Soc. J., 1,55-60.

Martin-du-Pan RC, Bischof P. Increased follicle stimulating hormone in infertile men. Is increased plasma FSH always due to damaged germinal epithelium? Hum Reprod. 1995 Aug;10(8): 1940-5.

Martin-du Pan RC, Campana A. Physiopathology of spermatogenic arrest. Fertil Steril. $1993 \mathrm{Dec} ; 60(6): 937-46$. 
Mulhall JP, Burgess CM, Cunningham D, Carson R, Harris D, Oates RD. Presence of mature sperm in testicular parenchyma of men with nonobstructive azoospermia: prevalence and predictive factors. Urology. $1997 \mathrm{Jan} ; 49(1): 91-5$.

Nagy Z, Liu J, Cecile I, Silber S, Devroey P, Van Steirteghem A. Using ejaculated, fresh, and frozen-thawed epididymal and testicular spermatozoa gives rise to comparable results after intracytoplasmic sperm injection. Fertil Steril. $1995 \mathrm{Apr} ; 63(4): 808-15$.

Palermo G, Joris $H_{*}$ Devroey $P$, Van Steirteghem AC. Pregnancies after intracytoplasmic injection of single spermatozoon into an oocyte. Lancet. $1992 \mathrm{JuI} 4 ; 340(8810): 17-8$.

Patrizio P, Asch RH, Handelin B, Silber SJ. Aetiology of congenital absence of vas deferens: genetic study of three generations. Hum Reprod. 1993 Fieb $b_{;}^{*}(2): 215-20$.

Pryor J, Parsons J, Goswamy R, Matson P, Vaid P, Wilson L, Whitehead M. In-vitro fertilisation for men with obstructive azoospermia. Lancet. 1984 Sep 29;2(8405):762.

Schlegel PN, Berkeley AS, Goldstein M, Cohen J, Alikani M, Adler A, Gilbert BR, Rosenwaks Z. Epididymal micropuncture with in vitro fertilization and oocyte micromanipulation for the treatment of unreconstructable obstructive azoospermia. Fertil Steril. 1994 May;61(5):895-901.

Schoysman R, Vanderzwalmen P, Nijs M, Segal-Bertin G, van de Casseye M. Successful fertilization by testicular spermatozoa in an in-vitro fertilization programme. Hum Reprod. 1993 Aug;8(8):1339-40.

Schoysman R, Vanderzwalmen P, Nijs M, Segal L, Segal-Bertin G, Geerts L, van Roosendaal $\mathrm{E}_{\mathrm{x}}$ Schoysman D. Pregnancy after fertilisation with human testicular spermatozoa. Lancet. 1993 Nov 13;342(8881):1237.

Silber SJ, Balmaceda J, Borrero C, Ord T, Asch R. Pregnancy with sperm aspiration from the proximal head of the epididymis: a new treatment for congenital absence of the vas deferens. Fertil Steril. 1988 Sep;50(3):525-8.

Silber SJ, Ord T, Balmaceda J, Patrizio P, Asch RH. Congenital absence of the vas deferens. The fertilizing capacity of human epididymal sperm. N Engl J Med. $1990 \mathrm{Dec}$ $27 ; 323(26): 1788-92$.

Silber SJ, Nagy ZP, Liu J, Godoy H, Devroey P, Van Steirteghem AC. Conventional invitro fertilization versus intracytoplasmic sperm injection for patients requiring microsurgical sperm aspiration. Hum Reprod. 1994 Sep;9(9): il 705-9.

Silber SJ, Van Steirteghem AC, Liu J, Nagy Z, Tournaye H, Devroey P. High fertilization and pregnancy rate after intracytoplasmic sperm injection with spermatozoa obtained from testicle biopsy. Hum Reprod. 1995 Jan;10(1):148-52.

Silber SJ, van Steirteghem A, Nagy Z, Liu J, Tournaye H, Devroey P. Normal pregnancies resulting from testicular sperm extraction and intracytoplasmic sperm injection for azoospermia due to maturation arrest. Fertil Steril. $1996 \mathrm{Jul} ; 66(1): 110-7$. 
Smith A, Fraser IS, Elliot G. An infertile male with balanced Y; 19 translocation. Review of $Y$; autosome translocations. Ann Genet. 1979;22(4):189-194.

Steinberger E, Tjioe DY. A method for quantitative analysis of human seminiferous epithelium. Fertil Steril. 1968 Nov-Dec;19(6):959-61.

Temple-Smith PD, Southwick GJ, Yates CA, Trounson AO, de Kretser DM. Human pregnancy by in vitro fertilization (IVF) using sperm aspirated from the epididymis. $J$ In Vitro Fert Embryo Transf. $1985 \mathrm{Sep} ; 2(3): 119-22$.

Tesarik $\mathbf{J}_{8}$ Mendoza $\mathbf{C}$. Spermatid injection into human oocytes. I. Laboratory techniques and special features of zygote development. Hum Reprod. 1996 Apr;11(4):772-9.

Tournaye H, Devroey P, Liu J, Nagy Z, Lissens W, Van Steirteghem A. Microsurgical epididymal sperm aspiration and intracyloplasmic sperm injection: a new effective approach to infertility as a result of congenital bilateral absence of the vas deferens. Fertil Steril. 1994 Jun;61.(6): 1045-51.

Tournaye H, Camus M, Goossens A, Liw J, Nagy P, Silber S, Van Steirteghem AC, Devroey $P$. Recent concepts in the management of infertility because of non-obstructive azoospermia. Hum Reprod. 1995 Oct: 10 Suppl 1:115-9.

Tournaye H, Verheyen G, Nagy P, Ubaldi F, Goossens A, Silber S, Van Steirteghem AC, Devroey P. Are there any predictive factors for successful testicular sperm recovery in azoospermic patients? Hum Reprod. 1997 Jan;12(1):80-6.

Tsirigotis M, Pelekanos M, Beski S, Gregorakis S, Foster C, Craft IL. Cumulative experience of percutaneous epididymal sperm aspiration (PESA) with intracytoplasmic sperm injection. J Assist Reprod Genet. 1996 Apr; 13(4):315-9.

Van Steirteghem AC, Nagy Z, Joris H, Liu J, Staessen C, Smitz J, Wisanto A, Devroey P. High fertilization and implantation rates after intracytoplasmic sperm injection. Hum Reprod. $1993 \mathrm{Jul} ; 8(7): 1061-6$.

Vogt PH. Genetic aspects of human infertility. Int J Androl. $1995 \mathrm{Dec} ; 18 \mathrm{Suppl} 2: 3-6$.

Vogt P, Chandley AC, Hargreave TB, Keil R, Ma K, Sharkey A. Microdeletions in interval 6 of the $\mathrm{Y}$ chromosome of males with idiopathic sterility point to disruption of AZF, a human spermatogenesis gene. Hum Genet. 1992 Jul;89(5):491-6. 


\section{Chapter 10}

Multifetal pregnancy reduction: Modification of the technique and analysis of the outcome

Ragaa T. Mansour, Mohamed A. Aboulghar, Gamal Serour, Mehany A. Sattar, Ahmed Kamal, Yehia M. Amin

FERTILITY AND STERILITY VOL. 71, NO. 2, FEBRUARY 1999 
Abstract

Objective: To modify the technique of multifetal pregnancy reduction and to study the outcome of reduced twins in comparison with nonreduced twins and high-order multiple gestations.

Design: Prospective controlled study.

Setting: The Egyptian IVF-ET Center, Cairo.

Patient(s): Seventy-five patients with high-order multiple pregnancies resulting from assisted reproduction. Controls were 40 nonreduced twin pregnancies and 22 high-order multiple gestations.

Intervention(s): Transwaginal ultrasonically guided multifetal pregnancy reduction was performed. The first 30 cases were done using $\mathrm{KCl}$ as a cardiotoxic agent. The modified technique was used for the last 45 cases at an earlier gestational age (approximately 7 weeks) by eliminating the use of $\mathrm{KCl}$ and by aspirating the embryonic parts.

Main Outcome Measure(s): Miscarriage rate, gestational age at delivery, birth weight, and pregnancy complications.

Result(s): Using the modified technique, the miscarriage rate was $8.8 \%$ and 41 patients delivered between 32 and 39 weeks of gestation (mean $\pm S D, 36.9 \pm 2.45$ weeks). The mean (4 SD) birth weight was $2,450.51 \pm 235.44 \mathrm{~g}$. The miscarriage rate, fetal wastage rate, mean gestational age, and mean birth weight were similar in reduced and nonreduced twins and were significantly better than in nonreduced triplets and quadruplets.

Conclusion(s): The modified technique of multifetal pregnancy reduction significantly improved outcomes, which were similar to those of nonreduced twins resulling from assisted reproduction and significantly better than those of nonreduced triplets and quadruplets. (Fertil Steril ${ }^{1999 ; 71: 380-4 . ~(01999 ~ b y ~ A m e r i c a n ~ S o c i e t y ~ f o r ~ R e p r o d u c t i v e ~ M e d i c i n e .) ~}$ 


\section{INTRODUCTION}

During the past 20 years, the use of ovulation-induction drugs for various assisted reproduction techniques has increased significantly. This practice has led to a marked increase in the multiple pregnancy rate, with all of its complications. To reduce the incidence of multiple gestations, most IVF centers reduce the dose of ovulation induction drugs and limit the number of embryos per transfer. However, multiple pregnancies are still unavoidable.

Multifetal pregnancy reduction was introduced to avoid the increased incidence of abortion and premature labor associated with multiple pregnancies (1). Since the beginning of our TVF program in 1986, multifetal pregnancies have been a problem. Multiple gestation is a highrisk condition because of the marked increase in maternal complications and perinatal mortality and morbidity. Faced with potentially tragic situations such as the agony of infertile couples who lose their premature infants, we introduced multifetal pregnancy reduction in our center in 1990 after obtaining institutional review board approval.

We report our experience in performing 75 cases of multifetal pregnancy reduction for highorder multifetal pregnancies with special emphasis on our technique, which is a modification of previously described techniques. We allso anallyzed the obstetric outcomes to see whether this technical improvement has made this method a better approach for high-order multifetal pregnancies. A control group consisted of 40 nonreduced twin pregnancies resulting from assisted reproduction. Pregnancy outcomes were also compared with a group of 22 patients with high-order multiple gestations that did not undergo reduction. 


\section{MATERIALS AND METHODS}

From January 1990 to December 1997, we counseled 94 patients with high-order multiple gestations for embryo reduction after obtaining institutional review board approval. Seventyfive women underwent the procedure. Sixty-eight patients were from our center and 7 patients were referred to us from other doctors. Forty-five gestations were triplets, 27 were quadruplets, and three were quintuplets. All the patients were counseled to reduce the number of sacs to two. Two patients requested the reduction to a single sac, but we convinced them to leave two viable fetuses.

Embryo reduction was done as an outpatient procedure under IV general anesthesia using propofol 10\% (Diprivan; Zeneca Limited, Macclesfield, Cheshire; United Kingdom). The vagina was prepared with $10 \%$ povidone iodine and was then thoroughly rinsed with sterile saline solution and drying to remove any traces of povidone iodine. Transvaginal ultrasound was used (Bruel and Kaejer model 3536 with transvaginal transducer model 8538; Naerum, Denmark). The number of gestational sacs with pulsating echoes was confirmed.

The most accessible gestational sac was chosen, and the fetal heart was visualized and aligned with the puncture guideline on the screen. An nocyte retrioval noddlo (Labotoot oat. 10.322109; Gottingen, Germany), was advanced sharplly toward the fetal heart. For successful puncture of the fetal heart, the ultrasound transducer should be introduced deeply inside the vagina so as to firmly stretch the vaginal vault before introducing the needle. It is sometimes helpfil to support the uterus lightly in the suprapubic region.

In the lirst 30 patients in this series, we injected $0.5-3 \mathrm{~mL}$ of $\mathrm{KCl} \mathrm{(15 \% )} \mathrm{according} \mathrm{to} \mathrm{a}$ previously described technique (2). We modified this technique by eliminating the use of $\mathrm{KCl}$ completely. After introduction of the needle into the fetal echoes, we applied suction (using a $20-\mathrm{mL}$ syringe) repeatedly until all or most of the embryonic parts were aspirated. We did not 
aspirate any amniotic fluid. In most cases, the fetal echoes disappeared completely and the sac remained of the same size or slightly smaller, but empty of fetal parts. After making sure that the fetus was aspirated, or, if not completely aspirated, that there were no more pulsations, we withdrew the needle.

The procedure was repeated for another gestational sac (or two) in the case of quadruplet or quintuplet pregnancies. The patients were given $1 \mathrm{~g}$ of IV cefotaxime (Claforan; Hoechst Orient SAE, Cairo, Egypt) before the procedure and were discharged after 3 hours. Followup ultrasound examination was done 1 week after the procedure. All patients received routine antenatal care and follow-up of the pregnancy except for those who traveled abroad. Outcome data was obtained for all pregnancies.

An age-matched group of 40 patients with nonreduced twin pregnancies resulting from assisted reproductive techniques was chosen as a control. In addition, we compared outcomes between the study group and 22 high-order multiple pregnancies that did not undergo fetal reduction.

Student's t-test was used to compare the mean gestational ages and birth weights. Fisher's exact test was used to compare the miscarriage rates. 


\section{RESULTS}

The gestational age at reduction ranged between 6 and 9 weeks (mean \pm SD of $7.2 \pm 0.1$ weeks). At first the procedure lasted 5-10 minutes per gestationall sac; but after the clinician gained more experience, the procedure took only 1-5 minutes per sac. In addition, in the beginning 0.5 to $3 \mathrm{~mL}$ of $\mathrm{KCl}$ was injected $(\mathrm{n}=30$ cases), but the procedure was later done without use of $\mathrm{KCl}(\mathrm{n}=45)$. No immediate complications of the procedure (e.g., vaginal bleeding) occurred, and all the cases were technically successful. No chorioamnionitis or septic abortion occurred.

We analyzed the 45 cases using the modified technique. First-trimester miscarriage occurred in one patient and second-trimester miscarriage occurred in three patients (miscarriage rate of $8.8 \%$ ). Forty-one patients delivered 73 infants (nine deliveries were singietons). The mean ( \pm SD) gestational age was $36.9 \pm 2.45$ weeks, and the mean ( \pm SD) birth weight was $2,450.51 \pm 235.44 \mathrm{~g}$. One stillbirth and one neonatal death occurred.

The first group of patients $(\mathrm{n}=30$ ) that had the procedure with $\mathrm{KCl}$ had nine miscarriages $(30 \%)$, three stillbirths, and two neonatal deaths. Twenty-one patients delivered 41 infants (3 singletons, 2 triplets, and 16 twins). The mean ( \pm SD) gestational age was $36.3 \pm 1.64$ weeks, and the mean ( \pm SD) birth weight was $2,198.06 \pm 656.3 \mathrm{~g}$.

The outcome of an age-matched group of nonreduced twin pregnancies resulting from medically assisted reproduction was compared with our study group in which we did not use

$\mathrm{KCl}$ (Table 1). The study and control groups were similar in matemal age (32.6 versus 33.4 years, respectively) and duration of infertility (5.4 versus 6.1 years, respectively). There were no statistically significant differences in the abortion tate, mean gestational age, mean birh weight, and fetal wastage between the groups. 
The outcomes of high-order multiple pregnancies that did not undergo reduction were compared with the outcomes after multifetal reduction with the modified technique (Table 2). There was a significantly higher abortion rate and fetal wastage rate and a significantly lower gestational age and birth weight when no fetal reduction was performed.

\section{DISCUSSION}

In this study, we modified the technique of multifetal pregnancy reduction by avoiding completely the use of any cardiotoxic substance such as $\mathrm{KCl}$. Our approach depends mainly on performing the procedure early (as soon as fetal pulsations are confirmed), usually between 6 and 8 weeks of gestation. At this stage, it is not difficult to aspirate all or most of the embryonic parts, leaving the gestational sac almost intact and full of amniotic fluid but empty of any embryonic tissues.

Itskovitz et al. (3) described two cases of multifetal reduction without the use of an

embryotoxic substance. Their technique differed from ours in two respects. First, they applied suction only to stop fetal pulsations and not to aspirate the embryonic tissues. Second, they partially aspirated the amniotic fluid.

The rate of miscarriage in this study using the modified technique was $8.8 \%$. This is less. than the $12.6 \%$ loss rate reported by Sebire et al. (4) in their series of 127 multifetal pregnancies undergoing embryo reduction and also less than the $13.7 \%$ loss rate reported by Evans et al. (2) in a multicenter study of 380 multifetal embryo reductions.

In the first 30 cases when we used $\mathrm{KCl}$ as an embryotoxic substance, we had a high fetal wastage rate $(30 \%)$. One explanation for the lower miscarriage rate using the modified technique is that we performed it after gaining more experience and at an earlier gestational 
age. It has been reported that it is feasible to complete the procedure as early as 6 weeks $^{\circ}$ gestation, although it might be preferable to wait until 8 weeks or later for fear of the natural phenomenon known as "vanishing twin." We recommend performing the procedure as early as possible without excessive concen about the phenomenon of vanishing twins because two gestational sacs will remain. Even if one sac vanishes, a singleton pregnancy will result. In this series of 75 fetal reductions to twins, the pregnancies continued as a singleton in 12 cases (16\%)

Another factor that maly have played a role in reducing the miscarriage rate using the modified technique is that we aspirated most of the embryonic tissues at an earlier stage. Aspiration leaves a minimal amount of necrotic tissue, which may have detrimental effects on the remaining gestational sacs. In the beginning, it was difficult to imagine that it was possible to aspirate an embryo of 6-8 weeks with visible pulsations. However, the embryo at this stage is composed of three primary germ layers (ectoderm, endoderm, and mesoderm) folding to form the head, tail, and lateral body folds, and these soft tissues and membranes are easily removed with repeated suction.

One of the causes of pregnancy loss in reduced twins is the development of an inflammatory response to the resorbing necrotic fetoplacental tissues, with the resulting release of cytokites and prostaglandins (4). High concentrations of a-fetoprotein (AFP) are found in We ammotic fludd of twin pregnancies after spontaneous death of one of the fetuses, as reported by Bass et al. (5) and in reduced twins.

Abbas et al. (6) reported that after reduction of multifetal pregnancies, the matemal serum AFP concentration increases in proportion to the amount of dead fetoplacental tissue, and this increase persists for several months after the procedure. We believe that performing multifetal reduction at an earlier stage (i.e., before 8 weeks of gestation) probably decreases the concentration of AFP remaining after the neduction. This has yet to be confirmed. 
Another reason for the lower miscarriage rate is that the injection of $\mathrm{KCl}$ is not strictly limited to the fetal heart. During injection, the fetus is sometimes pushed away from the needle and $\mathrm{KCl}$ diffuses into the amniotic sac; consequently it may diffuse to the adjacent gestational sacs. Toxic effects of $\mathrm{KCl}$ on the remaining fetuses have been reported by Tabsh et al. (7) and Wapner et al. (8).

In comparison with the nonreduced twins, the outcome of the twins resulting from the modified reduction technique was not significantly different with regard to the miscarriage rate, fetal wastage rate, mean gestational age, and birth weight. Nonreduced twins that were chosen as a control in this study resulted from IVF or intracytoplasmic sperm injection. It has been shown that twin pregnancies conceived by assisted reproductive techniques resulted in more frequently discordant birth weight and low birth weight compared with those conceived spontaneously. In 1996, Smith-Levitin et al. (9) demonstrated that reduced twins were similar to nonreduced twins conceived with assisted reproduction in all variables studied.

It was also noted in this series that the early $(<12$ weeks) miscarriage rate was only $2.6 \%$, which is similar to that of early amniocentesis in singleton pregnancies $(2.2 \%)$. This leads to the assumption that most miscarriages associared with multifetal reduction are not the consequence of spontaneous loss, nor are they directly due to the procedure and the use of needles in the reduction.

The mean gestational age at delivery $(36.9 \pm 2.45$ weeks) of the twins resulting from the modified technique was similar to that of the nonreduced twins conceived by assisted reproduction $(36.5 \pm 2.58$ weeks). This finding is probably due to the minimal amount of necrotic tissues remaining after reduction and thus the smaller likelihood that their resorption could trigger labor. 
Compared with the outcome of high-order multiple pregnancies, our results indicate that the gestational age at birth and mean birth weight increased after multifetal reduction. The miscarriage rate and perinatal mortality also decreased significantly with fetal reduction. Among six cases of quadruplets that were managed without embryo reduction, three $(50 \%)$ resulted in late miscarriage. At delivery, the mean ( \pm SD) birth weight was $1,400 \pm 316 \mathrm{~g}$ and the mean $( \pm \mathrm{SD}$ ) gestational age was $32.67 \pm 2.31$ weeks. The fetal wastage rate (miscarriage, stillbirth, and neonatal death) was $66.6 \%$.

The control group also included 16 cases of nonreduced triplets. Miscarriage occurred in four cases $(25 \%)$. At delivery, the mean ( \pm SD) birth weight was $2,042.8 \pm 500.5 \mathrm{~g}$ and the mean ( \pm SD) gestational age was $34.46 \pm 2.787$ weeks, which were significantly lower than those of the reduced twins. Five infants were stillborn and five died in the neonatal period (45.8\% fetal wastage). This very high fetal wastage rate in triplets and quadruplets used as a control group in this study was mainly due to prematurity and low birth weight.

Bollen et al. (10) and Smith-Levitin et al. (9) demonstrated that multifetal pregnancy reduction gave better outcomes than expectant management of triplets. In a large British study by Botting et al. (1.1), the perinatal mortality rate was $41.6 \%$ in sextuplets, $21.9 \%$ in quintuplets, $20 \%$ in quadruplets, and $16.4 \%$ in triplets.

Multifetal pregnancy reduction raises considerable ethical and religious debates. It is a difficult situation for both the physician and the patient. Our study was approved by otur institution's ethics commiltee, but it was difficult to counsel patients because of the lack of sufficient data about the procedure. We did not know initially what the chances would be of successfully performing the procedure or the risks of long-term effects of the procedure on the remaining pregnancy. The emphasis was placed on the incidence of early pregnancy loss and the perinatal complications of prematurity. We also emphasized that the procedure could result in total loss of the pregnancy and that the future risks were still unknown. 
Our approach to counseling has evolved over the years. At present, we inform patients that the chance of successfully performing the procedure with minimal risk is very high and that the outcome of reduced twins is significantly better than for nonreduced high-order multiple pregnancies. However, the long-term complications and potential risks of the procedure are still uncertain. 


\section{TAELE 1}

Analyste of the results of reduced and nonreduced twins:

\begin{tabular}{|c|c|c|c|c|c|c|c|c|c|c|}
\hline \multirow[b]{2}{*}{ Group } & \multirow[b]{2}{*}{ Now of cares } & \multicolumn{3}{|c|}{ Miscantage } & \multirow{2}{*}{ Ma. of } & \multirow{2}{*}{ 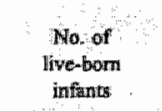 } & \multirow{2}{*}{$\begin{array}{l}\text { Mean } \\
\text { gestational } \\
\text { age (wk) }\end{array}$} & \multirow[b]{2}{*}{$\begin{array}{l}\text { Wlegin binh } \\
\text { weight (t) }\end{array}$} & \multirow{2}{*}{ 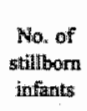 } & \multirow{2}{*}{ 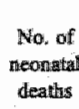 } \\
\hline & & $\begin{array}{l}<12 \\
w k\end{array}$ & $\begin{array}{l}>12 \\
\text { wh }\end{array}$ & Ratio & & & & & & \\
\hline Rethuced twitut & $\begin{array}{l}26 \text { triplets } \\
17 \text { quadmiplets } \\
2 \text { quantuplets } \\
45 \text { towal }\end{array}$ & 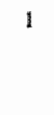 & 3 & $8.8 *$ & 4! & 72 (9 singletions) & $36.9 \pm 2.45^{\circ}$ & $2,450,51 \pm 235.44^{Z}$ & 1 & 1 \\
\hline Nonneduned twims & 40 & 1 & 3 & $10 *$ & 36 & 62 (s singletons) & $36.5 \pm 2.584$ & $2,316.04 \pm 603.09$ & 1 & 1 \\
\hline
\end{tabular}

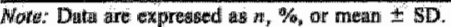

$\psi p=211$ (not sigoulficant)

$t=0$ (mot thenifeatit)

$t=0.75$ (not significatit).

\section{$1 A B \perp 2$}

Arialysis of the results of reduced twins and nonreduced triplets and quadruplets.

\begin{tabular}{|c|c|c|c|c|c|c|c|c|c|c|}
\hline \multirow[b]{2}{*}{ Group } & \multirow[b]{2}{*}{$\mathrm{No}_{\text {" of }}$ cases } & \multicolumn{3}{|c|}{ Miscarriage } & \multirow[b]{2}{*}{$\begin{array}{c}\text { Ma. of } \\
\text { deliveries }\end{array}$} & \multirow{2}{*}{$\begin{array}{l}\text { No. of } \\
\text { live-boria } \\
\text { infants }\end{array}$} & \multirow{2}{*}{$\begin{array}{c}\text { Mean } \\
\text { gestationtil age } \\
\text { (wik) }\end{array}$} & \multirow[b]{2}{*}{$\begin{array}{l}\text { Mean birth } \\
\text { weight }(\mathrm{g})\end{array}$} & \multirow{2}{*}{$\begin{array}{l}\text { Mo. of } \\
\text { stillborn } \\
\text { infants }\end{array}$} & \multirow{2}{*}{$\begin{array}{l}\text { No. of } \\
\text { neonatsi } \\
\text { deaths }\end{array}$} \\
\hline & & $\begin{array}{l}<12 \\
w k\end{array}$ & $\begin{array}{l}>12 \\
w i k\end{array}$ & $\begin{array}{l}\text { Rate } \\
(\%)\end{array}$ & & & & & & \\
\hline Reffuced twitus & $\begin{array}{l}26 \text { tripliets: } \\
17 \text { quadruplets } \\
2 \text { quintuplets } \\
45 \text { total }\end{array}$ & $\llbracket$ & 3 & $8.8^{*}$ & 41 & 72 (9 singletons) & $36.9 \pm 2.45^{*}$ & $2,450.51 \pm 235$ & 1 & 1 \\
\hline Nonreduced luiplets & 16 & - & 4 & $25 *$ & 12 & 29 & $33.46 \pm 2.787^{*}$ & $2,002.8 \pm 500.9 *$ & 5 & 5 \\
\hline Montraclue d quadruplets & 6 & - & 3 & $50 \%$ & 3 & 10 & $32.67 \pm 2.31^{*}$ & $1,400 \pm \pm 3162^{*}$ & 2 & 2 \\
\hline
\end{tabular}

Hote: Dathe ane expressed as $n, \%$ or mean $\$$ SD.

$\rho<05$ 


\section{REFERENCES}

1. Kanhai HH, van Rijssel EJ, Meerman RJ, Bennebroek Gravenhorst J. Selective termination in quintuplet pregnancy during first trimester.Lancet. 1986 Jun $21 ; 1(8495): 1447$.

2. Evans MI, Dommergues M, Wapner RJ, Lynch L, Dumez Y, Goldberg JD, Zador IE, Nicolaides KH, Johnson MP, Golbus MS, et al. Efficacy of transabdominal multifetal pregnancy reduction: collaborative experience among the world"s largest centers. Obstet Gynecol. 1993 Jul;82(1):61-6.

3. Itskovitz J, Boldes R, Thaler I, Bronstein M, Erlik Y, Brandes JM. Transvaginal ultrasonography-guided aspiration of gestational sacs for selective abortion in multiple pregnancy. Am J Obstet Gynecol. 1989 Jan; 160(1):215-7.

4. Sebire NJ, Sherod C, Abbas A, Snijders RJ, Nicolaides KH. Preterm delivery and growth restriction in multifetal pregnancies reduced to twins. Hum Reprod. $1997 \mathrm{Jan} ; 12$ (1):1735.

5. Bass HN, Oliver JB, Srinivasan M, Petrucha $\mathrm{R}, \mathrm{Ng}$ W, Lee JE. Persistently elevated AFP and $\mathrm{AChE}$ in amniotic fluid from a normal fetus following demise of its twin. Prenat Diagn. 1986 Jan-Feb;6(1):33-5.

6. Abbas A, Johnson M, Bersinger $N$, Nicolaides $K$. Maternal alpha-fetoprotein levels in multiple pregnancies. Br J Obstet Gynaecol. 1994 Feb;101(2):156-8.

7. Tabsh KM. Transabdominal multifetal pregnancy reduction: report of 40 cases. Obstet Gynecol. 1990 May;75(5):739-41.

8. Wapner RJ, Davis GH, Johnson A, Weinblatt VJ, Fischer RL, Jackson LG, Chervenak FA, McCullough LB. Selective reduction of multifetal pregnancies. Lancet. $1990 \mathrm{Jan}$ $13 ; 335(8681): 90-3$.

9. Smith-Levitin M, Kowalik A, Birnholz J, Skupski DW, Hutson JM, Chervenak FA, Rosenwaks Z. Selective reduction of multifetal pregnancies to twins improves outcome over nonreduced triplet gesitations. Am J Obstet Gynecol. 1996 Oct;175(4 Pt 1):878-82.

10. Bollen N, Camus M, Tournaye H, Wisanto A, Van Steirteghem AC, Devroey P. Embryo reduction in triplet pregnancies after assisted procreation: a comparative study. Fertil Steril. 1993 Sep;60(3):504-9.

11. Botting BJ, Davies IM, Macfarlane AJ. Recent trends in the incidence of multiple births and associated mortality.Arch Dis Child. 1987 Sep;62(9):941-50. 
Chapter 11

General Discussion 
IVF is a delicate and complicated procedure that depends on many factors for success. Taking utmost care of minute details is essential. Our group was interested in conducting research in several areas that are believed to have an impact on the success rate of IVF. The research was focused on:

\section{Patient preparation before starting the IVF cycle:}

a- The diagnosis and treatment of hydrosalpinges.

Our group reported for the first time in the literature that the presence of fluid in the uterine cavity in association with hydrosalpinges was a possible hindrance to implantation (1). It was suggested that in such cases, closing the cornual end of the tube combined with a neosalpingostomy could be a possible solution. It was also suggested that transvaginal US guided aspiration or a salpingectomy may improve the IVF outcome. Following this report by our group, several other investigators reported that IVF outcomes were in fact worse in the presence of hydrosalpinges (2-4). Moreover, it was demonstrated that hydrosalpinges adversely affect implantation and pregnancy rates in donor oocyte cycles (5) and cryopreserved embryos (6). In a recent large study that included 1000 patients with tubal factor infertility, the authors concluded that there was a decrease in the implantation rate and an increase in the pre-clinical miscarriages in patients with hydrosalpinges compared to tubal factor patients without sonographic evidence of dilated tubes (7). The exact mechanism for the negative effect of hydrosalpinges is not known. Different theories have been studied including the toxic effect of hydrosalpinx fluid on the embryos as well as on endometrial receptivity (8-11), or simply a mechanical hindrance of the hydrosalpinx fluid to implantation $(1,2,12)$. However, other studies have shown that embryo development was not impaired by hydrosalpinx fluid $(13,14)$. A recent debate on the possible reasons of the negative effect of hydrosalpinx on IVF results discussed all the above mentioned mechanisms and concluded that the hydrosalpinx is of crucial 
importance, but the actual mechanism of action needs to be clarified (15). Although the exact mechanism is not known, there is definitely a negative effect of hydrosalpinges on IVF results. Moreover, several retrospective studies have proven the positive effect of salpingectomy on IVF results for patients with hydrosalpinges $(3,16,17)$. On the basis of these retrospective studies IVF programs began counseling patients with hydrosalpinges to undergo a salpingectomy before starting IVF. However, one should not offer a major surgical intervention such as salpingectomy unless it is based on a proper prospective randomized study. The first prospective randomized trial was a pillot study by Dechand et al, (18) which showed a positive effect of salpingectomy on implantation rates. Recently, Strandell and group did a large multicenter prospective randomized study on 204 patients (19). The results of their study demonstrated that in patients with hydrosalpinges, salpingectomies improved the pregnancy rates. Patients with bilateral hydrosalpinges, especially if ultrasonically visible gained a clear benefit from a salpingectomy. Since the publication of this study, we routinely counsel our patients with hydrosalpinges to undergo a salpingectomy before starting the IVF cycle. It is difficult for young patients to accept having their tubes removed even if they were told that the chances of spontaneous pregnancy are almost nil. It seems preferable in those cases only to do salpingostomy to leave the patient with an open tube. Proximal tubal occlusion and distal fenestration may be another option $(1,20)$. However, further studies need to be done to investigate the efficacy of distal tubal opening with or without proximal ligation compared to salpingectomy in such cases. Recently, the cumulative results after salpingectomy in the study by Strandell et al., was published (21). The results of the cumulative cycles strengthened the recommendation for a laparoscopic salpingectomy prior to IVF in patients with ultrasound-visible hydrosalpinges (21). 
Moreover the same authors conducted another randomized conitrolled study in which they demonstrated that removal of hydrosalpinx, as a prophylactic laparoscopic procedure does not compromise ovarian function (22).

b- Performing a dummy embryo transfer in an attempt to improve the embryo transfer technique.

We have demonstrated in a randomised study that performing a "dummy" or "trial" embryo transfer before the start of an IVF cycle significantly improves the implantation and pregnancy rates (23). It is a simple procedure that helps in determining the most suitable kind of catheter to be used for $\mathrm{ET}$, and allows us to measure the length and direction of the uterine cavity. It is also helpful in discovering any unanticipated difficulty such as cervical stenosis, anatomical distortion of the cervix from previous surgery, or cervical fibroid. It is like performing a rehearsal before the real transfer. Following this study we have been performing dummy ET routinely for all our patients before starting the IVF cycle and right before the embryo transfer. Many IVF centers routinely perform dummy ET, however, the published data on this is minimal. In one study, it was reported that mock ET was performed immediately before the real transfer on 113 patients and they achieved a $45 \%$ pregnancy rate (24).

In another prospective study the actual ET was simulated using a methylene blue dye to study the effect of some factors on the rate of uterine expulsion of the dye (25). It was demonstrated that the dye was extruded at the external cervicall os, at least partially, in $42 \%$ of all cases. This may indirectly indicate that in the case of the actual 
ET, some of the patients might have lost their chance of pregnancy. The results of this study are similar to the results of another study in which the authors used a radioopaque dye, mimicking the embryo transfer (26). The authors found that the dye remained primarily in the uterine cavity in only $58 \%$ of the cases. In the rest of the cases, the dye was extruded from the cervix or into the tubes. Consequently, it is possible that the embryos may be extruded partially or totally after embryo transfer $(27,28)$. However, if the embryo was extruded into the tube, it may not necessarily interfere with implantation in patients with healthy tubes. In our study, the effect of three factors on the rate of extrusion of the dye was investigated: 1-, the kind of ET catheter used, 2-the presence of cervical mucus, 3- the presence of air bubbles in the catheter. The results of the study demonstrated that the use of soft catheters was associated with a significantly reduced rate of extrusion of the dye compared to the use of more rigid ones. Regarding the effect of cervical mucus, the dye appeared at the external cervical os at a significantly higher rate when the cervical mucus was not removed. The presence of air bubbles in the catheter did not affect the rate of extrusion of the dye.

Several other studies have been done comparing different kinds of catheters and they all demonstrated that soft catheters are the best in terms of pregnancy rattes (29-31). The stimulus of the catheter passing through the internal cervical os can initiate contractions probably mediated by the release of prostaglandins (32). The more rigid the catheter is, the more likely that it will agitate the cervix. The presence of cervical mucus can be a serious obstacle in proper embryo replacement. It can plug the tip of the catheter, causing difficulty in delivering the embryos inside the uterine cavity, especially with such a small wolume of culture media to inject the embryos. Moreover, the embryos can stick to the mucus around the ET catheter and be dragged 
out during withidrawal of the catheter. If the mucus is pushed or injected higher in the uterine cavity, it may interfere with implantation. In a large study analyzing $1204 \mathbb{E T}$ procedures, it was shown that the embryos were much more likely to be retained in the catheter when the ET catheter was contaminated with mucus or blood (33).

\section{Optimizing fertilization:}

In 1992 , a breakthrough occurred in the field of IVF through the introduction of intracytoplasmic sperm injection (ICSD (34). Our IVF program quickly adopted the technique of ICSI in order to improve fertilization. We conducted a number of studies on modifying the technique of ICSI itself (35) as well as studying the effect of different semen parameters (36) and the use of epididymal and testicular spermatozoa in ICSI $(37,38)$. We have demonstrated that the fertilization and pregnancy rates in ICSI were not affected by different semen parameters as long as morphologically normal living sperm could be used for the injection (36). Other investigators studied the relationship between the sperm parameters and outcome of ICSI, and found that none of the single sperm parameters, such as concentration, progressive motility, or morphology, correlated with the outcome $(39,40)$. The technique of ICSI enabled men with very few living spermatozoa in their ejaculates to achieve fertilization and parenthood $(41,42)$. In our study it was also demonstrated that patients who previously failed fertilization with IVF had successful fertilization with ICSI. ICSI offered these patients an equal chance of fertilization compared to patients with other indications (43).

We have also demonstrated that the use of epididymal and testicular spermatozoa for ICSI in cases of obstructive azoospermia provided an efficient method for achieving fertilization and pregnancy (37). Microsurgical epididymal sperm aspiration (MESA) was the first method described for surgical retrieval of spermatozoa in cases of obstructive azoospermia (44). The 
introduction of ICSI has made fertilization very efficient and precise, to the extent that a very low number of spermatozoa are required to inject all the oocytes retrieved for the procedure (45). High fertilization and pregnancy rates have been reported with the combination of MESA and ICSI (45-47). However, the technique is lengthy, requires general anaesthesia, special skills, and equipment. For these reasons, percutaneous sperm aspiration (PESA) was. introduced (48). Until recently, the fertilizing capacity of testicular spermatozoa was not explored. In 1993, it was reported that the use of testicular spermatozoa in ICSI for cases of obstructive azoospermila could achieve fertilization and pregnancy (49-51). Following our study (37) many of our patients with obstructive azoospermia were encouraged to undergo ICSI. Such patients were considered absolutely infertile, and no sperm donation is allowed in our country.

Furthermore, our group investigated the technique of performing injection of the sperm inside the oocyte. In a prospective randomized study on sibling oocytes we studied the effects of cytoplasmic aspiration versus non-aspiration on the rate of oocyte damage, fertilization and embryo quality (35). Cytoplasmic aspiration has been considered to be an integral part of the ICSI procedure and an essential step for oocyte activation (42). Moreover, vigorous aspiration of the oocyte cytoplasm has been reported to be pivotal for the success of ICSI (52). However; in our study it was demonstrated that cytoplasmic aspiration before sperm injection was not essential for oocyte activation, as it did not improve the fertilization rate. It was only a way of making sure of piercing the oolemmal membrane. Moreover, it significantly increased the rate of oocyte damage. Also, our technique of no aspiration resulted in a significantly higher percentage of grade I embryos compared to cytoplasmic aspiration. Our report was the first in the literature that demonstrated that cytoplasmic aspiration in the ICSI procedure is not essential for oocyte activation. 
In another study by our group (38) the results of ICSI were compared in: 1- obstructive versus non-obstructive azoospermia, 2- testicular versus epididymal spernatozoa in obstructive azoospermia. The results have demonstrated that ICSI using spermatozoa from patients with acquired obstructive azoospermia resulted in significantly higher fertilization and pregnancy rates compared to congenital absent vas deferens (CAVD) and nonobstructive azoospermia. Our data demonstrated that in obstructive azoospermia testicular spermatozoa used for ICSI achieved fertilization and pregnancy rates comparable to those obtained with epididymal spermatozoa, which is in agreement with other studies (51). Also, in this study we compared the results of ICSI in acquired obstructive azoospermia with those of CAVD. The fertilization rate was not significantly different, however the pregnancy rate was significantly higher in the acquired obstructive group. In another study comparing acquired and congenital obstructive azoospermia, there was also no significant difference in the fertilization rate (53). However, contrary to our findings, the authors concluded that CAVD patients seemed to have a stronger tendency to achieve pregnancy than the acquired obstructive group. Recently with a large number of cases reaching 1000 cycles (448 obstructive azoospermia) of ICSI using surgically retrieved spermatozoa, we did not find any significant difference in the fertilization and pregnancy rates between acquired obstructive and BCAV patients (Tables 1,2). Moreover the results of our study demonstrated that the fertilizing ability of testicular spermatozoa obtained from obstructive azoospermia was significantly higher than those obtained from non-obstructive cases. These results confirm other studies in the literature (54). This may be due to the fact that, in non-obstructive azoospermia there is a severe impairment of spermatogenesis, and even testicular failure, which might have a genetic origin (55). Finally, in this study we have demonstrated that spermatozoa could be retrieved in $67 \%$ of the testicular biopsies obtained from nonobstructive azoospermic patients. It is clear from these data that even in non-obstructive 
azoospermia there are usually tiny foci of spermatogenesis that allow TESA with ICSI to be performed in cases that were previously considered hopeless. Therefore, we do not deny patients with non-obstructive azoospermia the chance to undergo ICSI.

\section{Multifetal pregnancy reduction as an attempt to improve the outcome:}

The use of ovulation induction drugs for different assisted reproduction techniques has increased considerably during the past 20 years. Consequently, this practice has resulted in a marked increase in the multiple pregnancy rates with al. its complications. Most IVF programs have reduced the dose of ovulation induction drugs and limited the number of embryos for transfer in an attempt to reduce the incidence of multiple gestations.

However, the problem of high onder multiple pregnancies is still not completely avoidable. Multifetal pregnancy reduction was introduced to avoid the increased incidence of abottion and premature labor associated with multiple pregnancies (56). A modification of the previously described technique of multifetal reduction was introduced by our group (57). The modified approach depends mainly on performing the procedure early, usually between 7 and 8 weeks of gestation and eliminating the use of any cardiotoxic substance such as $\mathrm{KCl}$, which may diffuse to the adjacent sacs and induce detrimental effects $(58,59)$. At this early stage of

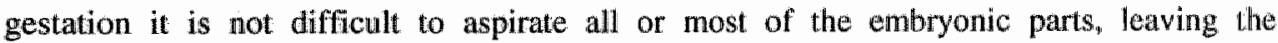
gestational sac almost empty of embryonic tissues but full of amniotic fluid. This leaves minimal amounts of necrotic tissues, which also might have a detrimental effect on the remaining embryonic sacs (60-62). Using this technique, the miscarriage and perinatal mortality rates decreased significantly compared to high order multiple pregnancies. The gestational age at birth and the mean birth weight significantly improved after multifetal reduction as compared to non-reduced twins and higher order multiple pregnancy (Table 3). The mean gestational age at delivery of multiples reduced to twins was $36.9 \pm 2.45$ weeks 
and the mean birth weight was $2450.51 \pm 235.44 \mathrm{~g}$. which was similar to twins conceived by assisted reproduction $(36.5 \pm 2.58$ weeks and $2316.04 \pm 603.09 \mathrm{~g}$.). For the past three years, we have been limiting the number of embryos per transfer to a maximum of three in patients less than 40 years old and undergoing their first IVF-ICSI trial. Unfortunately, we are still facing the problem of triplet pregnancy and we routinely offer these patients the option of multifetal reduction. It was also demonstrated by others that multifetal pregnancy reduction gave better outcomes than expectant management of triplets $(63,64)$. However, in a large study of 1000 consecutive cases of multi-fetal pregnancy reduction, it was demonstrated that the gestational age of delivery for finishing numbers of one, two and three fetuses are similar to that of non-reduced pregnancies (65). In another review it was demonstrated that multifetal pregnancy reduction does not have a significant impact on the probability of live birth or: on gestational age at delivery for women with triplets conceived with assisted reproductive technology (66).

An over view on how to optimize IVF results:

Numerous measures have been suggested for optimizing IVF results. Only some have been proven to have an impact on the results and will be discussed. The formation of a good staff team is the key to assure that all the procedures of IVF are conducted properly. Patient preparation before stating the IVF cycle is very important. Special consideration should be given to the diagnosis and treatment of hydrosalpinges, $(1,19,20)$ the diagnosis and treatment of lower genital tract infection $(67,68)$ and proper ultrasonic (US) evaluation of the uterine cavity (69-71). Performing a dummy or trial embryo transfer is also important (23). The choice of the most suitable protocol for ovulation induction is important to obtain an 
adequate number of high quality oocytes (72). Strict quality control and quality assurance is vital in any IVF program to produce viable embryos (73). Optimizing fertilization has been successfully achieved through the development of ICSI (34). The technique by which the embryos are transferred into the uterine cavity has a significant impact on the results (74). High order multiple pregnancies must be prevented by limiting the number of transferred embryos (75). However, in cases of high order multiple pregnancies, multifetal reduction might be an option to improve the outcome (57). In a recently conducted survey (76), a questionnaire was sent to the 40 leading ART centers in the USA. The questionnaire included 11 factors for optimizing IVF results and the centers were asked to put them in order of importance. The questionnaire was answered by 38 of the 40 centers. The results of the survey showed that the most important factors in optimizing IVF results are: 1- IVF laboratory including quality control, culture media, lab condition, embryologists, culture and grading of oocytes and embryos. 2- Selection and screening methods for quality embryos. 3Patient selection. 4- Embryo transfer technique. 5- Improving implantation.

The following are some of the factors that are believed to have an impact on IVF success rates in detail.

\section{Quality control in the IVF laboratory:}

IVF, from its name, implies that fertilization is done outside the body, which means that human gametes have to be provided with the exact conditions as in vivo. This requires strict rules and regulations to be observed in order to assure quality control. Several procedures have been proposed, howewer some are practical and valuable in the discovery of the potential pitfalls that might affect the outcome of IVF. Quality control means routine monitoring of all procedures involved in IVF, while quality assurance means evaluation of the results, identifying problems and finding means for correction. Quality control is essential 
for daily montoring and recording of the temperature and gas levels in the incubators, temperature of all heating stages, watter baths, and heating blocks. Environmental control is very important in the IVF laboratory. It is advisable to avoid the use of excessive alcohol to disinfect the facility to avoid extraordinary levels of isopropanol in the laboratory (77). The single and most important measure is to use lots of clean fresh air. The process of fresh clean air going into the laboratory requires two kinds of filtration. A HEPE filter to remove biological material such as molds and bacteria, and an aetivated carbon filter to absorb organic compounds (78). Moreover, new construction in the vicinity of the laboratory should be awoided. Apart from daily measurements and testing of every procedure related to IVF, it is much more important to have a laboratory director who is continuously following every test to be done, and can interpret and understand from the results what may be a potential risk and how to solve it. Moreover, the laboratory director should individually superwise all the embryologists and lab technicians. The most important factor in quality control and assurance is the quality of the personnel working in the laboratory.

\section{Optimizing the rechnique of embryo transfer:}

There is no doubt that one of the most important factors that contributed to the improvement of IVF results is the increased awareness and expertise in performing the embryo transfer. The importance of the technique by which the embryos are transferred into the uterine cavity is very well illustrated by the fact that there is a significant difference in the pregnancy rates, within the same IVF program, according to the clinician performing the transfer $(74,79)$. Searching Medline on the Internet revealed that the number of scientific publications on human IVF from 1978 till 2001 is 40500 . However, the number of scientific publications on 
the technique of embryo transfer is only 54 (79). That discrepancy reflects how little attention has been given to the technique of embryo transfer (79). The embryo transfer is routinely done using the transcervical route, which is basically a blind technique and is associated with multiple potential negative factors. The following are some suggestions for optimizing the embryo transfer technique:

\section{Avoid the initiation of uterine contractions}

The presence of physiological subendometrial movements has been recognized by different groups (80-87). There are slow subendometrial movements that usually benefit implantation and limit it to the upper uterine cavity, especially if the direction is from cervix to fundus (83). Endometrial wavelike activity was observed in $71 \%$ of spontaneous cycles (83) as compared to $91 \%$ in stimulated cycles (85). It was found out that fundus to cervix waves never occur after ovulation in spontaneous cycles, nor after ovum pick-up in IVF cycles (87). The later the wave direction switch from fundus to cervix to become cervix to fundus, the higher the likelihood of pregnancy in that cycle (87).

The pathological reflex contractions due to aggressive handling during embryo transfer should be avoided. Following embryo transfer, the embryos might be expelled. About $15 \%$ of the transferred embryos have been collected from the external os, the tip of the catheter and vaginal speculum after embryo transfer (27). In a study using radio opaque dye it was demonstrated that the dye remained primarily inside the uterine cavity in only $58 \%$ of cases (26). In another study done by our group, using methylene blue dye, it was shown that the dye was visualized at the external os in $42 \%$ of the cases (25). Myometrial contractile activity was recorded and an overall uterine contraction frequency of 4.3 per minute was found (88). The pregnancy and implantation rates decreased as the frequency of uterine contractions 
increased (88). Several precautions should be taken to avoid the initiation of pathological reflex uterine contractions during embryo transfer:

a) The use of soft catheters:

Several studies have been done comparing different kinds of catheters for ET and most of them have demonstrated that soft catheters are the best in terms of pregnancy rates (29-31). An ultrasonographic monitoring revealed disruption in the endometrium in $50 \%$ of women in whom a Tomcat catheter was used compared to $12.5 \%$ with the use of a Wallace catheter (89). Changing from Toncat to Wallace catheters has been associated with a better pregnancy rate (89). To benefit from the advantages of the softness of the catheter, the outer rigid sheath should minimally be used to stop short of the internal os. The stimulus of the catheter passing through the internal os can also initiate contractions probably mediated by the release of prostaglandins (32).

b) Avoid touching the uterine fundus:

Depositing the embryos in the mid fundal area was found to improve the pregnancy rate (90). In another study it was found that transferring the embryos at $6 \mathrm{~cm}$ without tracing the position of the fundus improved the pregnancy rates (91). Other groups routinely place the catheter $0.5 \mathrm{~cm}$ below the fundus (92). Therefore, individual measurements of the cervical canal and uterine cavity are important to know exactly how much you can introduce the catheter without touching the fundus.

c) Gentle manipulation:

As a general tule, ET should be a simple and painless procedure. It has been observed that the use of tissue forceps to hold the cervix triggers uterine contractions (93). The use of soft catheters should be the rule except when it cannot be introduced. Technically difficult transfers were found to be associated with reduced pregnancy 
rates $(24,94)$. This is probably due to stimulation of uterine contractions that might expel the embryos (88).

\section{Getting rid of cervical mucus}

It has been demonstrated that removing the cervical mucus before a methylene blue dummy embryo transfer significantly reduced the rate of extrusion of the dye at the external cervical os (25). It was also shown that the embryos were much more likely to be retained in the ET catheter if it was contaminated with mucus or blood $(33,94)$. Therefore it advisable to gentle aspirate the cervical mucous before ET to avoid its introduction with the catheter inside the uterine cavity and the possibility of blocking the tip of the catheter.

\section{Proper delivery of the embryos inside the uterine cavity}

The most important point in ET is to be absolutely sure that the catheter has passed the internal os and entered the uterine cavity. Soft catheters can sometimes be misleading when they curve inside the cervical canal. With experience, a simple test can confirm that the catheter is in the cavity. Rotating the catheter $360^{\circ}$ will show when it is bent if it recoils (79). One important cause of the failure of the catheter to pass the internal os is the lack of alignment between the catheter (straight) and the cervico-uterine angle (curved and sometimes acutely angulated) (79). A simple procedure of gently curving the outer sheath of the catheter will overcome this problem in most of the situations "Perlorming a dummy $\mathrm{ET}$ right before the actual one and revising the previously taken US picture of the uterus will help to find the right direction.

The use of US guidance to facilitate embryo transfer has been described by some IVF programs $(95,96)$. It has proven to be useful in women with a previously difficult embryo transfer. It has also been found to be simple, reassuring, and it significantly improved the 
pregnancy rate $(31,97,98)$. However, other investigators found no sigmificant difference in the pregnancy rate between US guidance and clinical touch ET $(99,100)$. It seems that, using either one of the two techniques; the IVF outcome depends on the experience of the clinician performing the ET.

\section{Awoiding high order multiple pregnancies:}

To avoid triplet pregnancy, some European ART centers adopted the policy of transferring only two embryos (101). However, the number of twin pregnancies after transferring only two embryos is still high (102). In a recent study elective single embryo transfer (eSET) was

performed for 127 patients achieving a clinical pregnancy rate of $38.6 \%$ in fresh embryos and $17.4 \%$ in cryo-thawed embryos $(75)$. The cumulative delivery rate per oocyte retrieval was $52.8 \%$ and the monozygotic twin rate was $7.6 \%$ (75). Results from several centers were presented during an ESHRE campus course (103) and it was recommended that sound clinical trials are needed to clarify several points such as: a) the clinical profile of patients in whom eSET should be considered. b) will the overall pregnancy rate decrease? c) will the financial gain of prevented twins be balanced by the likely needed to perform extra IVF/CSI cycles?

The problem of high order multiple pregnancies is better solved by prevention rather than multifetal pregnancy reduction. The ideal situation is to transfer one or two embryos only without jeopardizing the pregnancy rate. 


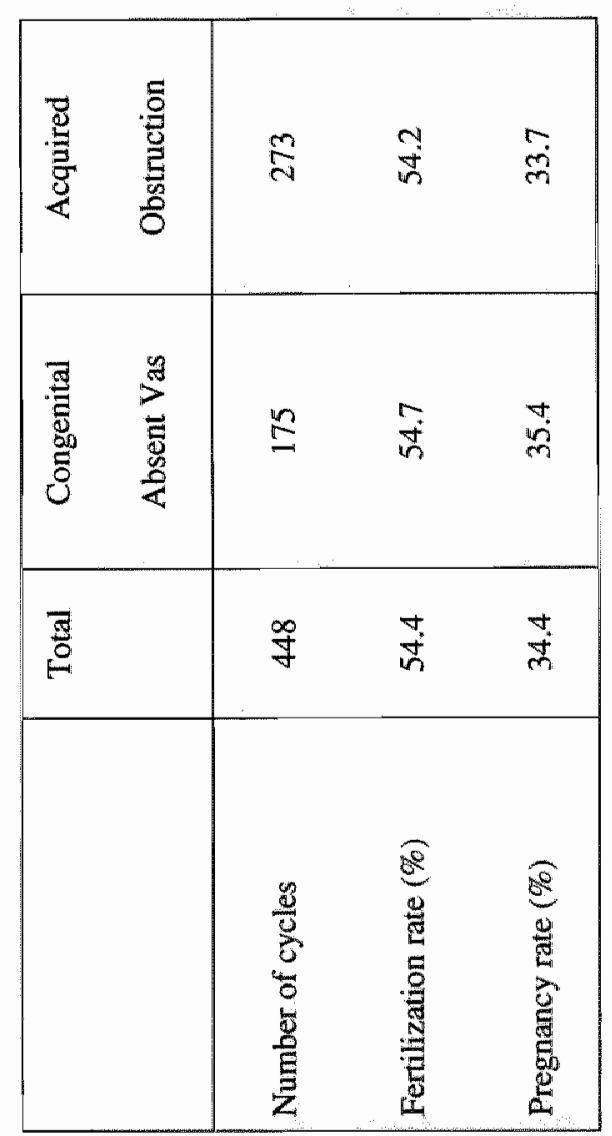




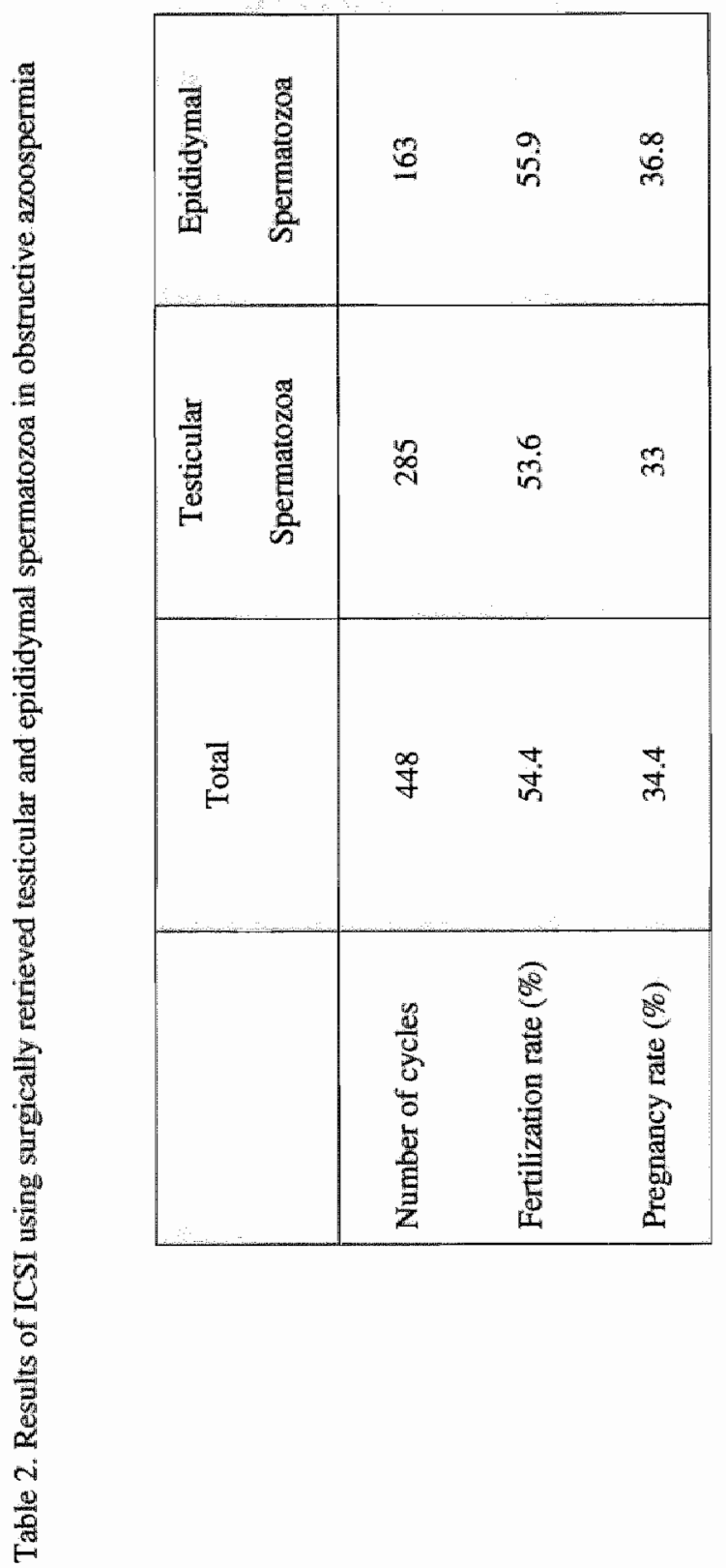




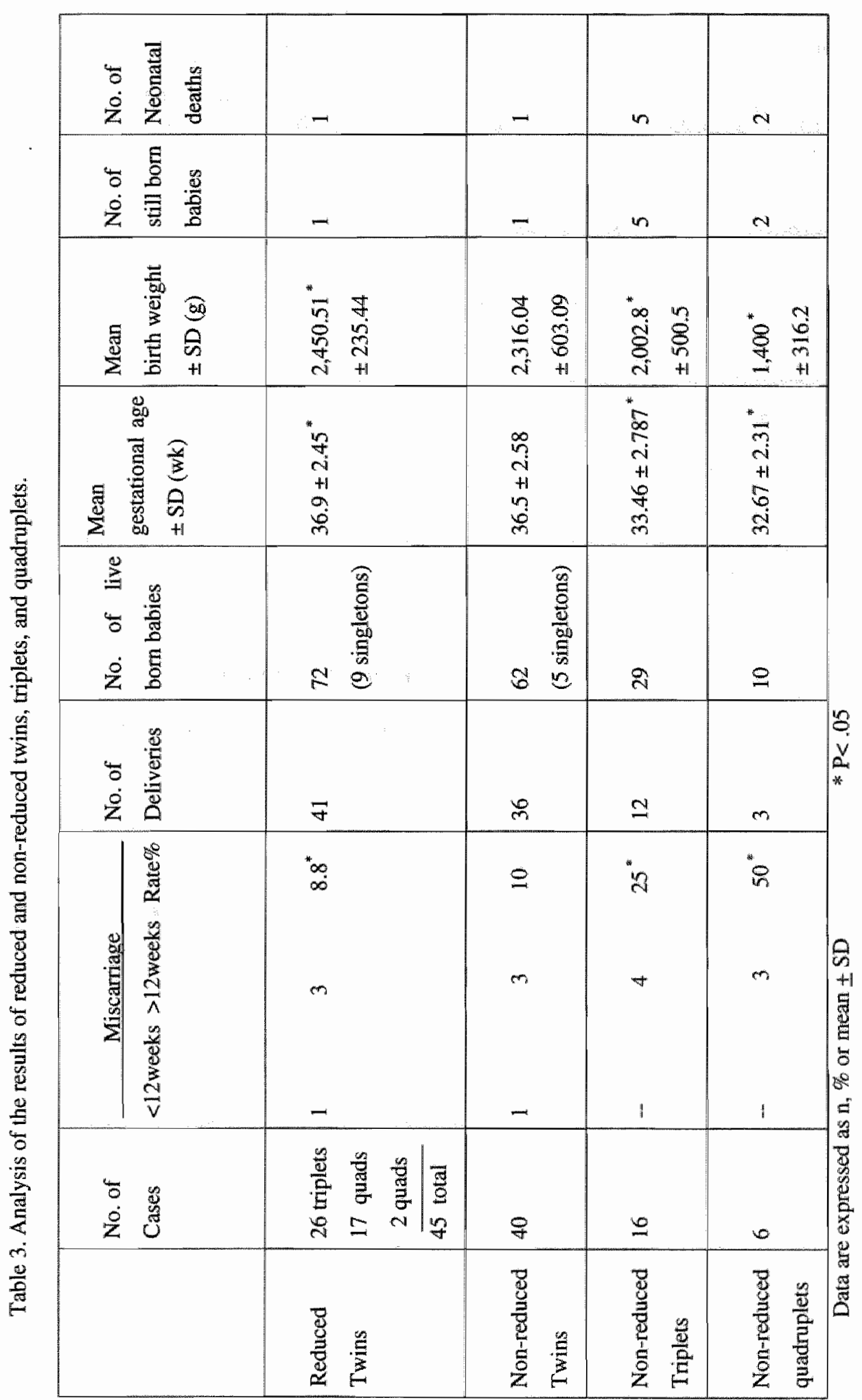




\section{Future Perspectives}

Salpingectomy has been shown to improve IVF outcome in patients with hydrosalpinges. Further research is needed to investigate the efficacy of distall opening of the tube with or without proximal ligation as compared to salpingectomy in patients with hydrosalpinges before starting IVF.

For improving the technique of embryo transfer, and decreasing the rate of extrusion of the embryos after embryo transfer, future studies need to be done on experimenting with different uterine relaxant drugs that may decrease the initiation of uterine contractility.

ICSI has significantly improved fertilization and even made it possible in azoospermic patients to achieve parenthood. However, there still are about $35 \%$ of non-obstructive azoospermic patients in whom no spermatozoa could be retrieved. Future research should concentrate on the use of diploid spermatogenic cells. In cases of spermatogenic arrest, many primary spermatocytes are present that could be matured in-vitro or be used as diploid cells for injection. After triploid fertilization, one male pronucleus can be removed.

The problem of high order multiple pregnancies should be considered more seriously. Single embryo transfer needs to be further studied to delineate the criteria of patients suitable for single embryo transfer. 


\section{REFERENCES}

1. Mansour RT, Aboulghar MA, Serour GI, Riad R. Fluid accumulation of the uterine cavity before embryo transfer: a possible hindrance for implantation. J In Vitro Fert Embryo Transf. 1991 Jun;8(3):157-9.

2. Strandell A, Waldenstrom U, Nilsson L, Hamberger L. Hydrosalpinx reduces in-vitro fertilization/embryo transfer pregnancy rates. Hum Reprod. 1994 May;9(5):861-3.

3. Vandromme J, Chasse E, Lejeune B, Van Rysselberge M, Delvigne A, Leroy F. Hydrosalpinges in in-vitro fertilization: an unfavourable prognostic feature. Hum Reprod. 1995 Mar; 10(3):576-9.

4. Fleming C, Hull MG. Impaired implantation after in vitro fertilisation treatment associated with hydrosalpinx. Br J Obstet Gynaecol. 1996 Mar;103(3):268-72.

5. Cohen MA, Lindheim SR, Sauer MV. Hydrosalpinges adversely affect implantation in donor oocyte cycles. Hum Reprod. 1999 Apr; 14(4):1087-9.

6. Akman MA, Garcia JE, Damewood MD, Watts LD, Katz E. Hydrosalpinx affects the implantation of previously cryopreserved embryos. Hum Reprod. 1996 May;11(5):1013-4.

7. Barmat LI, Rauch E, Spandorfer S, Kowalik A, Sills ES, Schattman G, Liu HC, Rosenwaks Z. The effect of hydrosalpinges on IVF-ET outcome. J Assist Reprod Genet. 1999 Aug; 16(7):350-4.

8. Murray CA, Clarke HJ, Tulandi T, Tan SL. Inhibitory effect of human hydrosalpingeal fluid on mouse preimplantation embryonic development is significantly reduced by the addition of lactate. Hum Reprod. 1997 Nov; 12(11):2504-7.

9. Mukherjee T, Copperman AB, McCaffrey C, Cook CA, Bustillo M, Obasaju MF. Hydrosalpinx fluid has embryotoxic effects on murine embryogenesis: a case for prophylactic salpingectomy. Fertil Steril, 1996 Nov;66(5):851-3.

10. Beyler SA, James KP, Fritz MA, Meyer WR. Hydrosalpingeal fluid inhibits in-vitro embryonic development in a murine model. Hum Reprod. 1997 Dec;12(12):2724-8.

11. Freeman MR, Whitworth CM, Hill GA. Permanent impairment of embryo development by hydrosalpinges. Hum Reprod. 1998 Apr;13(4):983-6.

12. Sharara FI. The role of hydrosalpinx in IVF: simply mechanical? Hum Reprod. 1999 Mar;14(3):577-8.

13. Strandell A, Sjogren A, Bentin-Ley U, Thorburn J, Hamberger L, BrannstromM. Hydrosalpinx flluid does not adversely affect the normal development of human embryos and implantation in vitro.Hum Reprod. 1998 Oct; 13(1O):2921-5. 
14. Koong MK, Jun JH, Song SJ, Lee HJ, Song IO, Kang IS. A second look at the embryotoxicity of hydrosalpingeal fluid: an in-vitro assessment in a murine model. Hum Reprod. 1998 Oct; 13 (10):2852-6.

15. Strandell A, Lindhard A. Why does hydrosalpinx reduce fertility: The importance of hydrosalpinx fluid. Hum Reprod 2002 May; $17(5): 1141-5$.

16. Shelton KE, Butler L, Toner JP, Oehninger S, Muasher SJ. Salpingectomy improves the pregnancy rate in in-witro fertilization patients with hydrosalpinx. Hum Reprod. 1996 Mar, 11(3).523-5.

17. Murray DL, Sagoskin AW, Widra EA, Levy MJ. The adverse effect of hydrosalpinges on in vitro fertilization pregnancy rates and the benefit of surgical correction. Fertil Steril. 1998 Jan; $69(1): 41-5$.

18. Dechaud H, Daures JP, Amal F, Humeau C, Hedon B. Does previous salpingectomy improve implantation and pregnancy rates in patients with severe tubal factor infertility who are undergoing in witro fertilization? A pilot prospective randomized study. Fertil Steril. 1998 Jun;69(6):1020-5.

19. Strandell A, Lindhard A, Waldenstrom U, Thorburn J, Janson PO, Hamberger L. Hydrosalpinx and IVF outcome: a prospective, randomized multicentre trial in Scandinavia on salpingectomy prior to IVF. Hum Reprod. 1999 Nov;14(11):2762-9.

20. Zeyneloglu HB. Hydrosalpinx and assisted reproduction: options and rationale for treatment. Curr Opin Obstet Gynecol. 2001 Jun;13(3):281-6.

21. Standell A, Lindhard A, Waldenstrom U, Thorburn J. Hydrosalpinx and IVF outcome: cumulative results after salpingectomy in a randomized controlled trial. Hum Reprod 2001 Nov; 16(11)2403-10.

22. Standel] A, Lindhard A, Waldenstrom U, Thorburn J. Prophylactic salpingectomy does not impair the ovarian response in IVF treatment. Hum Reprod 2001 Jun; 16(6):1135-9.

23. Mansour R, Aboulghar M, Serour G. Dummy embryo transfer: a technique that minimizes the problems of embryo transfer and improves the pregnancy rate in human in vitro fertilization. Fertil Steril. 1990 Oct;54(4):678 81 .

24. Sharif K, Afnan M, Lenton W. Mock embryo transfer with a full bladder immediately before the real transfer for in-vitro fertilization treatment: the Birmingham experience of 113 cases. Hum Reprod. $1995 \mathrm{Jul} ; 10(7): 1715-8$.

25. Mansour RT, Aboulghar MA, Serour GI, Amin YM. Dummy embryo transfer using methyllene blue dye. Hum Reprod. 1994 Jul;:9(7):1257-9.

26. Knutzen V, Stratton CJ, Sher G, McNamee PI, Huang TT, Soto-Albors C. Mock embryo transfer in early luteal phase, the cycle before in vitro fertilization and embryo transfer: a descriptive study. Fertil Steril. 1992 Jan;57(1):156-62. 
27. Poindexter AN 3rd, Thompson DJ, Gibbons WE, Findley WE, Dodson MG, Young RL. Residual embryos in failed embryo transfer. Fertil Sterill 1986 Aug;46(2):262-7.

28. Schulman JD. Delayed expulsion of transfer fluid after IVF/ET. Lancet. 1986 Jan $4 ; 1(8471): 44$.

29. Meldrum DR, Chetkowski R, Steingold KA, de Ziegler D, Cedars MI, Hamilton M. Evolution of a highly successful in vitro fertilization-embryo transfer program. Fertil Steril. 1987 Jul; $48(1): 86-93$.

30. Ghazzawi IM, Al-Hasani S, Karaki R, Souso S. Transfer technique and catheter choice influence the incidence of transcervical embryo expulsion and the outcome of IVF. Hum Reprod. 1999 Mar; 14(3):677-82.

31. Wood EG, Batzer FR, Go KJ, Gutmann JN, Corson SL. Ultrasound-guided soft catheter embryo transfers will improwe pregnancy rates in in-vitro fertilization. Hum Reprod. $2000 \mathrm{Jan} ; 15(1): 107-12$.

32. Fraser IS. Prostaglandins, prostaglandin inhibitors and their roles in gynaecological disorders. Baillieres Clin Obstet Gynaecol. 1992 Dec;6(4):829-57.

33. Nabi A, Awonuga A, Birch H, Barlow S, Stewart B. Multiple attempts at embryo transfer: does this affect in-vitro fertilization treatment outcome? Hum Reprod. 1997 Jun; 12(6):"1188-90.

34. Palermo $G_{*}$ Joris $H$, Devroey $P$, Van Steirteghem AC. Pregnancies after intracytoplasmic injection of single spermatozoon into an oocyte. Lancet. $1992 \mathrm{Jul}$ $4 ; 340(8810): 17-8$.

35. Mansour RT, Aboulghar MA, Serour GI, Tawab NA, Amin Y, Sattar MA. Successful intracytoplasmic sperm injection without performing cytoplasmic aspiration. Fertil Steril. 1996 Aug;66(2):256-9.

36. Mansour RT, Aboulghar MA, Serour GI, Amin YM, Ramzi AM. The effect of sperm parameters on the outcome of intracytoplasmic sperm injection. Fertil Steril. 1995 Nov:64(5):982-6.

37. Mansour RT, Aboulghar MA, Serour GI, Fahmi I, Ramzy AM, Amin Y. Intracytoplasmic sperm injection using microsurgically retrieved epididymal and testicular sperm. Fertil Steril. 1996 Mar;65(3):566-72.

38. Mansour RT, Kamal A, Fahmy I, Tawab N, Serour GI, Aboulghar MA. Intracytoplasmic sperm injection in obstructive and non-obstructive azoospermia. Hum Reprod. 1997 Sep;12(9):1974-9.

39. Cohen J, Schattman G, Suzman M, Adler A, Alikani M, Rosenwaks Z. Micromanipulating human gametes. Reprod Fertil Dev. 1994;6(1):69-81; discussion $81-3$. 
40. Payne D, Flaherty SP, Jeffrey $R$, Wames GM, Matthews CD. Successful treatment of severe male factor infertility in 100 consecutive cycles using intracytoplasmic sperm injection. Hum Reprod. 1994 Now;9(11):2051-7.

41. Van Steirteghem AC, Nagy Z, Joris H, Liu J, Staessen C, Smitz J, Wisanto A, Devroey P. High fertilization and implantation rates after intracytoplasmic sperm injection. Hum Reprod. 1993 Jul:;8(7):1061-6.

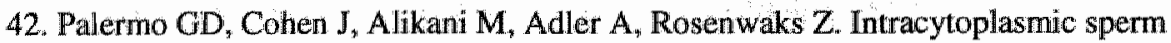
injection: a novel treatment for all forms of male factor infertility. Fertil Steril. 1995 Jun:63(6): 1231-40.

43. Palermo G, Joris H, Derde MP, Camus M, Devroey $P_{*}$ Van Steirteghem A. Sperm characteristics and outcome of human assisted fertilization by subzonal insemination and intracytoplasmic sperm injection. Fertil Steril. 1993 Apr;59(4):826-35.

44. Temple-Smith PD, Southwick GJ, Yates CA, Trounson AO, de Kretser DM. Human pregnancy by in vitro fertilization (IVF) using sperm aspirated from the epididymis. J In Vitro Fert Embryo Transf. 1985 Sep;2(3):119-22.

45. Tournaye H, Devroey P, Liu J, Nagy Z, Lissens W, Van Steirteghem A. Microsurgical epididymal sperm aspiration and intracytoplasmic sperm injection: a new effective approach to infertility as a result of congenital bilateral absence of the vas deferens. Fertil Steril. 1994 Jun;61(6):1045-51.

46. Silber SJ, Nagy ZP, Liu J, Godoy H, Devroey P, Van Steirteghem AC. Conventional in-vitro fertilization versus intracytoplasmic sperm injection for patients requiring microsurgical sperm aspiration. Hum Reprod. 1994 Sep;9(9):1705-9.

47. Hovatta O, Moilanen J, von Smitten K, Reima I. Testicullar needle biopsy, open biopsy, epididymal aspiration and intracytoplasmic sperm injection in obstructive azoospermia. Hum Reprod. 1995 Oct;10(10):2595-9.

48. Craft IL, Khalifa Y, Boulos A, Pelekanos M, Foster C, Tsirigotis M. Factors influencing the outcome of in-vitro fertilization with percutaneous aspirated epididymal spermatozoa and intracytoplasmic sperm injection in azoospermic men. Hum Reprod. $1995 \mathrm{Jul} ; 10(7): 1791-4$.

49. Schoysman R, Vanderzwalmen P, Nijs M, Segal L, Segal-Bertin G, Geerts L, van Roosendaal E, Schoysman D. Pregnancy after fertilisation with human testicular spermatozoa. Lancet. 1993 Nov 13;342(8881): 1237.

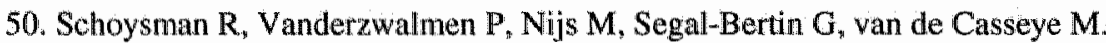
Successful fertilization by testicular spermatozoa in an in-vitro fertilization programme. Hum Reprod. 1993 Aug;8(8): 1339-40.

51. Silber SJ, Van Steirteghem AC, Liu J, Nagy Z, Tournaye H, Devroey P. High fertilization and pregnancy rate after intracytoplasmic sperm injection with spermatozoa obtained from testicle biopsy. Hum Reprod. 1995 Jan; 10(1):148-52. 
52. Tesarik J, Sousa M. Key elements of a highly efficient intracytoplasmic sperm injection technique: Ca2+ fluxes and oocyte cytoplasmic dislocation. Fertil Steril. 1995 Oct; $64(4): 770-6$.

53. Chen CS, Chu SH, Soong YK, Lai YM. Epididymal sperm aspiration with assisted reproductive techniques: difference between congenital and acquired obstructive azoospermia? Hum Reprod. 1995 May; 10(5):1104-8.

54. Kahraman S, Ozgur S, Alatas C, Aksoy S, Tasdemir M, Nuhoglu A, Tasdemir I, Balaban B, Biberoglu K, Schoysman R, Nijs M, Vanderzwalmen P. Fertility with testicular sperm extraction and intracytoplasmic sperm injection in non-obstructive azoospermic men. Hum Reprod. 1996 Apr;11(4):756-60.

55. Vogt PH. Genetic aspects of human infertility. Int J Androl. 1995 Dec; 18 Suppl 2:3-6.

56. Kanhai HH, van Rijssel EJ, Meerman RJ, Bennebroek Gravenhorst J. Selective termination in quintuplet pregnancy during first trimester. Lancet. $1986 \mathrm{Jun}$ $21 ; 1(8495): 1447$.

57. Mansour RT, Aboulghar MA, Serour GI, Sattar MA, Kamal A, Amin YM. Multifetal pregnancy reduction: modification of the technique and analysis of the outcome. Fertil Steril. 1999 Feb;71(2):380-4.

58. Tabsh KM. Transabdominal multifetal pregnancy reduction: report of 40 cases. Obstet Gynecol. 1990 May;75(5):739-41.

59. Wapner RJ, Davis GH, Johnson A, Weinblatt VJ, Fischer RL, Jackson LG, Chervenak FA, McCullough LB. Selective reduction of multifetal pregnancies. Lancet. 1990 Jan $13 ; 335(8681): 90-3$.

60. Sebire NJ, Sherod C, Abbas A, Snijders RJ, Nicolaides KH. Preterm dellivery and growth restriction in multifetal pregnancies reduced to twins. Hum Reprod. 1997 Jan; 12(1): 173-5.

61. Bass HN, Oliver JB, Srinivasan M, Petrucha R, Ng W, Lee JE. Persistently elevated AFP and AChE in amniotic fluid from a normal fetus following demise of its twin. Prenat. Diagn. 1986 Jan-Feb;6(1):33-5.

62. Abbas A, Johnson M, Bersinger $\mathbb{N}$, Nicolaides $\mathrm{K}$. Maternal alpha-fetoprotein levels in multiple pregnancies. Br J Obstet Gynaecol. 1994 Feb;101(2):156-8.

63. Bollen N, Camus M, Tournaye H, Wisanto A, Van Steirteghem AC, Devroey P. Embryo reduction in triplet pregnancies after assisted procreation: a comparative study. Fertil Steril. 1993 Sep;60(3):504-9.

64. Smith-Levitin M, Kowalik A, Birnholz J, Skupski DW, Hutson JM, Chervenak FA, Rosenwaks Z. Selective reduction of multifetal pregnancies to twins improves outcome over nonreduced triplet gestations. Am J Obstet Gynecol. 1996 Oct; 175(4 Pt 1):878-82. 
65. Stone J, Eddleman $\mathrm{K}$, Lynch L, Berkowitz RL. A single center experience with 1000 consecutive cases of multifetal pregnancy reduction. Am J Obstet Gynecol 2002 $\mathrm{Nov}_{*}, 187(5): 1163-7$

66. Leondires MP, Ernst SD, Miller BT, Scott RT Jr. Triplets: outcomes of expectant management versus multifetal reduction for 127 pregnancies. Am J Obstet Gynecol 2000 Aug; $183(2) 454-9$.

67. Guillet-Rosso F, Fari A, Taylor S, Forman R, Belaisch-Allart J, Testart J, Frydman R. Systematic semen culture and its influence on IVF management. Br J Obstet Gynaecol. 1987 Jun:94(6):543-7.

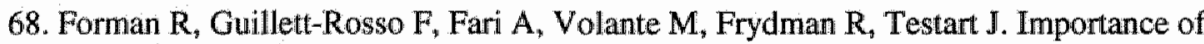
semen preparation in avoidance of reduced in vitro fertilization results attributable to bacteria. Fertil Steril. 1987 Mar;47(3):527-30.

69. Lewit N, Thaler I, Rottem S. The uterus: a new look with transvaginal sonography. J Clin Uitrasound. 1990 May;18(4):331-6.

70. Kovacs GT. Which factors are important for successful embryo transfer after in-vitro fertilization? Hum Reprod. 1999 Oct; 14(10):2679.

71. Schoolcraft WB, Surrey ES, Gardner DK. Embryo transfer: techniques and variables affecting success. Fertil Steril. 2001 Now;76(5):863-70.

72. Rutherford AJ, Subak-Sharpe RJ, Dawson KJ, Margara RA, Franks S, Winston RM. Improvement of in vitro fertilisation after treatment with buserelin, an agonist of luteinising hormone releasing hormone. $\mathrm{Br}$ Med $\mathrm{J}$ (Clin Res Ed). $1988 \mathrm{Jun}$ $25 ; 296(6639): 1765-8$.

73. Davidson A, Vermesh M, Lobo RA, Paulson RJ. Mouse embryo culture as quality control for human in vitro fertilization: the one-cell versus the two-cell model. Fertil Steril. 1988 Mar; $49(3): 516-21$.

74. Hearns-Stokes RM, Miller BT, Scott L, Crenss D, Chakraborty PK, Segars JH. Pregnancy rates after embryo transfer depend on the provider at embryo transfer. Fertil Steril. 2000 Jul; 74(1):80-6.

75. Tiitinen A, Halttunen $M$, Harkki $P$, Vuoristo $P$, Hyden-Granskog C. Elective single embryo transfer: the value of cryopreservation. Hum Reprod. 2001 Jun; 16(6):1140-4.

76. Moon H. Kim. Survey: the most important factors in optimizing IVF results. Presented at the meeting of optimizing IVF results. Aswan, Egypt. February 1-2,2001.

77. Hall J, Gilligan A, Schimmel T, Cecchi M, Cohen J. The origin, effects and control of air pollution in laboratories used for human embryo culture. Hum Reprod: 1998 Dec;13 Suppl $4: 146-55$.

78. Boone WR, Johnson JE, Locke AJ, Crane MM 4th, Price TM. Control of air quality in an assisted reproductive technology laboratory. Fertil Steril. 1999 Jan;71(1):150-4. 
79. Mansour RT, Aboulghar MA. Optimizing the embryo transfer technique. Hum Reprod. 2002 May; 17(5):1149-53.

80. Birnholz JC. Ultrasonic visualization of endometrial movements. Fertil Steril. 1984 Jan; $41(1): 157-8$.

81. IJland MM, Evers JL, Dunselman GA, van Katwijk C, Lo CR, Hoogland HI. Endometrial wavelike movements during the menstrual cycle. Fertil Steril. 1996 Apr;65(4):746-9.

82. Kunz G, Noe M, Herbertz M, Leyendecker G. Uterine peristalsis during the follicular phase of the menstrual cycle: effects of oestrogen, antioestrogen and oxytocin. Hum Reprod Update. 1998 Sep-Oct;4(5):647-54.

83. IJland MM, Evers JL, Dunselman GA, Volovics L, Hoogland HJ. Relation between endometrial wavelike activity and fecundability in spontaneous cycles. Fertil Sterill. 1997 Mar;67(3):492-6.

84. IJland MM, Evers JL, Dunselman GA, Hoogland HJ. Subendometrial contractions in the nonpregnant uterus: an ultrasound study. Eur J Obstet Gynecol Reprod Biol. 1996 Dec; 70(1):23-4.

85. IJland MM, Evers JL, Dunselman GA, Hoogland HJ. Endometriall wavelike activity, endometrial thickness, and ultrasound texture in controlled ovarian hyperstimulation cycles. Fertil Steril. 1998 Aug; 70(2):279-83.

86. IJland MM, Evers JL, Hoogland HJ. Velocity of endometrial wavelike activity in spontaneous cycles. Fertil Steril. 1997 Jul;68(1):72-5.

87. IJland MM, Hoogland HJ, Dunselman GA, Lo CR, Evers JL. Endometrial wave direction switch and the outcome of in vitro fertilization. Fertil Steril. 1999 Mar;71(3):476-81.

88. Fanchin $R$, Righini $C$, Olivennes $F$, Taylor $S$, de Ziegler D, Frydman R. Uterine contractions at the time of embryo transfer alter pregnancy rates after in witro fertilization. Hum Reprod. 1998 Jul;13(7): 1968-74.

89. Lavie O, Margalioth EJ, Geva-Eldar T, Ben-Chetrit A. Ultrasonographic endometrial changes after intrauterine insemination: a comparison of two catheters. Fertil Steril. 1997 Oct;68(4):731-4.

90. Rosenlund B, Sjoblom P, Hillensjo T. Pregnancy outcome related to the site of embryo deposition in the uterus. J Assist Reprod Genet. 1996 Ju1; 13(6):511-3.

91. Waterstone J, Curson $R_{*}$, Parsons J. Embryo transfer to low uterine cavity. Lancet. 1991 Jun $8 ; 337(8754): 1413$.

92. Diedrich $\mathrm{K}$, van der Ven $\mathrm{H}$, al-Hasani S, Krebs D. Establishment of pregnancy related to embryo transfer techniques after in-vitro fertilization. Hum Reprod. 1989 Nov;4(8 Suppl): $111-4$. 
93. Lesry P, Killick SR, Robinson J, Raven G, Maguiness SD. Junctional zone contractions and embryo transfer: is it safe to use a tenaculum? Hum Reprod. 1999 Sep;14(9):236770.

94. Visser DS, Fourie FL, Kruger HF. Multiple attempts at embryo transfer: effect on pregnancy outcome in an in vitro fertilization and embryo transfer program. I Assist Reprod Genet, 1993 Jan; $10(1): 37-43$.

95. Strickler RC, Christianson C, Crane JP, Curato A, Knight AB, Yang V. Ultrasound guidance for human embryo transfer. Fertil Steril. 1985 Jan;43(1):54-61.

96. Leong $\mathrm{M}$, Leung $\mathrm{C}$, Tucker $\mathrm{M}$, Wong $\mathrm{C}$, Chan $\mathrm{H}$. Ultrasound-assisted embryo transfer. In Vitro Fert Embryo Transf. 1986 Dec;3(6):383-5.

97. Coroleu B, Carreras O, Veiga A, Martell A, Martinez F, Belil I, Hereter L, Barri PN. Embryo transfer under ultrasound guidance improves pregnancy rates after in-vitro fertilization. Hum Reprod. 2000 Mar;15(3):616-20.

98. Kojima K, Nomiyama M, Kumamoto T, Matsumoto Y, Iwasaka T. Transvaginal ultrasound-guided embryo transfer improves pregnancy and implantation rates after IVF. Hum Reprod. 2001 Dec;16(12):2578-82.

99. al-Shawaf T, Dave R, Harper J, Linehan D, Riley P, Craft I. Transfer of embryos into the uterus: how much do technical factors affect pregnancy rates? J Assist Reprod Genet. 1993 Jan; 10(1):31-6.

100.Kan AK, Abdalla HI, Gafar AH, Nappi L, Ogunyemi BO, Thomas A, Ola-ojo OO. Embryo transfer: ultrasound-guided versus clinical touch. Hum Reprod. 1999 May; 14(5):1259-61.

101. Templeton A, Morris JK. Reducing the risk of multiple births by transfer of two embryos after in vitro fertilization. N Engl J Med. 1998 Aug 27;339(9):573-7.

102. Coetsier T, Dhont M. Avoiding multiple pregnancies in in-vitro fertilization: who's afraid of single embryo transfer? Hum Reprod. 1998 Oct; 13(10):2663-4.

103.ESHRE Campus Course Report (2001). Prevention of twin pregnancies after IVF/CSI by single embryo transfer. ESHRE Campus Course Report. Hum Reprod. 2001 Apr;16(4):790-800. 
Chapter 12

Summary 


\section{Summary}

In Chapter 1, the history of IVF was reviewed and an outline about the results of IVF in different parts of the world was written. Different factors that resulted in improving IVF results were discussed with specilal emphasis on ovarian stimulation protocols, development of US in ovum pick-up techniques, improvement in fertilization due to ICSI, and the development in tissue culture media.

The aim of the work, as illustrated in chapter 2, is optimizing IVF results through the liollowing: First, in patient preparation before starting an IVF cycle, focusing on the diagnosis and management of hydrosalpinges, performing dummy embryo transfers and studying different factors that may affect the embryo transfer. Second, experimenting with the technique of ICSI in an attempt to improve fertilization. The research was focused on modifying the technique of ICSI, studying the effect of different sperm parameters, and using testicular and epididymal spermatozoa in cases of azoospermia. Third, modification of the technique of multifetal pregnancy reduction in cases of high order multiple pregnancies in an attempt to improve the outcome.

In chapter 3, the presence of fluid in the uterine cavity in association with hydrosalpinges was reported as a hindrance to implantation and poor IVF outcome. This was the first report in the literature that was followed by several studies by other investigators and finally led to the conclusion that salpingectomy is recommended in patients with hydrosalpinges before performing IVF.

In chapter 4 , we have demonstrated that performing a dummy embryo transfer significantly improved the IVF outcome. It helps in choosing the most suitable kind of catheter, evaluating the length and clirection of the uterine cavity, and discovering any unanticipated difficulty.

In chapter 5 , the research on the technique of embryo transfer was continued using methylene blue dye. The effect of different factors on the rate of extrusion of the dye was 
studied. It was demonstrated that the rate of extrusion of the dye was significantly less when soft catheters were used as compared to more rigid ones and when the cervical mucous was aspirated.

In chapter 6, the effect of different sperm parameters on the outcome of ICSI was studied. It was demonstrated that the fertilization and pregnancy rates in ICSI were not affected by different sperm parameters as long as morphologically normal living sperm was used for the injection. It was also demonstrated that patients who previously failed fertilization with IVF had successful fertilization with ICSI.

In Chapter 7, a study was done on the use of epididymal and testicular spermatozoa in ICSI. It was demonstrated that ICSI using epididymal and testicular spermatozoa in cases of obstructive azoospermia is an efficient method in achieving fertilization and pregnancy.

In Chapter 8, a prospective randomized study was done on sibling oocytes to investigate performing ICSI without cytoplasmic aspiration. The study demonstrated that cytoplasmic aspiration before sperm injection was not essential for oocyte activation because it did not improve the fertilization rate. Moreover, aspiration significantly increased the rate of oocyle damage. The technique of no aspiration resulted in a significantly higher rate of good quality embryos as compared to performing cytoplasmic aspiration before injecting the spermatozoa.

In Chapter 9, a study of the outcome of ICSI was done in obstructive and non-obstructive azoospermia. It was demonstrated that ICSI using spermatozoa from patients with acquired obstructive azoospermia resulted in significantly higher fertilization and pregnancy rates as compared to congenitally absent vas deferens and non-obstructive azoospermia. There was no difference in the fertilization and pregnancy rates using epididymal or testicular spermatozoa in obstructive azoospermia. The results also demonstrated that the fertilizing ability of testicular spermatozoa obtained from non-obstructive azoospermia was significantly lower than those obtained from obstructive azoospermic cases. Finally it was demonstrated that spermatozoa 
could be retrieved in $67 \%$ of the testicular biopsies obtained from non- obstructive azoospermic patients.

In Chapter 10, modified technique was described for multifetal pregnancy reduction in cases of high order multiple pregnancy. The modified technique eliminated completely the use of any cardiotoxic substance such as $\mathrm{KCl}$. It is done as early as 7.8 weeks of gestation by transvaginal US guided aspiration of the fetal echoes. Using the modified technique the outcome of the reduced twins was comparable to non-reduced twins.

In Chapter $\mathbb{1} 1$, an attempt was done to correlate these chapters with the literature and an overview was given about how to optimize IVF results. It was stressed that IVF is a delicate and complicated procedure that depends on many factors for success. The formation of a good team is the key to assure that every procedure of the IVF is conducted properly. Patient preparation before starting the IVF cycle is very important. Special attention should be given to the diagnosis and treatment of hydrosalpinges, and performing a dummy embryo transfer to choose the most suitable kind of catheter. One should use the most suitable protocol for ovulation induction to obtain an adequate number of high quality oocytes. Strict quality control and quality assurance is vital in any IVF program to produce viable embryos. Optimizing fertilization has been achieved through ICSI. The technique of embryo transfer has a significant impact on the results. Multiple pregnancy must be avoided, however, in cases of high order multiple pregnancy, the modilied technique of multifetal reduction is an option to improve the outcome.

Further research should focus on studying distal tubal opening with or without proxinual tubal ligation as compared to salpingectomy in patients with hydrosalpinges before undergoing IVF.

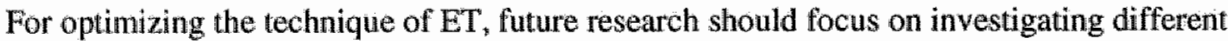
drugs that may decrease uterine contractility during ET. Another area of research is the use of diploid spermatogenic cells to achieve fertilization in non-obstructive azoospermia patients in 
whom no spermatozoa could be retrieved. The problem of high onder multiple pregnancies should be completely solved and more research should be directed towards improving implantation and single embryo transfer. 


\section{SAMENVATTING}

In hoofdstuk 1 wordt de geschiedenis van de in vitro fertilisatie (IVF) besproken en worden de resultaten van IVF in de diverse delen van de wereld beschreven. De diverse factoren die het resultaat van IVF beïnvloeden komen aan de orde met nadruk op ovariële stimulatieprotocollen, de ontwikkeling die plaatswond in de technieken voor het verzamelen van eicellen, de verbetering van de laboratoriumresultaten met name wat betreft de fertilisatie en die ontwikkeling van weefselkweekmedia.

Het doel van dit promotie onderzoek is, zoals besproken in hoofdstuk 2, het optimaliseren van de IVF resultaten door de volgende aspecten extra aandacht te schenken: ten eerste het vooronderzoek van de patiënt en het voorbereiden voor de eerste IVF cyclus, waarbij met name de diagnostiek en de behandeling van hydrosalpingen aan bod komt, het uitvoeren van een dummy embryotransfer, en de diverse factoren die de uitkomst van de embryotransfer zouden kunnen beïnvloeden. Ten tweede de rol van Intra Cytoplasmatische Sperma Injectie (ICSI) bij het pogen de fertilisatieresultaten te verbeteren. Hierbij komt met name het modificeren van de ICSI techniek aan bod, het belang van de afzonderlijke semenparameters, en het gebruik van testiculair en epididymaal verzamelde spermatozoa in het geval van azospermie. Ten derde het bestrijden van een van de negatieve bijwerkingen van IVF, de meervoudige zwangerschap, niet behulp van het reduceren van het aantal concepti, en het effect van die reductie op de uitkomst van de zwangerschap.

In hoofdstuk 3 wordt de aanwezigheid van vloeistof in het cavum uteri bestudeerd in relatie tot het voorkomen van hydrosalpingen. Dit lijkt een negatief effect te hebben op de implantatiekansen van het embryo na IVF. De conclusie die op basis van dit, en later in de literatuur gerapporteerd, onderzaek getrokken wordt is dat bij patiènten met hydrosalpingen een salpingectomie moet worden aanbevolen alvorens tot IVF over te gaan. 
In hoofdstuk 4 wordit aangetoond dat het uitvoeren van een dummy embryotransfer de IVF resultaten significant verbetert. Het uitvoeren van een dummy embryotransfer stelt de arts in staat de beste katheter woor de transfer op voorhand te kiezen, de diepte van het cavum uteri te bepalen alsmede de hoek waaronder dit zich presenteert, terwijl tevens onvoorziene problemen bij de terugplaatsing kunnen worden opgespoord.

In hoofdstuk 5 wordt additioneel onderzoek beschreven naar de techniek van embryotransfer met behulp van methyleenblauw kleurstof. Het effect van diverse factoren op de expulsie van de kleurstof uit het cavum uteri werd bestudeerd. Er werd gevonden dat de mate van expulsie van de kleurstof significant minder was indien zachte katheters werden gebruikt, in vergelijking met meer rigide katheters, en indien het cervixslijm voor de transfer eerst werd geaspireerd.

In hoofdstuk 6 wordt het effect van de afzonderlijke semenparameters op de uitkomst van ICSI bestudeerd. Fertilisatie en zwangerschapscijfers na ICSI blijken niet te worden beïnvloed door de afzonderlijke semenparameters voorzover er morfologisch normale zaadcellen gebruikt worden voor de Intra Cytoplasmatische Sperma Injectie. Daarnaast wordt aangetoond dat patiënten die tevoren een mislukte fertilisatie bij reguliere IVF hadden, met vrucht gebruik kunnen maken van ICSI om een hernieuwde fertilisatiestoornis te voorkomen.

In hoofdstuk 7 wordt een studie beschreven naar het gebruik van epididymaal en testiculair verzamelde zaadcellen bij ICSI. Het bleek dat ICSI met epididymaal of testiculair zaad in gevallen van obstructieve azospermie een efficiënte methode is om fertilisatie en zwangerschap te bewerkstelligen.

In hoofdstuk 8 wordt een prospectief gerandomiseerde studie beschreven bij "sibling" eicellen om te bestuderen of cytoplasmatische aspiratie nodig is bij het uitwoeren van ICSI. De studie toont aan dat dit niet essentieel is voor eicelactivatie aangezien het de fertilisatiefrequentie niet verhoogt. Wel bestaat het risico dat cytoplasmatische aspiratie de mate van schade aan de eicel 
verhoogt. De techniek zonder aspiratie resulteerde in een significant hogere frequentie van embryo's van een goede kwaliteit in vergelijking met de techniek waarbij wel cytoplasma wordt geaspireerd voordat de zaadicel in de eicel wordt geînjecteerd.

In hoofdstuk 9 wordt een onderzoek beschreven naar de uitkomst van ICSI bij obstructieve en non-obstructieve azospermie. ICSI bij patiënten met een verworven obstructieve azospermie bleek in een significant hogere fertilisatie- en zwangerschapsfrequentie te resulteren dan ICSI bij patiènten met een congenitale obstructieve of non-obstructieve azospermie. Er werd geen verschill gevonden in fertilisatie- en zwangerschapsfrequenties na ICSI wegens obstructieve azospermie tussen epididymale en testiculaire zaadcellen. De resultaten van dit onderzoek laten ook zien dat het fertilisatievermogen van testiculair verzamelde zaadcellen bij non-obstructieve azospermie significant lager is dan bij obstructieve azospermie. Tenslotte werd aangetoond dat zaadcellen konden worden gewonnen uit $67 \%$ van de testisbiopsieën bij patiënten met een nonobstructieve azospermie.

In hoofdstuk 10 wordt een gemodificeerde techniek beschreven om het aantal embryo"s te reduceren in geval van meerlingzwangerschappen. De gemodificeerde techniek bestaat uit het aspireren van embryonale delen en maakt het gebruik van $\mathrm{KCL}$ als cardiotoxische substantie overbodig. De techniek kan bij 7 tot 8 weken zwangerschap via transwaginale ultrageluidsaspiratie van de foetale echo's worden uitgevoerd. De na toepassing van deze techniek resterende tweelingzwangerschappen hadden een uitkomst die vergelijkbaar was met die van "gewone" na IVF ontstane tweelingzwangerschappen. Reductie van meerlingen tot tweelingen kan aldus veilig geschieden en de prognose van de zwangerschap verbeteren. In hoofdstuk 11 worden de bevindingen van de voorga ande hoofdstukken geíntegreerd met literatuurbevindingen en wordt een overzicht gegeven van alle beschreven ontwikkelingen in het kader van het optimaliseren van de IVF resultaten. Het wordt benadrukt dat IVF een gevoelige en complexe procedure is waarvan het succes van vele factoren afhangt. Het belang 
van een goed team wordt benadrukt, evenals het goed woorbereilden van de patiënt op de behandeling. De diagnostiek en behandeling van hydrosalpingen wordit in een breder kader geplaatst, evenals het uitvoeren van dummy embryotransfers in het kader van het kiezen van een optimale terugplaatskatheter. Ook komen in dit hoofdstuk de diverse ovalatie inductie protocollen aan de orde die tot doel hebben eicellen wan voldoende hoge kwaliteit te verkrijgen. Quality Control and Quality Assurance zijn essentieel voor een goed IVF programma. ICSI kan de resultaten, met name bij patiënten met fertilisatiestoornissen, verbeteren. De techniek van embryotransfer verdient meer aandacht. Het is van groot belang meervoudige zwangerschappen te voorkomen, echter het reduceren van het aantal embryo"s is een efficiènte methode on de uitkomst van zulke zwangerschappen te verbeteren. Toekomstig onderwoek zal zich moeten concentreren op alternatieve behandelingen voor hydrosalpingen dan salpingectomie. Tevens zal meer aandacht geschonken moeten worden aan het verbeteren van de embryo terugplaatstechniek, 0.a. in relatie tot de inherente en de geïnduceerde contractiliteit van de (niet zwangere) uterus. Een ander toekomstig onderzoeksgebied is gelegen in het gebruik van diploïde spermatogene cellen die gebruikt kunnen worden om fertilisatie te bewerkstellingen bij patiënten bij een non-obstructieve azo spermie bij wie op geen enkele wijze zaadcellen kunnen worden gewonnen. Het ultieme doel van de moderne IVF dient het voorkomen van meerlingzwangerschappen te zijn. Het valt te verwachten dat meer onderzoek naar het verbeteren van de implantatiekansen van individuele embryo's zal leiden tot electieve terugplaatsing van én enkel embryo. 


\section{Dankwoord (Acknowledgements)}

Professor Dr. Exers, thank you very much for offering me this rare opportunity to achieve my doctoral degree from the distinguished University of Maastricht, in the Netherlands. May I express my great appreciation for your help and guidance all throughout the preparation of the manuscript. Not only have you provided me with scientific guidence, but also an opportunity to gain a grasp of the rich Dutch culture.

Professor Dr. Moon H. Kim, without your everlasting support, I would never have been where I am today . By supporting me in my strive to enter the field of reproductive medicine, by allowing me to enter the in-vitro fertilization program at Ohio State University in 1980, and subsequently supervising over my first two publications, you have helped me to take my first and most important steps of my reproductive career. For this, Dr. Kim, I thank you from the bottom of my heart.

Professor Aboulghar, thank you for encouraging me to return to my homeland, and start the first reproductive technology center in Egypt. Thanks to you and professor Serour, these past. 17 years were full of good cooperation, mutual respect and partnership in both clinical activities and research. During this period we have shared many moments of despair, but also many moments of success that we can be proud of today.

Dear colleagues at the Egyptian IVF-ET Center; physicians, biologists, nurses, secretaries and porters. Thank you all for making such a pleasent atmosphere of team work and cooperation. Dear Egyptian patients... "Thank you for your unlimited trust in us, the Egyptian IVF-ET" Center and assisted reproductive technology as a whole. Your trust and support have helped us to grow, excel and prove that these new techniques are successful. For this I thank each and every patient, and hope for successful trials for all. 
Last, but definitely not least, my dear sons: Mohamed, Taha and Kareem. You are my inspiration. In you I find the will to work and struggle to achieve my greastest joys. Thank you for your love and support. 


\section{Curriculum Vitae}

Ragaa Taha Ahmed Mansour was bom on January $1^{\text {st }}, 1950$ in Kalyobia, Egypt. She graduated from the Faculty of Medicine, Cairo University, in 1973, with honors. This was followed up by completing a three-year residency in Obstetrics and Gynecology at Cairo University (1975 1978) during which she earned her master's degree in Ob/Gyn. She then completed ber Educational Commission for Foreign Medical Graduates (ECFMG) Certification, in Kansas City (USA), in 1980. She completed a postdoctoral fellowship "in vitro fertilization and embryo transfer" at Ohio State University, USA, 1982. In 1985, she retumed back to her home country, and started the first in-vitro fertilization program in Egypt, in March 1986. She has held the position of director of The Egyptian IVF-ET Center since 1986 until the present. In addition, today she is a deputy editor of the Middle East Fertility Society Joumal, and a corresponding editor for the American Joumal of Obstetrics and Gynecology. She is a member of many reproductive medicine societies in Egypt, Europe and the United States. She is currently the author of 93 scientific publications. 


\section{Scientific Publications}

1. Schmidt GE, Sites C, Mansour RT, Friedman CI, Kim MH. Embryo toxicity of clomiphene citrate on mouse embryos fertilized in vitro and in vivo. Am J Obstet Gynecol.1985,153:679

2. Schmidt GE Kim MH, Mansour RT, Torello L, Friedman CI: The effects of enclomiphene and zuclomiphene citrates on mouse embryos fertilized in vitro and in vivo. Am J Obstet and Gynecol. 1986, 154:727

3. Mansour TR, Aboulghar MA, Serour GI: In vitro fertilization and embryo transfer: Report of the Egyptian IVF-ET center. J. Egyptian. Sac. Obstet. Gynecol. 1988; 14:17

4. Aboulghar MA, Mansour RT, Serour GI. Prevention and Management of ovarian Hyperstimulation Syndrome. Jour. of the Egypt. Soc. of Obst \& Gyn. No.1, JAN..1988.

5. Aboulghar MA, Mansour RT, Serour GI: Vaginal ultrasonography in an in vitro fertilization programme. Echorevue L 'information Special Afrique. 1989, P.108

6. Aboulghar MA, Mansour RT, Serour GI. Ovarian superstimulation in the treatment of infertility due to peritubal and periovarian adhesions. Fertil Steril. 1989 May;51(5):8347.

7. Mansour RT, Serour GI, Aboulghar MA. Intrauterine insemination with washed capacitated sperm cells in the treatment of male factor, cervical factor and unexplained infertility. Asia Oceania J Obstet Gynaecol. $1989 \mathrm{Jun} ; 15(2): 151-4$.

8. Aboulghar MA, Mansour RT, Serour GI, Almudaris E: Some ethical and legal aspects of medically assisted reproduction in Egypt. International Journal of Bioethics. 1990 , $1: 265$

9. Aboulghar MA, Mansour RT, Serour GI. Successful treatment of long-term unexplained infertility with gonadotropin-releasing hormone agonist analogue and human menopausal gonadotropin. Acta Obstet Gynecol Scand. 1990;69(4):313-5.

10. Aboulghar MA, Mansour RT, Serour GI, Sattar MA, Awad MM, Amin Y.

Transvaginal ultrasonic needle guided aspiration of pelvic inflammatory cystic masses before ovulation induction for in vitro fertilization. Fertil Steril. 1990 Feb;53(2):311-4.

11. Aboulghar MA, Mansour RT, Serour GI, Amin Y. Ultrasonically guided vaginal aspiration of ascites in the treatment of sewere ovarian hyperstimulation syndrome. Fertil Steril. 1990 May;53(5):933-5.

12. Aboulghar MA, Mansour RT, Serour GI, Ramzy AM. Successful treatment of infertile women with hypothalamic primary and secondary protracted amenorthoea using gonadotrophin releasing hormone analogue and human menopausal gonadotrophin. Hum Reprod. $1990 \mathrm{Jul} ; 5(5): 557-60$. 
13. Aboulghar MA, Mansour RT, Serour GI. Transvaginal injection of potassium chloride and methotrexate for the treatment of tubal pregnancy with a live fetus. Hum Reprod. 1990 Oct:5(7):887-8.

14. Mansour R, Aboulghar M, Serour G. Dummy embryo transfer: a technique that minimizes the problems of embryo transfer and improves the pregnancy rate in human in vitro fertilization. Fertil Steril. 1990 Oct:54(4):678-81.

15. Serour GI, Aboulghar MA, Mansour RT: In vitro fertilization and Embryo transfer: Ethical aspects in techniques in the Moslem world. Population Sciences.1991, 9:45-54

16. Serour G1, EI Ghar M, Mansour RT. Infertility: a health problem in the Muslim world. Popul Sci. 1991 Jan; 10:41-58.

17. Aboulghar MA, Mansour RT, Serour GI, Ramsy AM. Severe ovarian hyperstimulation syndrome complicated by ectopic pregnancy. Acta Obstet Gynecol Scand. 1991;70(45):371-2.

18. Aboulghar MA, Mansour RT, Serour GI, Rizk P, Riad R. Improvement of spontaneous pregnancy rate after stopping gonadotropin therapy for anovulatory infertility. Fertil Steril. 1991 Apr;55(4):722-5.

19. Mansour RT, Aboulghar MA, Serour GI, Riad R. Fluid accumulation of the uterine cavity before embryo transfer: a possible hindrance for implantation. J In Vitro Fert Embryo Transf. 1991 Jun;8(3):157-9.

20. Serour GI, ell Ghar M, Mansour RT. In vitro fertilization and embryo transfer in Egypt. Int J Gynaecol Obstet. 1991 Sep;36(1):49-53.

21. Aboulghar MA, Mansour RT, Serour GI, Rizk B. Ultrasonic transwaginal aspiration of endometriotic cysts: an optional line of treatment in selected cases of endometriosis. Hum Reprod. 1991 Nov;6(10):1408-10.

22. Aboulghar MA, Mansour RT, Serour GI, Sattar MA, Elattar I. Cryopreservation of the occasionally improved semen samples for intrauterine insemination: a new approach in the treatment of idiopathic male infertility. Fertil Steril. 1991 Dec;56(6):1151-5.

23. Aboulghar MA, Mansour RT, Serour GI: Ovarian cysts during pregnancy: The role of ultrasonically guided transwaginal aspiration. Ultrasound Obstet. Gynecol. 1992, 2:349351

24. Aboulghar MA, Mansour RT, Serour GI, Elattar I, Amin Y. Follicular aspiration does not protect against the development of ovarian hyperstimulation syndrome. J Assist Reprod Genet. 1.992 Jun;9(3):238-43.

25. Aboulghar MA, Mansour RT, Serour GI. Pathophysiology of ovarian hyperstimulation syndrome. Fertil Steril. 1992 Aug;58(2):449-51. 
26. Aboulghar MA, Mansour RT, Serour GI, Riad R, Ramzi AM. Autotransfusion of the ascitic fluid in the treatment of severe ovarian hyperstimulation syndrome. Fertil Steril. 1992 Nov;58(5):1056-9.

27. Aboulghar MA, Mansour RT, Serour GI, Sattar MA, Amin YM, Elattar I. Managenent. of severe ovarian hyperstimulation syndrome by ascitic fluid aspiration and intensive intravenous fluid therapy. Obstet Gynecol. $1993 \mathrm{Jan} ; 81$ (1):108-11.

28. Mansour RT, Aboulghar MA, Serour GI, Abbas AM, Ramzy AM, Rizk B. In vivo survival of spermatozoa in the human fallopian tube for 25 days: a case report. J Assist Reprod Genet. 1993 Jul; $10(5): 379-80$.

29. Aboulghar MA, Mansour RT, Serour GI, Amin Y, Abbas AM, Salah IM. Ovarian superstimulation and intrauterine insemination for the treatment of unexplained

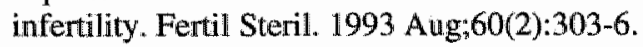

30. Aboulghar MA, Mansour RT, Serour GI, Sattar M, Ramzy AM, Amin YM. Treatment of recurrent chocolate cysts by transvaginal aspiration and tetracycline sclerotherapy. I Assist Reprod Genet. 1993 Nov; 10(8):531-3.

31. Aboulghar MA, Mansour RT, and Serour GI: Prewention and management of ovarian hyperstimulation syndrome. J Egyptian soc Obstet. Gynecol. 1993, 19:7-22

32. Mansour RT, Aboulghar MA, Serour GI, Amin YM. Dummy embryo transfer using methylene blue dye. Hum Reprod. 1994 Jul;9(7):1257-9.

33. Mansour RT, Aboulghar MA, Serour GI, Abbass AM. Co-culture of human pronucleate oocytes with their cumulus cells. Hum Reprod. 1994 Sep;9(9):1727-9.

34. Mansour RT, Aboulghar MA, Serour GI. Study of the optimum time for human chorionic gonadotropin-ovum pickup interval in in vitro fertilization. J Assist Reprod Genet. 1994 Oct; $11(9): 478-81$.

35. Aboulghar MA, Mansour RT, Serour GI, Amin YM. The prognostic value of successful in-vitro fertilization in subsequent trials.. Hum Reprod. 1994 Oct;9(10):1932-4.

36. Mansour RT, Aboulghar MA, Serour GI, Abbas AM, Elattar I. The life span of sperm motility and pattern in cumulus coculture. Fertil Steril. 1995 Mar;63(3):660-2.

37. Aboulghar MA, Mansour RT, Serour GI. Ultrasonographically guided transvaginal aspiration of tuboovarian abscesses and pyosalpinges: an optional treatment for acute pelvic inflammatory disease. Am J Obstet Gynecol. 1995 May;172(5):1501-3.

38. Aboulghar MA, Mansour RT, Serour GA, Amin YM, Sattar MA, Ramzy AM. In vitro fertilization in a spontaneous cycle: a successful simple protocol. I Obstet Gynaecol. 1995 Aug;21(4):337-40.

39. Serour GI, Aboulghar MA, Mansour RT. Bioethics in medically assisted conception in the Muslim world. J Assist Reprod Genet. 1995 Oct; 12(9):559-65. 
40. Aboulghar MA, Mansour RT, Serour GL Amin XM. The role of intracytoplasmic sperm injection (ICSI) in the treatment of patients with borderline semen. Hum Reprod. 1995 Now: $10(11): 2829-30$.

41. Mansour RT, Aboulghar MA, Serour GI, Amin YM, Ramzi AM. The effect of sperm parameters on the outcome of intracytoplasmic sperm injection. Fertil Steril. 1995 Nov;64(5):982-6.

42. Aboulghar M, Mansour RT, Serour GI. Management of ascites and pleural effusions in ovarian hyperstimulation syndrome. Fertil Steril. 1995 Dec;64(6):1228-9.

43. Salah Nassar, Hanna Aboulghar, Mahmoud Hussein, Jaennette Boutros, Ragaa Mansour, Mohamed Aboulghar. Perinatal outcome after in vitro fertilization and spontaneous pregnancy: a comparative study. Midd East Fertil Soc J.1996; 1:151-58.

44. Aboulghar MA, Mansour RT, Serour GI, Rizk B. Ovarian hyperstimulation syndrome: Modern concepts in pathophysiology. Middle East Fertill Soc J. 1996;1:3

45. Mansour RT, Aboulghar MA, Serour GI, Kamal A, Tawab NA, Ramzy AI. ICSI in 650 consecutive cycles: The Egyptian IVF-ET experience. Middle East Fertil Soc J. $1996 ; 1: 55$

46. Ramzy AI, Mansour, RT, Serour GI, Attar I, Amin Y, Aboulghar M. Body weight and outcome of in vitro fertilization. Middle East Fertil Soc J. 1996;1:72

47. Mansour RT. Gamete micromanipulation and assisted fertilization. Middle East Fertil Soc J 1996;1:91-100

48. Mansour RT, Aboulghar MA, Serour GI, Kamal A, Tawab NA, Fahmy I, Amin YM. Pregnancy and delivery after intracytoplasmic injection of spermatids into human oocytes. Middle East Fertil Soc J 1996; 1:223-5

49. Falmmy I, Mansour RT, Aboulghar MA, Serour GI, Kamal A, Tawab NA, Ramzy AM, Amin $\mathrm{Y}$. Intracytoplasmic injection of surgically retrieved sperm and spermatids in obstructive and non-obstructive azoospermia: a comparative study. Middle East Fertil Soc J 1996:1:134-40

50. Aboulghar MA, Mansour RT, Serour GI, Sattar MA, Amin YM.. Intracytoplasmic sperm injection and conventional in vitro fertilization for sibling oocytes in cases of unexplained infertility and borderline semen. J Assist Reprod Genet. 1996 $\operatorname{Jan}_{1} 13(1): 38-42$.

51. Mansour RT, Aboulghar MA, Serour GI, Fahmi I, Ramzy AM, Amin Y. Intracytoplasmic sperm injection using microsurgically retrieved epididymal and testicular sperm. Fertil Steril. 1996 Mar;65(3):566-72.

52. Mansour RT, Aboulghar MA, Serour GI, Tawab NA, Amin Y, Sattar MA. Successful intracytoplasmic sperm injection without performing cytoplasmic aspiration. Fertil Steril, 1996 Aug;66(2):256-9. 
53. Aboulghar MA, Mansour RT, Serour GI, Amin YM, Sattar MA, Elattar $\mathbb{E}$. Recombinant follicle-stimulating hormone in the treatment of patients with history of severe ovarian hyperstimulation syndrome. Fertil Steril. 1996 Nov;66(5):757-60.

54. Aboulghar MA, Mansour RT, Serour GI, Amin YM; Kamal A. Prospective controlled randomized study of in vitro fertilization versus intracytoplasmic sperm injection in the treatment of tubal factor infertility with normal semen parameters. Fertil Steril. 1996 Nov;66(5):753-6.

55. Kamal A, Mansour RT, Aboulghar MA, Fahmy I, Serour GI, Tawab NA. Pregnancy after intracytoplasmic injection using cryo-thawed epididymal and testicular spermatozoa. Middle East Fertil Soc J 1997;2:30-4.

56. Fahmy I, Mansour R, Aboulghar M, Serour G, Kamal A, Tawab NA, Ramzy AM, Amin $Y$. Intracytoplasmic sperm injection using surgically retrieved epididymal and testicular spermatozoa in cases of obstructive and non-obstructive azoospermia. Int J Androl. 1997 Feb;20(1):37-44.

57. Aboulghar MA, Mansour RT, Serour GI, Fahmy I, Kamal A, Tawab NA, Amin YM. Fertilization and pregnancy rates after intracytoplasmic sperm injection using ejaculate semen and surgically retrieved sperm. Fertil Steril. $1997 \mathrm{Jul} ; 68(1): 108-11$.

58. Mansour RT, Kamal A, Fahmy I, Tawab N, Serour GI, Aboulghar MA. Intracytoplasmic sperm injection in obstructive and non-obstructive azoospermia. Hum Reprod. 1997 Sep;12(9):1974-9.

59. Aboulghar MA, Mansour RT, Serour GI, Ramzy AM, Amin YM. Oocyte quality in patients with severe ovarian hyperstimulation syndrome. Fertil Steril. 1997 Dec; $68(6): 1017-21$.

60. Mansour R. Intracytoplasmic sperm injection: a state of the art technique. Hum Reprod Update. 1998 Jan-Feb;4(1):43-56.

61. Aboulghar MA, Mansour RT, Serour GI. Transvaginal ultrasonic procedures a possible alternative to operative laparoscopy. The Egyptian J of Fertil and Steril 1998;2:9-16.

62. Mansour RT, Aboulghar MA "Serour GI, Kamal A, Tawab NA, Aboulghar HM: Abnormal oocytes: an underestimated fertility factor revealed by intracytoplasmic sperm injection. Middle East Ferti Soci J. 1998;3:1-7

63. Kamal A, Fahmy 1, Mansour R, Aboulghar M, Serour G, Tawab N, Ans T. Cryopreservation reduces the motility and viability of surgically retrieved spermatozoa but does not affect the outcome of ICSI. Middle East Fertil Soc I. 1998;3:178-84.

64. Aboulghar MA, Mansour RT, Serour GI, Elhelw BA, Shaarawy M. Elevated concentrations of angiogenin in serum and ascitic fluid from patients with severe ovarian hyperstimulation syndrome. Hum Reprod. 1998 Aug; 13(8):2068-71.

65. Serour GI, Aboulghar MA, Mansour RT. Tubal and pelvic iatrogentic infertility in the female. The Egyptian $\mathbb{J}$ of Fertil. Steril. 1997;1:31-40. 
66. Ramzy AM, Sattar M, Amin Y, Mansour RT, Serour GI, Aboulghar MA. Uterine myomata and outcome of assisted reproduction. Hum Reprod 1998;13:198-202.

67. Aboulghar MA, Mansour RT, Serour GI, Amin YM. Moderate ovarian hyperstimulation syndrome complicated by deep cerebrovascular thrombosis. Hum Reprod. 1998 Aug; 13(8):2088-91.

68. Serour GI, Aboulghar M, Mansour R, Sattar MA, Amin Y, Aboulghar H. Complications of medically assisted conception in 3,500 cycles. Fertil Steril. 1998 Oct; $70(4): 638-42$.

69. Aboulghar MA, Mansour RT, Serour GIl. Controversies in the modern management of hydrosalpinx. Hum Reprod Update. 1998 Nov-Dec;4(6):882-90.

70. Mansour RT, Aboulgar MA, Serour GI, Kamal A, Tawab NA, Fahmy I. Difficulties in distinguishing between a mature spermatid and testicular spermatozoon. Hum Reprod. $1999 \operatorname{Jan} ; 14(1): 267-8$.

71. Mansour RT, Aboulghar MA, Serour GI, Sattar MA, Kamal A, Amin YM. Multifetal pregnancy reduction: modification of the technique and analysis of the outcome. Fertil Steril. 1999 Feb; 71 (2):380-4.

72. Fahmy I, Mansour RT", Aboulghar MA, Serour GI, Kamal A, Tawab NA, Amin Y. Relationship between testicular histopathology and the outcome of testicular sperm extraction with intracytoplasmic sperm injection in patients with non-obstructive azoospermia. Middle East Fertil Soc J 1999;4:45-52.

73. Kamal A, Rhodes C, Fahmy I, Mansour RT, Aboulghar MA, Serour GI. Intracytoplasmic sperm injection in men with totally immotile ejaculated sperm. Middle East Fertil Soc J 1999;4: 154-61.

74. Fahmy I, Kamal A, Metwali M, Rhodes C, Mansour R, Serour G, Aboulghar M. Vigorous prostatic massage: a simple method to retrieve spermatozoa for intracytoplasmic sperm injection in psychogenic anejaculation: case report. Hum Reprod. 1999 Aug; 14(8):2050-3.

75. Serour GI, Rhodes CA, Sattar MA, Aboulghar MA, Mansour,RT. Complications of assisted reproductive techniques: a review. Assist Reprod 1999;9:214-32.

76. Aboulghar MA, Mansour RT, Serour GI, Amin Y, Ramzy AM, Sattar MA, Kamal A. Management of long-standing unexplained infertility: A prospective study. Am J Obstet Gynecol. 1999 Aug;181(2):371-5.

77. Kamal A, Mansour R, Fahmy I, Serour G, Rhodes C, Aboulghar M. Easily decapitated spermatozoa defect: a possible cause of unexplained infertility. Hum Reprod. 1999 Now; 14(11):2791-5.

78. Aboulghar MA, Mansour RT, Serour GI, El Helw BA, Shaarawy M. Elevated levels of interleukin-2, soluble interleukin-2 receptor alpha, interleukin-6, soluble interleukin-6 receptor and vascular endothelial growth factor in serum and ascitic fluid of patients 
with sewere owarian hyperstimulation syndrome. Eur J Obstet Gynecol Reprod Biol. 1999 Nov; $87(1): 81-5$.

79. Fahmy I, Rhodes CA, Kamal A, Metwally A, Mansour RT, Aboulghar M, Serour GI. Vigorous prostatic massage to retrive spermatozoa for intracyloplasmic sperm injection in anejaculation: a case series. Middle East Fertil Soc $32000 ; 5: \$ 37-42$.

80. Aboulghar MA, Mansour RT, Serour GI, Rhodes CA, Amin YM, Reduction of human menopausal gonadotropin dose before coasting prevents severe ovarian hyperstimulation syndrome with minimal cycle cancellation. I Assist Reprod Genet. 2000 May; 17(5):298-301.

81. Mansour RT, Rhodes CA, Aboulghar MA, Serour GI, Kamal A. Transfer of zona-free embryos improves outcome in poor prognosis patients: a prospective randomized controlled study. Hum Reprod. 2000 May;15(5):1061-4.

82. Mansour R, Aboulghar M, Serour GI. Controversies in the surgical management of hydrosalpinx. Curr Opin Obstet Gynecol. 2000 Aug; 12(4):297-301.

83. Aboulghar M, Mansour R, Serour G, Abdrazek A, Amin Y, Rhodes C. Controlled ovarian hyperstimulation and intrauterine insemination for treatment of unexplained infertility should be limited to a maximum of three trials. Fertil Steril. 2001 Jan; 75(1):88-91.

84. European and Middle East Orgalutran Study Group. Comparable clinical outcome using the GnRH antagonist ganirelix or a long protocol of the GnRH agonist triptorelin for the prevention of premature $\mathrm{LH}$ surges in women undergoing ovarian stimulation. Hum Reprod. $2001 \mathrm{Apr} ; 16(4): 644-51$.

85. Aboulghar H, Aboulghar M, Mansour R, Serour G, Amin Y, Al-Inany H. A prospective controlled study of karyotyping for 430 consecutive babies conceived through intracytoplasmic sperm injection. Fertil Steril. 2001 Aug;76(2):249-53.

86. Aboulghar MA, Mansour RT, Serour GI. Spontaneous intrauterine pregnancy following salpingectomy for a unilateral hydrosalpinx. Hum Reprod. 2002 Apr; 17(4): 1099-100.

87. Mansour RT, Aboulghar MA. Optimizing the embryo transfer technique. Hum Reprod. $2002 \mathrm{May} ; 17(5): 1149-53$.

88. Aboulghar M, Mansour R, Serour G. Standard IVF and ICSI - how much do the conclusions differ? Fertil Steril. 2002 Sep; 78(3):652-3.

89. Mansour RT, Aboulghar MA, Serour GI, Fahmy I, Amin YM, Al-Inany HG. The use of clomiphene citrate / human menopausal gonadotrophins in conjunction with GinRH antagonist in IVF/ICSI program is not a cost effective protocol. Acta Obstet Gynecol Scand (in press).

90. Mansour RT, Aboulghar MA, Serour GI, Al-Inany HG Amin YM, Abou-Setta AM. The use of GnRH antagonist in a flexible protocol: a prospective controlled study. Am J Obstet Gynecol (in press). 
91. Al-Inany HG, Aboulghar MA, Mansour RT, Serour GI. Meta-analysis of recombinant follicle stimulating hormone vs FSH containing urinary gonadotrophins: an update. Hum Reprod (in press).

92. Aboulghar MM, Aboulghar MA, Mansour RT, Serour GI, Amin YM, Abou-Setta AM. Pregnancy rate is not improved by dellaying embryo transfer from day two to day three. Eur J Obstet Gynecol Reprod Bioll (in press).

93. Aboulghar MA, Mansour RT, Serour GI, Al-Inany H, Aboulghar M. The outcome of IVF in advanced endometriosis with previous surgery: a case controlled study. Am J Obstet Gynecol (in press).

94. Aboulghar MA, Mansour RT, Serour GI, Al-Inany H. Diagnosis and management of unexplained infertility: an update. Arch Obstet Gynecol (in press). 


\section{Chapters in Books:}

1. Aboulghar MA, Serour GI, Mansour RT. Editors: Mori T, Tominaga T, Aono T, Hiroi M. Ethical issues in assisted reproduction: Ethics and assisted reproduction in Egypt. Ares Serono Symposia Publications, 1994: 169-73

2. Aboulghar M, Mansour RT. Intracytoplasmic sperm injection in difficult cases. In the Proceedings of the Serono Symposia International Conference on Maie Sterility for Motility Disorders, Paris, 1998. Edited by Samir Hamamah.

3. Aboulghar M, Mansour RT. Treatment of recurrent chocolate cysts by ultrasonically guided transvaginal aspiration and tetracycline slerotherapy. In transvaginal Sonography in Infertility - Edited by Guatam Allahbadia. 1998.

4. Aboulghar MA, Mansour RT, Serour GI. Intracytoplasmic sperm injection in nonmale factor patients. Fertility and Reproductive Medicine. R.D. Kempers, J. Cohen, A.F. Haney and J.B. Younger editors. Elsevier Science B.V. 1998.

5. Aboulghar M, Mansour RT, et al. Ultrasonically guided transvaginal aspiration of tuboovarian abscesses and pyosalpinges: an optional treatment for acute pelvic inflammatory disease. In transvaginal Sonography in Infertility - Edited by Guatam Allahbadia. 1998.

6. Aboulghar $\mathrm{M}$, Mansour RT, et al. Ultrasonically guided transvaginal aspiration of ascitic fluid in the treatment of severe ovarian hyperstimulation syndrome. In transvaginal Sonography in Infertility - Edited by Guatam Allahbadia. $\mathbb{9 9 8 .}$

7. Aboulghar MA, El Helw B, Mansour RT, Serour GI. Angiogenin: A new etiological factor for the development of OHSS. In Serono Fertility Series. Ares Serono Symposia Publications 1999.

8. Aboulghar MA, Mansour RT, Serour GI, Amin Y, Sattar M, Ramzy AM. Reutilizing ascitic fluid in the treatment of severe ovarian hyperstimulation syndrome. In Serono Fertility Series. Ares Serono Symposia Publications 1999.

9. Aboulghar M, Mansour R, Serour G, Amin Y. Kamal A, Tawab N. Intracytoplasmic sperm Injection in Difficult cases: The Egyptian Experience. Serono Samposia S.A Publication 1999. 